\title{
PREDICTING THE OFFENDING TRAJECTORIES OF CANADIAN JUVENILE PROBATIONERS: A LATENT GROWTH CURVE MODELING APPROACH
}

\author{
A thesis submitted to \\ the Faculty of Graduate Studies and Research \\ in Partial Fulfillment of the requirements for the degree \\ Doctor of Philosophy
}

by

Annie K. Yessine

Department of Psychology

Carleton University

$$
\text { April }
$$

(C)2008 Annie K. Yessine 


$\begin{array}{ll}\begin{array}{l}\text { Library and } \\ \text { Archives Canada }\end{array} & \begin{array}{l}\text { Bibliothèque et } \\ \text { Archives Canada }\end{array} \\ \begin{array}{l}\text { Published Heritage } \\ \text { Branch }\end{array} & \begin{array}{l}\text { Direction du } \\ \text { Patrimoine de l'édition }\end{array} \\ \begin{array}{l}\text { 395 Wellington Street } \\ \text { Ottawa ON K1A ON4 } \\ \text { Canada }\end{array} & \begin{array}{l}\text { 395, rue Wellington } \\ \text { Ottawa ON K1A 0N4 } \\ \text { Canada }\end{array}\end{array}$

Your file Votre référence ISBN: 978-0-494-43919-7

Our file Notre référence

ISBN: 978-0-494-43919-7

NOTICE:

The author has granted a nonexclusive license allowing Library and Archives Canada to reproduce, publish, archive, preserve, conserve, communicate to the public by telecommunication or on the Internet, loan, distribute and sell theses worldwide, for commercial or noncommercial purposes, in microform, paper, electronic and/or any other formats.

The author retains copyright ownership and moral rights in this thesis. Neither the thesis nor substantial extracts from it may be printed or otherwise reproduced without the author's permission.
AVIS:

L'auteur a accordé une licence non exclusive permettant à la Bibliothèque et Archives Canada de reproduire, publier, archiver, sauvegarder, conserver, transmettre au public par télécommunication ou par l'Internet, prêter, distribuer et vendre des thèses partout dans le monde, à des fins commerciales ou autres, sur support microforme, papier, électronique et/ou autres formats.

L'auteur conserve la propriété du droit d'auteur et des droits moraux qui protège cette thèse. $\mathrm{Ni}$ la thèse ni des extraits substantiels de celle-ci ne doivent être imprimés ou autrement reproduits sans son autorisation.
In compliance with the Canadian

Privacy Act some supporting forms may have been removed from this thesis.

While these forms may be included in the document page count, their removal does not represent any loss of content from the thesis.
Conformément à la loi canadienne sur la protection de la vie privée, quelques formulaires secondaires ont été enlevés de cette thèse.

Bien que ces formulaires aient inclus dans la pagination, il n'y aura aucun contenu manquant.

\section{Canada}




\section{Abstract}

This study sought to identify the distinctive criminal pathways, and specify the early characteristics that predict future offending trajectories for a Canadian sample of young offenders. The sample was comprised of 514 male and female adjudicated juveniles who were followed into middle adulthood. Using latent growth curve mixture modeling, the results revealed the existence of two main types of offenders who differed in composition, offending activity, and desistance throughout the life-course. One group, representing approximately $12 \%$ of the offenders, showed a chronic high level of offending behaviour throughout the life-course. The offending frequency/severity of this group increased steadily from adolescence onwards. The remainder of the sample was characterized by infrequent and/or less serious involvement in criminal behaviour over the years. The offending pattern of this latter group remained fairly stable although it tended to show a slight decline in frequency/severity from age 26 onwards. The offenders classified in the chronic high trajectory group disproportionally engaged in a wider variety of offences as well as more of the violent crimes. Of the criminogenic risk/needs domains studied, the youths' patterns of associations and their use of alcohol and/or drug predicted group membership. Not surprisingly, the chronic high trajectory group comprised more offenders who had negative and unconstructive ties with their peers and who had substance use problems than the stable low group. Overall, the findings are consistent with Loeber and Stouthamer-Loeber's (1996), Moffitt's (1993) and Patterson, Reid and Dishion's (1992) theoretical taxonomy. Policy and practical implications are discussed and directions for future research are suggested. 


\section{Acknowledgements}

I would like to express my outmost gratitude to Dr. Don Andrews and Dr. Jim Bonta for their continuous support and advice in the completion of this project. I am indebted to them in no small way for their many and generous contributions towards making this degree possible and ensuring I have the necessary skills to evolve as a proficient researcher and fulfill some of my uppermost aspirations. I consider myself privileged and fortunate to have received academic, professional and personal guidance by two of the most distinguished experts in the field.

I am also thankful to my committee members Dr. Shelley Brown and Dr. Warren Thorngate, as well as my examiners Dr. Alan Leschied and Dr. Ron Saunders for their thoughtful and constructive questions and comments. Additionally, this work could not have been possible without the analytical recommendations and statistical advice of Dr. Kenneth Bollen and Dr. Linda Muthén. I further wish to acknowledge the contributions of Dr. Karl Hanson and Dr. Guy Bourgon for their valued support and recommendations, as well as those of Jennifer Cooney, Louise Grace, Terri-Lynn Scott and Simon Young for their assistance with the coding of the recidivism data. I am also grateful to the Ministry of Training, Colleges and Universities, as well as the Social Sciences and Humanities Research Council for having provided financial assistance during my four years as a doctoral student.

Finally, it is difficult to imagine that this project would have materialized if not for the ongoing love and encouragement of my treasured parents Francine and Ahmed, grandparents Rose-Yvonne and Jean-Paul, and numerous other family members and 
friends. To my good fortune, my life has been blessed with incredibly supportive and caring individuals who have showed interest in my endeavours and demonstrated patience and understanding to help me bring this study to an end. 


\section{Table of Contents}

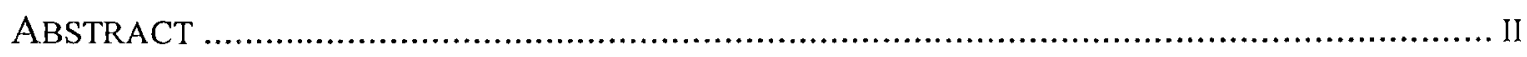

ACKNOWLEDGEMENTS............................................................................................ III

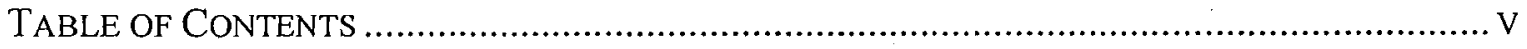

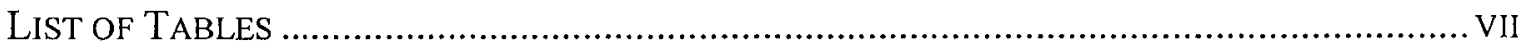

LIST OF FIGURES ............................................................................................ VIII

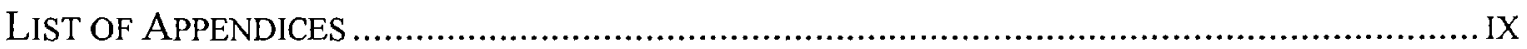

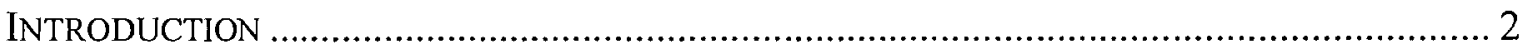

DEVELOPMENTAL TAXONOMIC THEORIES OF CRIMINAL BEHAVIOUR ............................ 4

OFFENDING TRAJECTORIES AMONG ADJUDICATED YOUTHS......................................... 8

THEORETICAL EXPLANATIONS OF ANTISOCIAL BEHAVIOUR.......................................... 9

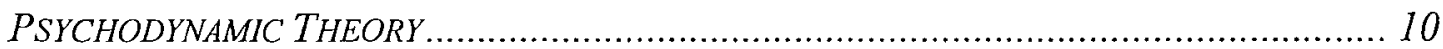

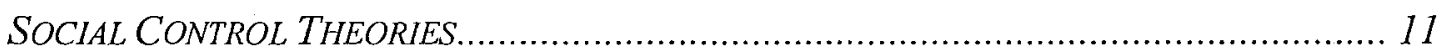

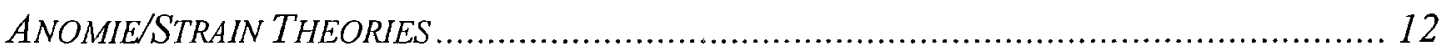

CRIMINAL PROPENSITY/PERSONALITY THEORIES................................................ 14

SOCIAL LEARNING THEORIES ................................................................... 15

The Predictability of Criminal BeHAviour and the Prospect of EfFiciency ... 16

LIMITATIONS WITHIN DEVELOPMENTAL CRIMINOLOGY ......................................... 18

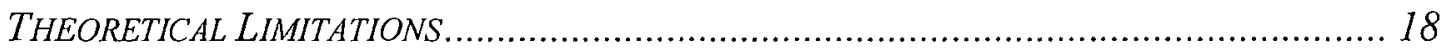

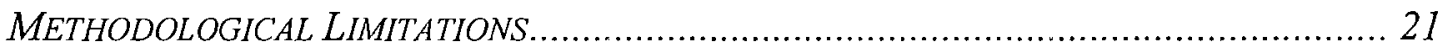

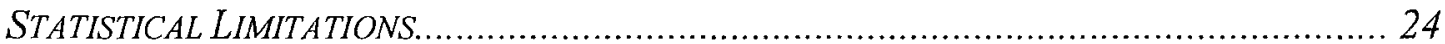

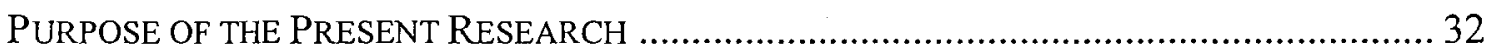

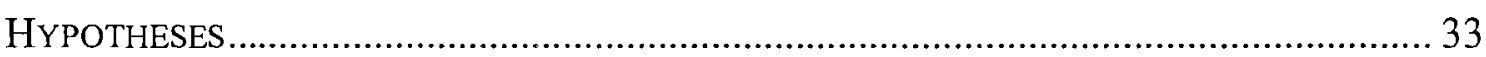

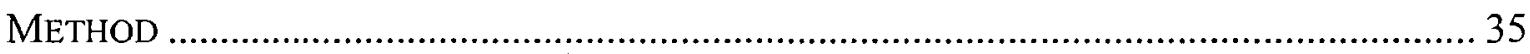

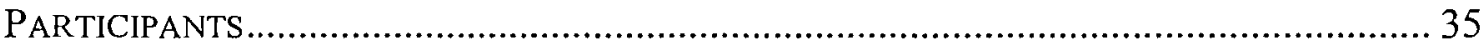

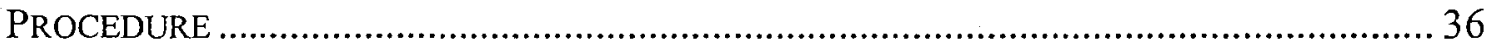

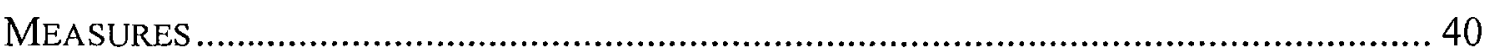

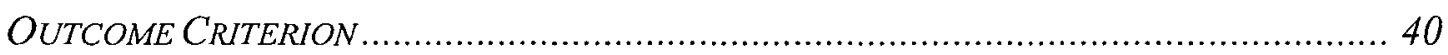

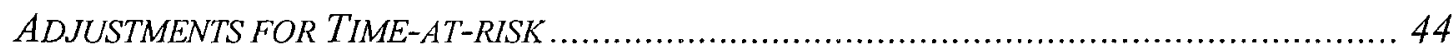

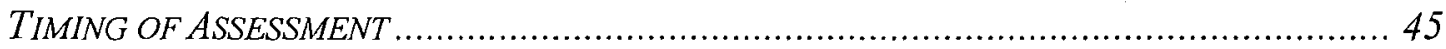

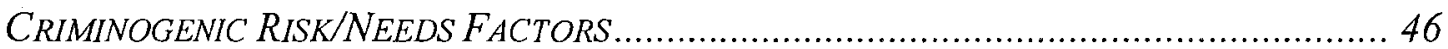

DATA MANAGEMENT AND RELATED IsSUES........................................................... 51

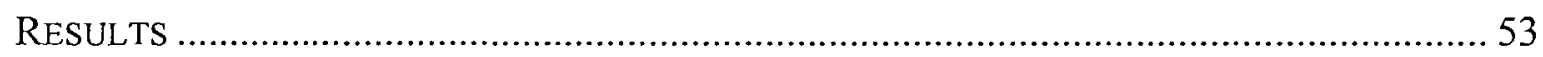

TEMPORAL PATTERNS OF GROWTH AND INDIVIDUAL VARIABILITY IN OFFENDING

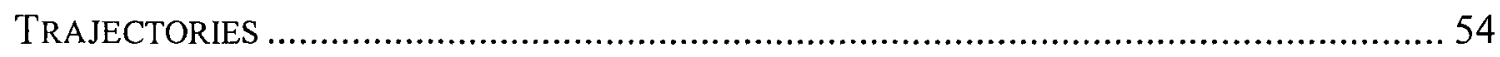

IDENTIFYING THE NUMBER AND TYPES OF OFFENDING TRAJECTORIES ...........................64 64

RISK FACTORS ASSOCIATED WITH OFFENDING TRAJECTORIES ...................................... 66 
DESCRIPTION OF THE OPTIMAL CONDITIONAL TWO-GROUP GROWTH MiXTURE

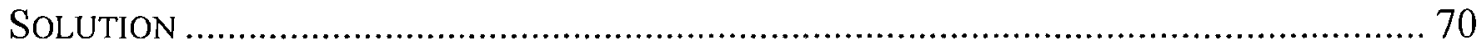

JuVENILE PREDICTORS OF OFFENDING TRAJECTORY GROUP MEMBERSHIP .................... 76

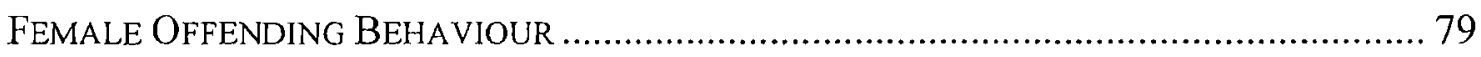

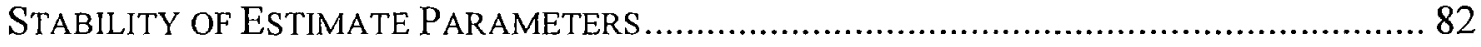

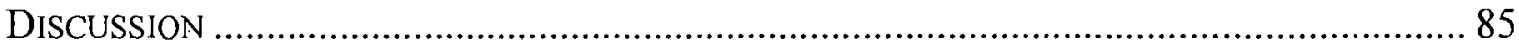

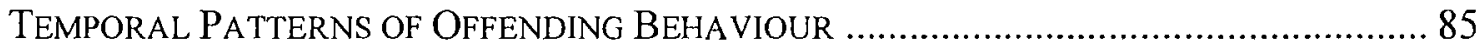

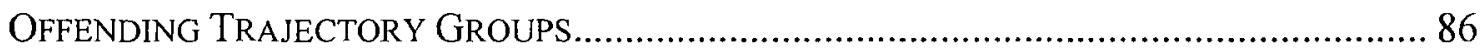

RISK FACTORS ASSOCIATED WITH OFFENDING TRAJECTORIES ....................................... 91

PREDICTION TO PRovinCIAL AND FEDERAL CUSTOdIAL AdMISSIONS........................... 93

POLICY AND PRACTICAL IMPLICATIONS ............................................................... 94

LIMITATIONS AND DIRECTIONS FOR FUTURE RESEARCH …….................................... 98

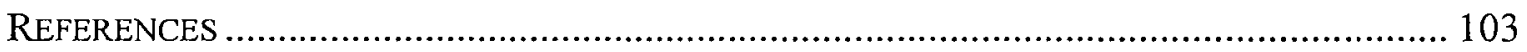




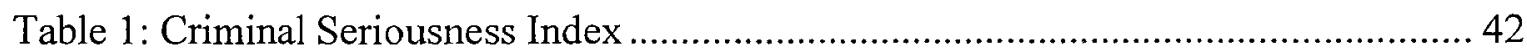

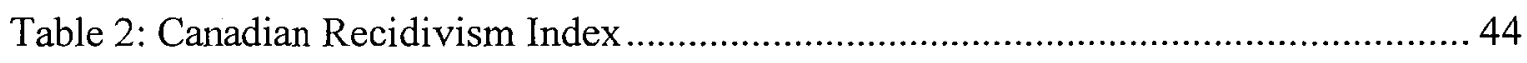

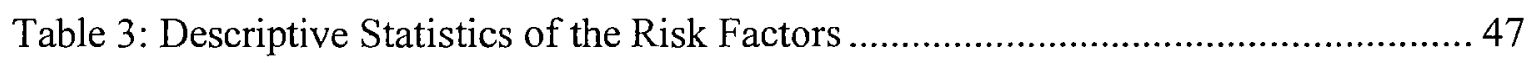

Table 4: Descriptive Longitudinal Analyses of the Sample ............................................. 54

Table 5: Fit Measures of the Linear and Quadratic Latent Growth Curve Models and Autoregressive Latent Trajectory Models for the CSI..................................................... 60

Table 6: Fit Measures of the Linear and Quadratic Latent Growth Curve Models and

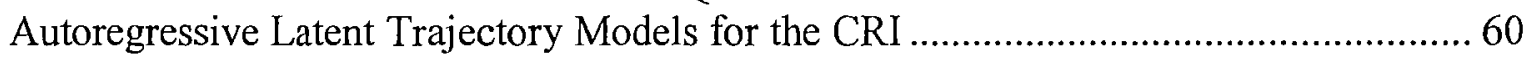

Table 7: Likelihood Ratio Tests for Comparison of Nested Models ................................ 61

Table 8: BIC Values of the Quadratic Latent Growth Curve Models for the CSI and CRI 65

Table 9: Comparison of Conditional Two-group Models for the CSI.............................. 68

Table 10: Comparison of Conditional Two-group Models for the CRI .......................... 69

Table 11: Recidivism Rates of the Chronic High and Stable Low Offending Trajectory

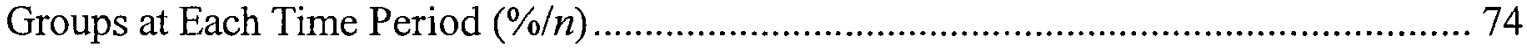

Table 12: Relationship between Trajectory Group Membership and Juvenile Risk Factors 


\section{List of Figures}

Figure 1: Unconditional Quadratic Latent Growth Curve (LGC) Model ......................... 57

Figure 2: Unconditional Quadratic Autoregressive Latent Trajectory (ALT) Model ..... 57

Figure 3: Estimated and Observed Growth Curves for the Criminal Seriousness Index

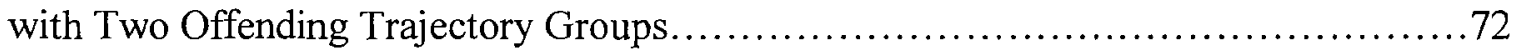

Figure 4: Estimated and Observed Growth Curves for the Canadian Recidivism Index with Two Offending Trajectory Groups .................................................................... 72

Figure 5: Observed Offending Trajectories of the Female Offenders, Stable Low Male Offenders, and Chronic High Male Offenders for the Criminal Seriousness Index......... 81

Figure 6: Observed Offending Trajectories of the Female Offenders, Stable Low Male Offenders, and Chronic High Male Offenders for the Canadian Recidivism Index.......... 81 


\section{List of Appendices}

Appendix A: Comparison Analyses of Offenders Included in, and Excluded from, the Study 130

Appendix B: Risk/need Distribution of the Offending Groups Based on the CSI and CRI

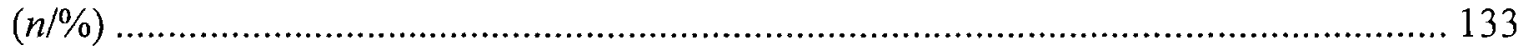

Appendix C: Bootstrap Sample Comparison Results …………............................... 136 
Findings from this follow-up [Dunedin longitudinal study at age 26] must be confirmed by other researchers and extended in our studies using trajectory and growth models (and future follow-ups) before there is a solid evidence base to support detailed recommendations for intervention.

(Moffitt, Caspi, Harrington \& Milne, 2002, p. 201-202) 


\section{Introduction}

Numerous studies examining trends in rates of criminality have indicated that offending escalates during early adolescence and peaks sharply in late adolescence before declining precipitously in young adulthood (e.g., Blockland, Nagin \& Nieuwbeerta, 2005; Blumstein \& Cohen, 1987; Elliott, 1994; Farrington, 1986; Farrington, Lambert \& West, 1998; Loeber, Wei, Stouthamer-Loeber, Huizinga \& Thornberry, 1999). This overall pattern between age and crime appears relatively universal in that it has been observed among both males and females, for various types of offences, in a number of different nations, and across historical periods (Hirschi \& Gottfredson, 1983). The period between late adolescence and young adulthood consequently comes into view as one of the most dynamic periods for criminal activity.

Although the shape of the curve describing criminal behaviour as a function of age is indisputable, theorists and researchers still voice disagreement over how best to explain the curve. Whereas some scholars contend that the adolescent peak in offending most likely represents a change in incidence, others argue that it is predominantly due to a change in prevalence. Does the age-crime curve mirror a transitory increment in the actual number of criminal acts committed by a small and constant subgroup of adolescents, or is the number of individuals willing to offend during adolescence simply greater? At the source of the debate is the recognition that there may be meaningful heterogeneity in offending trajectories with different causal mechanisms accounting for different stages of a delinquent career. 
Empirical evidence on the age-crime curve seems to indicate that the observed rise in offending during adolescence hides distinctive developmental pathways within the offending population. Findings from various studies have suggested that, for most, adolescence reflects a period of temporary increase in the actual number of individuals involved in criminal activity (Farrington, 1983; Wolfgang, Thornberry \& Figlio, 1987). However, there is a smaller proportion of individuals who commit a large number of criminal acts and continue to do so beyond adolescence, embarking on a criminal career (Blumstein, Cohen \& Farrington, 1988; Blumstein, Cohen, Roth \& Visher, 1986).

Theorists and researchers interested in accounting for the different patterns of offending (i.e., desisting or persisting in crime) work from the perspective of developmental criminology. Developmental criminology is specifically concerned with the issues of within-individual stability and change in criminal activity over time (Loeber \& LeBlanc, 1990). In essence, this sub-discipline of criminology suggests the importance of distinguishing the developmental course of offending within the offender population. There is a focus on explicating the factors that give rise to the onset of criminal behaviour and that are associated with a particular course of criminal involvement across different periods of an individual's life. The interest in such a conceptual and empirical framework more precisely resides in studying the nature and pattern of criminality, from onset to desistance, on a variety of dimensions (e.g., rate, type, variety, timing, severity). In sum, according to developmental criminologists, there are distinctive groups within the offender population that share distinctive etiologies and that follow distinctive trajectories of offending. 
Recent years have witnessed the advancement of a number of developmental taxonomic systems to account for within-individual continuity and change in criminal behaviour over time. Among the most influential taxonomies are those of Loeber and Stouthamer-Loeber (1996), Moffitt (1993) and Patterson, Reid and Dishion (1992). Despite some slight variation in emphasis, all outline the existence of two primary hypothetical categories of offenders who differ in composition, offending activity, and desistance throughout the life-course. They are: (a) the early onset persisters; and (b) the late onset desisters. Whereas early onset persisters are few, relatively permanent, and pathological, late onset desisters are common, relatively transient, and near normative (Moffitt et al., 2002). In the following section, major theoretical assumptions underlying these developmental taxonomies are described, and results of empirical studies derived from these assumptions are summarized.

Developmental Taxonomic Theories of Criminal Behaviour

Loeber and Stouthamer-Loeber's (1996), Moffitt's (1993) and Patterson et al.'s (1992) theories maintain that the antisocial behaviour of the early onset persisters originates in abnormal neurodevelopment as indicated by minor birth defects, brain damage, central nervous system dysfunction, and cognitive deficits. As a group, early onset persisters are very similar in personality descriptors as Chess and Thomas' (1984) concept of "difficult" temperament. Such temperament is generally characterized by a high energy level/hyperactivity, attention deficits, impulsivity and poor adaptation to change. What differentiates Chess and Thomas' (1984) concept of "difficult" temperament from Loeber and Stouthamer-Loeber's (1996), Moffitt's (1993) and 
Patterson et al.'s (1992) theories is that the latter hypothesize a cause for the condition by proposing a relationship between early onset persistent antisocial behaviour and neurophysiological and neuropsychological impairments. Many studies have demonstrated the link between a difficult temperament in infancy and conduct disorder, including aggressive behaviour and delinquency (e.g., Henry, Caspi, Moffitt \& Silva, 1996; Krueger, Schnutte, Caspi, Moffitt, Campbell \& Silva, 1994; Schwartz, Snidman \& Kagan, 1996). In turn, a diagnosis of conduct disorder early in life, when accompanied by other risk factors, was found to increase the risk of violence, including homicide (Loeber, Pardini, Homish, Wei, Crawford, Farrington, Stouthamer-Loeber, Creemer, Koehler \& Rosenfeld, 2005).

One important way through which children with a difficult temperament are at an increased risk for criminality relates to the inhibitory effect these traits have in the learning of the self-control and self-management skills necessary for appropriately responding to environmental stimuli. Accordingly, for this group of offenders, criminal conduct begins in childhood with less serious forms of offending, but continues to gradually worsen throughout the life-course as the individuals are in constant interactions with various high-risk environmental factors, such as inadequate parenting, disrupted family bonds, and poverty. Furthermore, offenders within that group are generally not expected to desist from offending across their adult life-course. Although they represent a small proportion of an age cohort, early onset persisters are thought to be responsible for the vast majority of all offences, and the most serious forms of offending. This proposition has been confirmed by various studies (e.g., Jeglum-Bartusch, Lynam, 
Moffitt \& Sylva, 1997; Moffitt, Caspi, Dickson, Silva \& Stanton, 1996). Loeber and Stouthamer-Loeber (1996) refer to these offenders as "persisters", whereas Moffitt (1993) and Patterson et al. (1992) refer to them as "life-course-persistent" (LCP) and "early starters", respectively.

In contrast, the second group of offenders, the late onset desisters, are hypothesized to begin offending later in life (i.e., during adolescence), and to desist in early adulthood. The antisocial behaviour of this latter group is not believed to originate from neuropsychological impairments, but rather from the influence of various social processes (e.g., maturity gap, social modeling, reinforcement for rule-breaking behaviour). According to the taxonomic theories, these offenders represent the majority of an age cohort whose acts may be characterized as "rebellious" and less serious forms of offending. These offenders have been referred to as "experimenters" (Loeber \& Stouthamer-Loeber, 1996), "adolescent-limited" (AL; Moffitt, 1993) and "late starters" (Patterson et al., 1992).

Given these assumptions about the developmental pathways of early onset persisters and late onset desisters, predictors of antisocial behaviour for the former group should include health problems, difficult temperament, cognitive deficits, antisocial personality traits (e.g., callousness, alienation), mental disorders, disrupted family bonds, inadequate parenting or child-rearing practices, parent and sibling deviance, lack of social and academic skills, and low socio-economic status, but not age (e.g., Moffitt, 1993; Moffitt et al., 2002; Patterson, 1982). In contrast, the strongest predictors of offending for the late onset desister group should not relate to indicators of individual differences that 
emerge early in life and that are further exacerbated by a disadvantaged social environment, but rather to experiences that occur alongside puberty, during the relatively "roleless" years between biological maturation and access to adult privileges and responsibilities (Moffitt et al., 2002). These include factors such as peer delinquency, self-conscious attitudes and values towards adolescence and adulthood (e.g., desire for autonomy), cultural and historical context influencing adolescence (e.g., reinforcement contingencies for antisocial behaviour), as well as age (e.g., Moffitt, 1993).

Empirical evidence on these distinctive offending pathways, and on the processes responsible for their emergence and continuity abounds ${ }^{1}$ (e.g., Jeglum-Bartusch et al., 1997; Moffitt, Lynam \& Silva, 1994). Most notably, the prediction that the antisocial behaviour of early onset persisters emerges from early neurodevelopmental factors (e.g., Piquero, 2001) and further aggravates through their transactions with family-adversity factors has been repeatedly supported (e.g., af Klinteberg, 2002; Patterson, DeGarmo \& Knutson, 2000; Rutter, Giller \& Hagell, 1998). Findings from a recent meta-analytic study that tracked the impact of a variety of early childhood and adolescent experiences on later adult criminal justice involvement has indicated that a variety of behavioural (e.g., aggression, attentional problems, attention-seeking), and emotional (e.g., withdrawal, anxiety, social alienation) concerns, apparent in the child's life, together with inadequate parenting strategies (e.g., coerciveness, lack of supervision) and other family variables (e.g., family/interparental conflict and stressors) predicted who, as adults, became involved in criminal justice systems (Leschied, Nowicki, Rodger \& Chiodo,

\footnotetext{
${ }^{1}$ Readers are referred to Moffitt (2003) for a complete overview of the research conducted on the dual taxonomic system.
} 
2006). Finally, although it has been the subject of less attention, the hypothesis that late onset desisters antisocial behaviour has its origins in social processes and is influenced by factors that relate to the maturity gap and by social mimicry of antisocial models has also received considerable empirical confirmation (e.g., Moffitt \& Caspi, 2001; Piquero \& Brezina, 2001).

Offending Trajectories among Adjudicated Youths

A great deal of past theoretical and empirical efforts have focused on understanding and predicting the naturally occurring offending trajectories and criminal careers among youths, initially identified as non-offenders. A different, yet closely related, body of literature has dealt with the identification and prediction of developmental pathways of adjudicated youths (i.e., known juvenile offenders). Despite some relatively minor methodological dissimilarities (e.g., differences in power and offending rate), it should be noted that the two lines of investigation have generated comparable findings.

For instance, a 20-year follow-up investigation of a large sample of juvenile offenders in California demonstrated that cognitive ability, early behaviour problems, and early age at first arrest, among other risk factors, were significant predictors of chronic criminal offending in adulthood (Ge, Donnellan \& Wenk, 2001). Similarly, both the studies of Eklund and af Klinteberg (2005) as well as that of Blokland et al. (2005) have found offending trajectory groups within a group of adolescent male lawbreakers and a Dutch conviction sample, respectively, to be consistent with those proposed by Loeber and Stouthamer-Loeber's (1996), Moffitt's (1993) and Patterson et al.'s (1992) theories. 
Using their sample of Dutch offenders, Blokland and Nieuwbeerta (2005) further demonstrated that within-individual changes in crime-inhibiting life circumstances had a differential effect on criminal behaviour across offending trajectory groups. As predicted by developmental taxonomists, getting married and/or becoming a parent did not significantly decrease the conviction rate of persistent offenders, unlike what was found in the desister groups.

\section{Theoretical Explanations of Antisocial Behaviour}

Developmental theories such as the ones proposed by Loeber and StouthamerLoeber (1996), Moffitt (1993) and Patterson et al. (1992) represent an appealing avenue to reconcile many of the disagreements in research and theorizing on antisocial behaviour. This is because the propositions advanced by the developmental criminological literature allow for the integration of the empirically valid and most promising aspects of each theory by suggesting that different processes may contribute to the delinquent behaviour of specific subgroups of offenders, or operate at different stages of their life-course. As noted by Loeber and Stouthamer-Loeber (1998):

It is necessary to substantiate a theory of antisocial behavior that cuts across the findings of specific outcomes, across onset in childhood and adolescence, and across gender by focusing on common elements in each of these domains. At the same time, however, it is argued that the utility of theories can be greatly enhanced by incorporating factors that are unique to different antisocial outcomes, to different age groups, and to each gender. (p. 255) 
What follows are the basic tenets of some of the most prominent theories that have been developed to examine, explain, predict and in turn influence occurrences in offending behaviour. Psychodynamic, social control, anomie/strain, criminal propensity/personality, and social learning theories have, one way or another, influenced the search and guided the selection of etiological predictors for the differential offending trajectories of early onset persister and late onset desister offenders.

\section{Psychodynamic Theory}

From its beginning in the Freudian model of the structure of human personality, the psychodynamic perspective (Freud, 1963) has acknowledged that different risk factors evident during the earliest stages of a person's development are linked with criminality. To be more precise, the theory postulates that an individual's set of internalized moral principles (i.e., superego or internal self-regulation), which are primarily acquired through parental identification and attachment, interact with the intense innate aggressive and sexual drive of the id, the continuing effects of stressful incidents from the immediate situation of action, and the problem-solving deficits of the ego (i.e., self-regulation directed by external cues), and lead to antisocial and/or other apparently aberrant behaviour. Despite some obvious differences in emphasis, psychodynamic notions have been useful to the elaboration of the developmental taxonomic systems proposed by Loeber and Stouthamer-Loeber (1996), Moffitt (1993) and Patterson et al. (1992) in that they suggest that criminal activity reflects a cumulative, integrated process involving the facilitating and inhibiting contingencies placed by the external environment on biological, temperamental, attitudinal, and cognitive factors. 


\section{Social Control Theories}

In the vein of the psychodynamic perspective, social control theories also focus on why some people do not commit crime, rather than attempting to explain why individuals actually engage in criminal activity. These theories were produced by sociological criminologists (Hirschi, 1969; Reckless, 1967) and emphasize weak social controls as the causes of burgeoning delinquency. Specifically, informal social bonds (i.e., various mechanisms of social control such as the family, school, employment, marriage, conventional recreational activities, etc.) predict involvement in antisocial and/or criminal activity throughout the lifespan. Accordingly, changes in such bonds are hypothesized to cause changes in offending behaviour, and can thus also contribute to desistance from crime.

Empirical evidence for the relevance of social factors or informal social bonds (e.g., early termination of school, attenuation in parental ties, marriage with a prosocial partner, regular employment) in accounting for both stability and change in crime and deviance over the life-course was provided by Ouimet and LeBlanc (1996), Wright and Cullen (2004), as well as Sampson and Laub (1993) in their follow-up of the Glueck and Glueck (1950) data. Similarly, Warr (2002) found that, as individuals assume conventional adult social roles, affiliations with antisocial peers tend to diminish resulting in a greater likelihood of desistance from crime. However, other studies have found that marital status and employment (e.g., Giordano, Cernkovich \& Rudolph, 2002) do not have a significant impact on the likelihood of desistance from crime. 
Consistent with Loeber and Stouthamer-Loeber's (1996), Moffitt's (1993) and Patterson et al.'s (1992) developmental perspective, social control theories point to the role of family practices, and the failure of other important socialization processes as forces that contribute to a lack of social competence and achievement as well as involvement in delinquent acts. The contradictory findings observed across studies could be due to the fact that social control variables have not been tested against other predictors present in the current developmental criminological literature, namely individual risk factors (Morizot \& LeBlanc, 2007). As found in Blockland and Nieuwbeerta's (2005) study, another potential explanation is that changes in risk factors and/or crime-inhibiting life circumstances have a differential impact on the criminal behaviour of distinct offending groups (i.e., early onset persisters and late onset desisters).

\section{Anomie/Strain Theories}

Anomie/strain theories minimize powerful psychological factors that have repeatedly been associated with an increased risk for criminality. These theories are based on the assumption that social class of origin is a major source of variation in criminal conduct at the individual level. According to Merton $(1938,1957)$ for instance, criminal behaviour is more likely to occur among individuals within the lower socioeconomic class because their opportunities to reach conventional goals (i.e., wealth, status, power) by way of legitimate behaviour are blocked. In order to fulfill their conventional aspirations, lower-class individuals must thus "innovate" and turn to illegitimate means to attain societal goals. 
Similarly, subcultural theorists (Cloward \& Ohlin, 1960; Cohen, 1955) take the notion of strain as a given and specifically assert that lower-class youths are pressured into delinquency by a host of frustrating and painful social relations that stem from their inability to compete effectively in a world of middle-class institutions (e.g., work, education). Furthermore, these youths are thought to persist in delinquency because of their inadequate socialization and subcultural support. Generally speaking then, subcultural theorists argue that antisocial behaviour represents a form of corrective action or successful adaptation in response to relational problems and accompanying distress.

The main problem with strain and personal distress theories, however, is that they are empirically weak. Time after time, findings from systematic research have demonstrated that the causal significance of social class of origin in accounting for variation in criminal behaviour at the individual level is rather distal and minimal (e.g., Andrews, Zinger, Hoge, Bonta, Gendreau \& Cullen, 1990; Gendreau, Little \& Goggin, 1996; Hindelang, 1972), and that negative emotional states such as depression, insecurity, worry and disappointment are inversely related to aggressive and criminal behaviour (e.g., Broidy, 2001; Glueck \& Glueck, 1950). Fortunately, Agnew (1992) reformulated anomie/strain theories in terms that are more psychologically-based by emphasizing anger as well as difficulties at home, school, and work as indicators of a strain-crime link. Agnew's General Strain Theory parallels psychology's frustration-aggression theory (Dollard, Doob, Miller, Mowrer \& Sears, 1939), and is thus more consistent with developmental notions. 


\section{Criminal Propensity/Personality Theories}

Unlike social control and early anomie/strain theories, criminal propensity/personality theories (e.g., Gottfredson \& Hirschi, 1990; Hare, 1993; Yochelson \& Samenow, 1976) recognize the importance of cognitive and temperamental influences on the onset, persistence and desistance of delinquent behaviour. Generally speaking, this set of theories contends that heterogeneity exists between individuals in their likelihood of engaging in criminal acts, and that this individual variation in criminal propensity is established early in life and remains relatively stable thereafter.

In view of that, criminal propensity/personality theorists propose an early age of onset of antisocial behaviour together with underlying individual differences as predictors of persistent criminal activity. A series of investigations offered support for the proposition that delinquency and crime, including violence, are related to early conduct problems (e.g., Farrington, 1997; Loeber \& Dishion, 1983; Loeber et al., 2005; Pardini, Obradovic \& Loeber, 2006) and relatively stable characteristics, such as low self-control, psychopathy and/or cognitive deficits (e.g., Farrington, 1995; Hart, Kropp \& Hare, 1988; Hemphill, Hare \& Wong, 1998; Hirschi \& Hindelang, 1977; Loeber, Lahey \& Thomas, 1991; Moffitt et al., 1994; Piquero \& White, 2003). Conceptually and empirically therefore, criminal propensity/personality theories are consistent with existing developmental theories (e.g., Loeber \& Stouthamer-Loeber, 1996; Moffitt, 1993; Patterson et. al., 1992), which as noted earlier, conceptualize crime-prone individuals as having subtle neuropsychological difficulties that among other things, predispose them toward poor self-control, impulsivity, and an inability to delay immediate gratification. 


\section{Social Learning Theories}

Social learning theories (e.g., Andrews \& Bonta, 1994, 1998, 2003, 2006; Bandura, 1977; Sutherland \& Cressey, 1978), in contrast to social control theories, anomie/strain theories and theories of individual criminal propensity/personality, argue that both enduring individual differences in propensity to commit crime as well as less static social factors contribute to antisocial behaviour. According to this theoretical perspective, behaviour is acquired, maintained and modified through various processes such as direct observation, reinforcement, and punishment.

Generally speaking, social learning models recognize that there are multiple routes to crime, but that the likelihood of criminal conduct increases dramatically with the presence of an increased number and more diverse set of risk factors for criminality. Some of the more proximal risk factors for criminal activity include antisocial attitudes and associates, personality attributes such as low self-control and self-management deficits, and criminal history. Additional important differences between offenders and non-offenders are also found in family practices, as well as achievement in the domains of school and/or work. These variables influence and can predict involvement in criminality by mediating the rewards/costs contingencies available for such behaviour.

Just like Loeber and Stouthamer-Loeber's (1996), Moffitt's (1993) and Patterson et al.'s (1992) developmental taxonomic systems, social learning theories postulate that criminal behaviour is largely determined by the person interacting with the immediate environment, and is restrained by the individual genetic as well as constitutional disposition and capability. Therefore, these general theories of crime have provided 
valuable insights about the more proximal variables that are responsible for delinquency and other forms of antisocial conduct.

On the whole then, we can see that the field of developmental criminology has, one way or another, benefited from the notions proposed by the various competing theoretical formulations reviewed here. Nevertheless, theorists and researchers working within the developmental paradigm argue that these general theories fail to provide a satisfying account of the emergence, continuation and cessation of criminality. As noted earlier, their contention is that, despite the fact that they may all provide valuable insights into criminal behaviour, the processes that control, strain, criminal propensity and social learning theories describe may fit better for different types of delinquents or may operate at different developmental stages in the natural history of antisocial behaviour.

\section{The Predictability of Criminal Behaviour and the Prospect of Efficiency}

Regardless of the particular theoretical orientation criminological theorists and researchers generally espouse, all agree on the importance of identifying juvenile delinquents most at risk of continued offending, understanding the factors contributing to persistent offending, and concentrating intervention resources on the chronic and serious offenders. The identification of high-risk, chronic offenders (and the characteristics that differentiate them from lower risk, relatively transient offenders) for the purpose of focusing resources on the former assumes that targeting and/or intervening with all offenders is neither feasible nor desirable. The efficiency of a criminal justice system in reducing rates of criminality, and the ensuing social and human costs typically associated with crime and other antisocial acts, can thus be gauged by its ability to successfully 
identify the small number of offenders who commit a high proportion of serious offences. Only then can intervention efforts and other resources be invested wisely and distributed profitably.

In this regard, there are two principal hazards that criminal justice systems face. There is the possibility of selectively focusing on offenders who may not be demonstrably more dangerous or at risk to reoffend than other offenders from the larger pool from which they are drawn. Yet again, there are the human costs associated with incorrectly classifying serious, chronic offenders as low risk for reoffending. The appropriate disposition of cases by criminal justice officials is therefore a crucial element to the proper functioning of any correctional or criminal justice system, especially when dealing with a relatively small group of high-risk offenders who commit a disproportionate share of crime.

Underlying this responsibility is the assessment of risk, which raises one fundamental question: Can we predict and treat well enough to make a difference on recidivism? Or, in other words, is the degree of predictive accuracy currently achieved when assessing risk to reoffend a sufficient basis for treating offenders differently? The answer is a definite yes, as evidenced by a view presented by most theorists and researchers. There is now a consensus that both general and violent reoffending can be predicted among typical criminal populations, as well as groups of violent and sexual offenders (e.g., Andrews \& Bonta, 2003; Campbell, French \& Gendreau, 2007; Gendreau, Little \& Goggin, 1996; Glover, Nicholson, Hemmati, Bernfeld \& Quinsey, 2002; Hanson \& Morton-Bourgon, 2007; Rice \& Harris 1997; Smith \& Aloisi, 1999). 
The degree of success in prediction, however, remains contingent upon the methods used by criminal justice professionals to assess offender risk level (i.e., clinical vs. actuarial) ${ }^{2}$. Most would argue that actuarial assessments of offender risk are superior to clinical, unstructured prediction procedures (e.g., Bonta, 2002; Grove \& Meehl, 1996; Grove, Zald, Lebow, Snitz \& Nelson, 2000; Hanson \& Morton-Bourgon, 2007) 3 .

Fortunately, the past several years have witnessed an increasing reliance on "actuarialism" by criminal justice systems in their preferred approach to risk assessment (Kemshall \& MacGuire, 2001). Acknowledging the current state of affairs, the adoption of a theoretical perspective and empirical methods that seek to understand and predict individual variation in criminal conduct in terms of offending pathways or criminal careers appears promising in assisting researchers develop improved, and refine existing, actuarial instruments.

Limitations within Developmental Criminology

Notwithstanding the potential theoretical, empirical and practical contributions that the developmental perspective has to offer to the field of criminology and criminal psychology, knowledge is still weak on certain important issues. These limitations fall into three broad classes: (a) theoretical; (b) methodological; and (c) statistical.

\section{Theoretical Limitations}

As previously noted, there exists a vast amount of empirical studies confirming Loeber and Stouthamer-Loeber's (1996), Moffitt's (1993) and Patterson et al.'s (1992)

\footnotetext{
${ }^{2}$ In contrast to clinical approaches, where the identified risk factors are interpreted into a probability for recidivism in a way that is not explicitly determined, actuarial risk assessments involve a formal, objective (i.e., predetermined), algorithmic or numerical calculation of levels of risk.

${ }^{3}$ See Litwack (2001) for an opposing view on the issue.
} 
theories. Still, mixed support for the dual taxonomies can be found in the literature. Some research has indicated that a number of offenders do not fit into either an early onset persister or late onset desister group. These studies have revealed a number of distinct trajectory groups typically ranging from three to five. Notably, a third type of offenders, characterized by a pattern of recurrent, but low level offending throughout a certain period of their life-course (e.g., childhood to adolescence), seems to replicate across longitudinal studies (e.g., Fergusson et al., 2000; Laub, Nagin \& Sampson, 1998; Moffitt et al., 2002; Sampson \& Laub, 2003).

Similarly, the finding that more than one group whose offending behaviour pattern resembles that of the proposed late onset desister and/or early onset persister: pathways has emerged (e.g., Day, Beve, Duschene, Rosenthal, Sun \& Theodor, 2007; D’Unger, Land, McCall \& Nagin, 1998; D’Unger, Land \& McCall, 2002; Land \& Nagin, 1996; Loeber, Farrington, Stouthamer-Loeber, Moffitt \& Caspi, 1998; Nagin, Farrington \& Moffitt, 1995; Nagin \& Land, 1993; White, Bates \& Buyske, 2001; Wiesner \& Silbereisen, 2003). For example, Chung, Hill, Hawkins, Gilchrist and Nagin (2002) identified two developmental trajectories of offending, in addition to the early onset persister and late onset desister groups predicted by Loeber and Stouthamer-Loeber's (1996), Moffitt's (1993) and Patterson et al.'s (1992) theories. These groups were labelled "escalators" and "desisters", respectively.

The escalators engaged in only minor offending in early adolescence, but continued to commit increasingly serious offences through early adulthood. Based on this description, escalators could be viewed as a subset of the early onset persister group, who 
merely demonstrate a different timing of antisocial manifestation. Given that additional analyses revealed differences in etiologies between escalators and chronics, however, the authors contended that the former group might be worthy of consideration in its own right. Likewise, the desister group identified by Chung et al. (2002) seemed to share certain features of late onset desisters in that they desisted from offending by early adulthood. In contrast to the Loeber and Stouthamer-Loeber's (1996), Moffitt's (1993) and Patterson et al.'s (1992) late onset desister group however, this desister group showed a relatively early onset of offending and were similar in seriousness of offending to escalators in early adolescence.

Using data from the large-scale Criminal Career and Life-Course Study (CCLS), Blockland et al. (2005) have partitioned the familiar age-crime curve into four distinct trajectory groups of offenders based on their timing, intensity and duration of criminal involvement. Their typological arrangement, however, differs somewhat from the one presented by Chung et al. (2002). According to Blockland et al. (2005), one group, called the sporadic offenders, was composed of individuals who showed very few, if any, convictions besides their initial conviction. Another group of offenders, the high-rate persisters, appeared to conform to the early onset persister group proposed by Loeber and Stouthamer-Loeber's (1996, Moffitt's (1993), and Patterson et al.'s (1992) theories, as they revealed a consistently high number of convictions throughout their life-course, compared to the other groups. In contrast, the offending trajectories of two distinct groups were comparable to the late onset desister pattern described in the dual typological theories. These groups were labelled low- and moderate-rate desisters in that 
they both showed a rise and decline in the number of convictions that resembled the familiar aggregated age-crime curve. What distinguished these two groups was the incidence of offending during the peak ages periods.

The theoretical propositions of Quinsey, Skilling, Lalumière and Craig (2004) are also worth mentioning. In addition to a late onset desister group, the researchers postulate the existence of two groups of early starting and persistently antisocial individuals. One group is composed of individuals whose antisocial and aggressive conduct is associated with neuropathology, while a second distinct group of early onset persistent offenders is composed of individuals who show no neurodevelopmental pathology, but rather pursue a genetically determined and adaptive life-history strategy involving risky and aggressive interpersonal behaviours. Empirical evidence in support of Quinsey et al.'s (2004) suggestion is, however, relatively scarce and often indirect (e.g., Coid, 1993; Harris, Rice \& Lalumière, 2001; Lalumière, Harris \& Rice, 2001).

Taken as a whole, it would appear that the dual taxonomic systems overlook the presence of other, logically possible, offender trajectory types. Theoretically and empirically, the issue of the actual number and type of distinct offending trajectories is therefore still somewhat unsettled.

\section{Methodological Limitations}

The existing literature is largely comprised of studies restricted to males. This represents the current state-of-affairs despite the fact that the original statement of Moffitt's (1993) developmental taxonomy asserted that the theory described the behaviour of females as well as that of males. Fewer females would, however, be thought 
to become delinquent overall, and within delinquents the percentage who are early onset persisters would be larger among males than among females.

With one exception (Aguilar, Stroufe, Egeland \& Carlson, 2000), the accumulating findings on the research examining the offending behaviour of females have suggested that most female antisocial behaviour is of the late onset desister type (e.g., Fergusson et al., 2000; Kratzer \& Hodgins, 1999). However, only two studies (Côté, Zoccolillo, Tremblay, Nagin \& Vitaro, 2001; D'Unger et al., 2002) have systematically addressed (i.e., using semi-parametric mixture or growth curve models) whether the criminal career typologies obtained among males applied adequately well to female offending. Among the females of the Second Philadelphia Cohort, D'Unger et al. (2002) for instance, have identified two groups of late onset desisters, but no distinct early onset persister pattern of offending.

Moffitt (2003) noted that the lack of research examining the offending pathways of females largely originates from pragmatic circumstances. Ideally, to adequately study the patterns of female offending within a developmental taxonomic framework, the research requires a sufficiently large representative sample that can potentially identify early onset persister and late onset desister females who would be followed from childhood through adolescence and up to adulthood with repeated measures of antisocial behaviour. Longitudinal samples with sizeable female populations are, however, scarce. Researchers employing cohort designs with normative populations are consequently hampered in their capacity to investigate the behaviour of female offenders with sufficient statistical power because of the markedly low base rate of early onset persister 
females relative to the size of their cohort. Methods that make use of cohort designs with adjudicated populations, while still limited, can facilitate the execution of gender comparisons analyses.

Another methodological shortcoming associated with the literature concerns the lack of consideration for incarceration time. Not controlling for incarceration time can have serious consequences when estimating offending trajectories (Eggleston, Laub \& Sampson, 2004; Piquero, Blumstein, Brame, Haapanen, Mulvey \& Nagin, 2001). This includes underestimation of offending frequency or severity of chronic offenders.

The length of follow-up period employed in the majority of previous longitudinal studies is a third limitation. Few studies designed to test the taxonomic theories have extended their findings into middle to late adulthood (e.g., Day et al., 2007; Farrington, Coid, Harnett, Jolliffe, Soteriou, Turner \& West, 2006; Laub \& Sampson, 2003). Although the prediction that early onset antisocial behaviour persists longer into adulthood than late onset delinquency lies on a solid theoretical footing (e.g., Blockland et al., 2005; Laub \& Sampson, 2003; Moffitt et al., 2002; Stattin \& Magnusson, 1991), empirical tests of the hypothesis that early onset, but not late onset, antisocial behaviour is associated with violence and continued serious criminal conduct into middle to late adulthood are needed.

Quite extensive information is available on the prevalence of crime. However, little is known about the stability or the causes of desistance, and there is still much to be learned about the discontinuity of individual offending over time (Kazemian \& Farrington, 2006; Morizot \& LeBlanc, 2007; Stattin \& Magnusson, 1991). As noted by 
Loeber \& Stouthamer-Loeber (1998), it is easy to oversimplify the conceptualization of stability and change of individual variation in criminal behaviour over time. Evidently, the duration of criminal careers or the trajectories of offending depends on length of follow-up. It cannot be assumed, for instance, that juvenile offenders who do not engage in criminal activity for a number of years have actually desisted from criminality in later periods of their adult lives ${ }^{4}$. Offenders may be experiencing intermittency in offending (Laub \& Sampson, 2001), or may be incarcerated. Within criminology, research designs that cover periods extending into middle to late adulthood could provide valuable insights into the desistance process.

Finally, it is worth noting that many of the findings obtained in the original study conducted by Moffitt and her colleagues (i.e., Dunedin Multidisciplinary Health and Development Study) to test their proposed theoretical taxonomic system have since been replicated with other samples in several different countries, including the United States, Finland, Great Britain, New Zealand, the Netherlands, and Sweden. Despite the body of research that has accumulated over the years, to date there has been only two longitudinal studies that examined the offending trajectories of Canadian offenders (Day et al., 2007; LeBlanc, 1996).

\section{Statistical Limitations}

A historical sketch of studies aimed at classifying individuals into groups based on their offending pattern reveals the popularity of several diverse approaches. Some

\footnotetext{
${ }^{4}$ As noted by Nagin and Tremblay (2005), a statistical model is a characterization of collected, not uncollected, data, and evidently, the reason to extend the collection of data in longitudinal studies of criminal behaviour is that the phenomenon under study has yet to unfold entirely.
} 
researchers have employed cluster analysis (e.g., Aalsma \& Lapsley, 2001; Eklund \& af Klinteberg, 2006; Raine, Moffitt, Caspi, Loeber, Stouthamer-Loeber \& Lynam, 2005; Stattin \& Magnusson, 1991; Vincent, Vitacco, Grisso \& Corrado, 2003), others have used factor analysis (e.g., LeBlanc, 1996), and still others have applied taxometric methods (e.g., Skilling, Quinsey \& Craig, 2001). While these traditions appear well suited to analyze data measured at one point in time, their application to the analysis of repeated measures data over time is limited for the simple reason that observations are not independent within units.

Still, longitudinal research questions have commonly been studied using estimated correlation coefficients and/or difference scores. These approaches, however, are not adequate to analyze change over time. On the one hand, the correlation coefficient only measures status (not change), and so simply conveys whether the rank order of the individuals is similar at both points in time. A high correlation can thus be obtained even when there is no average change over time. On the other hand, the difference score procedure assumes linear growth over time and cannot test the possibility that change is non-linear. In many scientific domains, including the study of criminal behaviour, this is a strong and often unreasonable assumption.

For the analysis of longitudinal data, individual growth modeling offers many opportunities, and has demonstrated to be superior to the approaches previously noted for various reasons. In addition to being flexible with regards to the research design (e.g., different data collection schedule and/or number of waves across individuals), the perspective allows researchers to identify the functional form or temporal patterns in the 
data (e.g., increase, decrease or stability in outcome over time, linear, quadratic or asymptotic relation), as well as to include time-varying predictors (e.g., participation in an intervention) and/or interactions with time (e.g., effects that are especially pronounced during a particular period). Two distinct, and relatively equivalent, techniques have evolved independently within the individual growth modeling framework. These are: (a) mixed modeling; and (b) latent trajectory (growth curve) modeling.

Mixed modeling is a general framework that encompasses several other types of analyses such as multilevel modeling and hierarchical linear modeling. The analytical perspective differs from the latent growth curve modeling approach in that mixed modeling assesses the fit of the model to the data using manifest variables, whereas latent trajectory modeling assesses the fit of the model to the covariances using latent variables. In practice, the main difference lies in how the time structure of the data is established (i.e., person-level $v s$. person-period). It should nonetheless be noted that, for the most part, what can be done with one framework can be done with the other framework, and vice versa. However, the latent growth curve modeling framework does not only model correlations or covariances (as is the case with mixed modeling), but also models the means of the observed measures. In addition, some model fit statistics, which are available in latent growth curve modeling, are not available in mixed modeling. Consequently, heterogeneity of offending patterns, and the factors responsible for this variability, were analyzed using a general latent growth curve modeling approach.

In a nutshell, latent trajectory models allow separate trajectories over time for repeated measures. Each case in the sample can have a distinct time trend as marked by a 
different intercept and/or slope when followed over time. It is a structural equation modeling (SEM) approach that has deep roots in social sciences methodology ${ }^{5}$. It has been used in such diverse areas of research as the democratization of countries (Kessler \& Greenberg, 1981), substance use (Chassin, Flora \& King, 2004; Curran, 2000; Duncan \& Duncan, 1994; Greenbaum, Del Boca, Darkes, Wang \& Goldman, 2005; SimonsMorton \& Chen, 2006), intelligence testing (McArdle \& Epstein, 1987; Raykov, 1997), academic achievement (Muthén \& Khoo, 1998), and offending behaviour (Blockland et al., 2005; Chung et al., 2002; Laub \& Sampson, 2003; Wiesner \& Silbereisen, 2003; Wiesner \& Windle, 2004).

Within the specific content domain of criminology and forensic/correctional psychology, there is an additional element that deserves attention. That is, there is a general consensus in the literature that one of the best determinants of future criminal behaviour is past instances of criminality, measured in terms of frequency, severity, intensity, and/or variety (e.g., Andrews \& Bonta, 1994, 1998, 2003, 2006; Elander, Rutter, Simonoff \& Pickles, 2000; Greenwood, 1986; Loeber \& Stouthamer-Loeber, 1998; Mulvihill \& Tumin, 1969; Stattin \& Magnusson, 1991). Fortunately, autoregressive (simplex) models have been developed to take this factor into consideration. Briefly, autoregressive models apply when the prior value of a variable has a direct effect on the current value of the same variable. A distinguishing characteristic of the autoregressive models thus involves the regression of a variable on its earlier value.

\footnotetext{
${ }^{5}$ Put simply, SEM is a general framework for describing and estimating parametric statistical models.
} 
Although the autoregressive and the latent trajectory models have evolved independently, some researchers have recently cast the two approaches as competing methodologies (e.g., Bast \& Reitsma, 1997; Curran, 2000; Kenny \& Campbell, 1989; Marsh, 1993; Rogosa \& Willett, 1985, cited in Bollen \& Curran, 2004). As demonstrated by Bollen and Curran (2004), however, both traditions are special cases of a more encompassing model referred to as the autoregressive latent trajectory (ALT) model.

Perhaps the most important distinguishing characteristic of ALT modeling is the inclusion of autoregressive parameters of outcome variables into the latent growth curve model. That is, ALT can be viewed as a hybrid approach that combines the classic autoregressive (or simplex) model with the latent growth curve model. Therefore, autoregressive latent trajectory modeling does not only take advantage of the timeordered nature of the data, but also recognizes that time-adjacent measures of an outcome variable are probably best interpreted as related (e.g., higher values of earlier criminal behaviour predict higher values of later criminal behaviour). In other words, the ALT analytical strategy allows for modeling at the level of the random curve components, as well as for estimating relations between time-specific assessments of each repeated measures, simultaneously.

To add to the statistical terminological complexity, latent trajectory models are referred to as semi-parametric group-based trajectory models or latent growth (finite) mixture models when group membership is unknown (Li, Duncan \& Duncan, 2001; 
Muthén \& Shedden, 1999; Nagin, 1999; Nagin \& Tremblay, 2001) ${ }^{6}$. These models are an elaboration of the conventional maximum likelihood models that form the statistical basis for many commonly used statistical methods (e.g., Poisson, logit regression). As a matter of fact, the mixture modeling approach utilizes maximum likelihood estimation to obtain the estimated probabilities of group membership to account for the probabilistic nature of group assignment.

Two central missions of latent growth mixture modeling are the identification of clusters of individuals with similar trajectories of development, and the testing for the presence of distinctive predictors of the groups. As such, the approach assumes that the population is composed of a mixture of distinct subgroups, each defined by a prototypical growth curve. Group membership is not known, but is inferred from the data. Unobserved heterogeneity in the development of an outcome over time is therefore captured by categorical and/or continuous latent variables.

Still, it should be noted that within the general mixture modeling framework, some experts have recommended the use of latent class growth analysis (LCGA; Nagin, 1999; Roeder, Lynch \& Nagin, 1999), while others have advocated growth mixture modeling (GMM; Muthén \& Shedden, 1999; Muthén, Brown, Masyn, Jo, Khoo, Yang,

\footnotetext{
${ }^{6}$ One primary alternative to semi-parametric group-based modeling is grouping based on subjective classification rules. Using this latter analytical strategy, individuals are sorted into groups based on certain classification criteria (e.g., placing individuals who are one standard deviation above the mean in four of five assessment periods into a chronic high group). Because it does not provide a metric that is equivalent to the posterior probability of group membership in mixture modeling, however, this approach does not provide any way to assess how well an individual fits in a group. As noted by Nagin and Tremblay (2005), a trajectory group-based definition identifies a substantively far more interesting and distinctive group than a static, subjective definition,
} 
Wang, Kellam, Carlin \& Liao, 2002) ${ }^{7}$. Yet another mixture model developed to analyze longitudinal data is latent transition analysis (LTA; Collins \& Wugalter, 1992; Reboussin, Reboussin, Liang \& Anthony, 1998) ${ }^{8}$. More recently, the latent difference score model (McArdle \& Hamagami, 2001), and the State-Trait model (STARTS; Kenny \& Zautra, 2001) have also been proposed. Whatever the underlying form or particular specifications of the semi-parametric group-based models, the ultimate objective remains the estimation of a set of parameters that perform the basic functions of defining the number and shapes of the trajectories and the probabilities of trajectory group membership (Nagin \& Tremblay, 2005).

In the present study, preference was given to a growth mixture modeling solution based on the latent growth curve model put forward by Muthén and Shedden (1999). Given the nature of the research, the utility of adding autoregression parameters to the more basic latent growth curve model using Bollen and Curran's (2004) proposed ALT framework was tested. By adopting this modeling strategy, the constraints and limitations of alternative strategies to analyze change over time were addressed.

Among other things, the modeling framework uses latent variables, which reduces measurement error. Furthermore, the latent classes are identified using dynamic (i.e., longitudinal) data rather than point estimates. This is especially important given the abundance of research that exists on differences between offending behaviour at a single

\footnotetext{
${ }^{7}$ In LCGA, the mixture corresponds to different latent trajectory groups and no variation across individuals is allowed within groups. An advantageous feature of the GMM framework relates to the fact that both cross- and within-group variation is allowed for the latent trajectory groups.

${ }^{8}$ In this approach, which is also known as hidden Markov modeling, latent class indicators are measured over time and individuals are allowed to transition between latent groups.
} 
time point, but the few attempts to distinguish between groups that differ in offending patterns over time (e.g., start at a similar level of offending but diverge in offending over time). It should also be noted that the techniques allow inclusion of contextual variables, and use all participants' data, even if incomplete. Finally, there are some suggestions in the literature that it is better to simultaneously model the latent classes and the structural equation modeling relations than to use alternative methods that analyze the data successively, such as cluster analysis and then using the resulting groups in multiple group analysis (e.g., Jedidi, Jagpal \& DeSarbo, 1997). The need to move towards specialized techniques designed to analyze repeated measures data over time has in fact been documented by Moffitt et al. (2002):

Our future studies will adopt growth modeling approaches (Muthén \& Curran, 1997) to examine whether change in antisocial participation is responsive to individual differences $[\ldots]$ and whether such responsiveness is a function of childhood history and snares. These methods will help to determine whether our taxonomic prototypes can be justified in place of the more parsimonious theories linking delinquency as a dimension to its correlates. (p. 201)

Nagin (2004) recently commented that criminal behaviour does not vary regularly throughout the population, but instead tends to reveal itself in markedly different intensities in specific groups of individuals. As such, the use of latent growth curve models within a mixture modeling framework appears especially suited to the specific content domain of criminology and criminal justice research in terms of identifying 
heterogeneity in the number and types of offending trajectories, and the factors that predict membership in these trajectories.

Purpose of the Present Research

The present study aimed at identifying the distinctive criminal pathways, and specifying the early characteristics that predict the future offending trajectories, of a sample of male and female Canadian juvenile probationers followed into middle adulthood, This was accomplished within a latent growth curve (mixture) modeling framework. Contributions to the developmental criminological literature included: (a) a replication of the theoretical work proposed by Loeber and Stouthamer-Loeber (1996), Moffitt (1993) and Patterson et al. (1992), and of the empirical findings that provided support for the developmental perspective, using (b) a Canadian sample of juvenile probationers, (c) a follow-up period that extends into middle adulthood, and (d) a trajectory-detection statistical method that considers within-individual change in criminal behaviour and that is less susceptible to misclassification error (Nagin, 1999; Roeder et al., 1999).

The study also hoped to address many of the limitations associated with the existing developmental criminological literature. For instance, the specification of distinctive offending trajectories and their predictors among normative or adjudicated populations can help focus criminological theories and research on the most promising causal variables for particular types of offenders (e.g., Brezina, 2000; Lahey, Waldman \& McBurnett, 1999; Osgood, 1998). Consistent with the principles of effective correctional treatment (Andrews \& Bonta, 1994, 1998, 2003, 2006), understanding the personal and 
social variables linked to serious and chronic offending can aid with the early identification of problematic individuals and assist in the development and implementation of effective rehabilitative strategies. Among other things, research efforts towards the identification of developmental pathways to serious and chronic offending may assist in the development of improved (and the refinement of existing) actuarial risk instruments, and further guide the timing and inform the design and strategies of deliberate rehabilitative interventions (e.g., Chung et al., 2002; Howell \& Hawkins, 1998; Loeber \& Stouthamer-Loeber, 1998; Nagin \& Tremblay, 2005; Scott \& Grisso, 1997). Consequently, findings from this research can inform policies and practices, and as such contribute to the ultimate goal of correctional or criminal justice systems to reduce the human and social costs associated with crime and its processing, and ensure public safety.

Hypotheses

The following predictions are made based on the aforementioned theoretical and empirical considerations:

1) The juvenile offenders will significantly differ both in their initial levels and rates of change in criminal behaviour over time.

2) Offending pathways from early adolescence to middle adulthood will best be described by four distinct trajectories: (a) chronic high persisters; (b) stable low desisters; (c) moderate desisters; and (d) moderate persisters.

3) The criminogenic risk/needs domains assessed when the offenders were admitted to supervision, and measuring Associates, Family, Education, Accommodation, 
Attitudes, Substance Use, Financial Management, and Criminal History will predict membership in the distinctive offending trajectory groups.

4) Unique patterns of female offending will not exist. That is, female offenders will follow a trajectory similar to that of male offenders. 


\section{Method}

\section{Participants}

The sample consists of 514 juveniles from Manitoba, Canada, under a probation sentence during the years 1986 to 1991. At this time, young offenders were defined by the Young Offender Act (YOA; 1984) as between the ages of 12 to 17 years. At the time of the conviction for the index offence, the participants ranged in age from 12 to 19 years, with a mean age of 16 years $(S D=1.6)^{9}$. Approximately $44 \%$ of the sample lived with both of their parents, less than ten percent with one parent, one third with an adult who was not a parent, and $14 \%$ had been placed in either a foster or group home. As would be anticipated when dealing with an offender population, the sample was not genderbalanced. Eighty-five percent $(85.4 \%, n=438)$ of the juvenile probationers were male and $14.6 \%(n=75)$ were female. Furthermore, slightly more than half of the participants were Aboriginal $(55.4 \%, n=285)$. The overrepresentation of Aboriginal offenders was expected given that the sample originated from the province of Manitoba.

Based on their Primary Risk Assessment - Version 1 (PRA - V1; Bonta, Parkinson, Pang, Barkwell \& Wallace-Capretta, 1994) scores upon admission to supervision, $19.8 \%(n=102)$ of the juvenile offenders were assigned to the low riskneeds category, $54.3 \%(n=279)$ to medium risk-needs, and $25.9 \%(n=133)$ to high riskneeds (the mean PRA - V1 risk score for the sample was $7.5[S D=3.4]$ with scores ranging from 0 to 18 ). The majority of the juvenile probationers were first-time offenders. Only $70(13.6 \%)$ juvenile probationers had one or more prior convictions with

\footnotetext{
${ }^{9}$ The cut-off age for inclusion in the study was set at 19 rather than 17 to account for delays between the actual date of occurrence and date of conviction for the index offence.
} 
non-violent incidents accounting for $84.3 \%(n=59)$ of the cases. Furthermore, only $3.9 \%$ $(n=23)$ had previously served time in an institutional setting (e.g., prison, open custody, closed custody) prior to the index offence conviction.

Out of the 506 offenders for whom details on the most serious type of offence at index were available, the data indicated that the sample was mostly comprised of nonviolent juvenile probationers. Specifically, approximately three quarters $(76.5 \%, n=393)$ of the offenders were convicted of a non-violent index offence, whereas violent person offences represented $21.3 \%$ and violent sexual offences a mere $2.2 \%$ of the probation sample. With regards to the dispositions resulting from those index offence convictions, $11.3 \%(n=58)$ of the overall sample $(N=514)$ received some form of custodial sentence along with their term of probation (five additional offenders were sentenced to time served). To be more precise, 15 offenders were incarcerated in an adult facility, 14 others served time in a closed custody setting, and 29 young offenders received an open custodial sentence. Sentence lengths for those 58 offenders ranged from 2 to 729 days, with a mean time of $180.6(S D=148.5)$ days.

\section{Procedure}

The original sample consisted of 600 youth probation offenders randomly drawn from each year of all cases closed between 1986 and $1991^{10}$. To be eligible for inclusion in the present study, offenders had to be less than 20 years of age at the time of the conviction for the index offence. The former rule was adopted to reduce the possibility of

\footnotetext{
${ }^{10}$ The sample selection was originally designed so that 100 offenders came from each cohort year. However, nine cases from the later years were dropped from the study as they represented recidivist offenders who were already in the database for a previous probation term (i.e., duplicates).
} 
data entry errors, and ensure that the study was restricted to juvenile offenders. Four offenders were excluded from the initial sample due to their age (age 20 years or more), reducing the sample size to 587 offenders.

It is standard practice for probation officers in Canada to interview offenders upon admission to supervision. The goal of the assessment is to garner information on the offender's personal-social demographic characteristics, including various indicators of criminal history, emotional functioning and personal circumstances. Many of these factors are regarded as relevant to involvement in criminal activity and, as such, can aid the probation officers' evaluation of risk to reoffend and identification of appropriate need areas for intervention.

At the time when the sample was initially selected, the information gathered by the probation officers was used to create a comprehensive database encompassing a number of background variables that a review of the literature had previously identified as relevant to understanding and predicting the criminal careers of juvenile offenders. A systematic search on the Offender Management System (OMS) of Correctional Service of Canada (CSC) was also undertaken to complement missing information from the original database (e.g., date of birth). In addition, criminal history records requested from the RCMP's Criminal Records Branch in 1993 (i.e., Canadian Police Identification Centre $[\mathrm{CPIC}]$ records), were obtained to supplement and corroborate information that was not readily available from the probation officers. The criminal history records from the RCMP include the convictions and dispositions of sentences for offenders. 
At the end of the follow-up period in 2005, updated criminal history records were requested from the $\mathrm{RCMP}^{11}$. For approximately one-quarter of the sample $(25.2 \%, n=$ 149), the RCMP had no record of criminal activity in its system, even though in many cases, a previous CPIC record was available. The failure on the part of the RCMP to locate information on the past criminal activities of a number of offenders included in the original sample was expected. A review of the policies and practices concerning the maintenance of criminal history records by the RCMP indicated that, with the exception of the Young Offenders Act, there is no legislation requiring police forces and/or provincial and federal correctional institutions in Canada to report all charges and dispositions to the RCMP. Furthermore, there exist a number of circumstances where an offender's criminal history record may have been purged following a first set of fingerprints. For instance, the RCMP removes information pertaining to the reporting of a charge if a disposition for that charge has not been received within five years. Similarly, each individual charge or disposition entered into an offender's criminal history record is assigned an automatic purged date, in accordance with various acts (e.g., Privacy Act, Criminal Code of Canada, Young Offenders Act, Criminal Records Act), at which time the information is removed from the system. This therefore means that the individual in question no longer has a criminal history record in the RCMP system.

The RCMP in many cases advises the contributing agency that the information on a particular individual has been purged. Then again, there is no way of ensuring that the contributing agency has purged the information from its own files and systems. In light of

\footnotetext{
"In reading this section of the paper, the reader is reminded that the present study was not designed to estimate recidivism rates, but rather examine patterns of offending behaviour.
} 
this, a request was made to the province of Manitoba to try and locate the criminal history record (on all offenders for whom the RCMP found no evidence of criminal activity) from its own system, the Offender Profile Manitoba Corrections. By doing so, criminal history information was recorded for an additional 38 offenders. Six Manitoba criminal history records were, however, discarded for having no entries (e.g., just names), allowing coding the criminal careers of an additional 32 juvenile probationers for whom the RCMP had no record.

Although offenders for whom there was no criminal activity information (i.e., no previous nor updated CPIC record and no provincial record) were excluded, those for whom a previous CPIC record was available were not excluded from the study. These cases $(n=44)$ were treated as non-recidivist offenders, beyond any convictions revealed by the 1993 CPIC record ${ }^{12}$. Using these exclusion criteria, only 73 of the 149 juvenile offenders for whom the RCMP could not retrieve criminal history information were dropped from the study, producing a final sample totalling 514 offenders ${ }^{13}$.

\footnotetext{
${ }^{12}$ It was also assumed that those cases remained alive and in the country until the end of the follow-up period.

${ }^{13}$ The overall attrition rate due to missing data or incomplete/unavailable recidivism information was therefore $12.4 \%$ (73/587), which appears reasonable within the context of a longitudinal study conducted on offender populations. Preliminary analyses comparing the present sample $(N=514)$ to the group of juvenile offenders who were excluded from the study due to incompleteness/unavailability of recidivism data $(n=73)$ revealed a slight systematic or selective attrition effect. The results suggested that the offenders excluded from the study were somewhat less likely to follow a violent and persistent criminal pathway than those included in the study. Although the two groups were similar on most of the personalsocial and demographic variables (e.g., age, educational level, substance use problems), the offenders who were included in the study were significantly more likely to be male, Aboriginal, and to have higher riskneeds PRA - V1 scores (see Appendix A).
} 
Measures

Outcome Criterion

Developmental trajectories of offending were identified from a retrospective examination of the offenders' criminal history records. Two different measures of offending were coded and subsequently served as the dependent variables in the statistical analyses. The use of multiple operationalizations of a given outcome was seen as advantageous in the present study because it reduces the possibility of misrepresenting the construct of interest (in this case the frequency/severity of offending behaviour), and consequently lessens reliability concerns and potential threats to construct validity (Shadish, Cook \& Campbell, 2002).

Criminal Seriousness Index. The Criminal Seriousness Index was developed specifically for the purpose of the present study to assess both the seriousness as well as the frequency of offending patterns. A measure that combines offence severity and frequency was constructed as both dimensions of criminal behaviour tend to correlate highly (although not perfectly) and to have the capacity to differentiate non-offenders from chronic offenders (Tolan \& Gorman-Smith, 1998). Generally speaking, frequent offenders are also serious offenders. However, just as an offender could obtain a high frequency score without having committed any of the more serious offences, another offender could receive a high severity score without having been involved in repeated criminal acts.

Theoretically, Moffitt's developmental typology of antisocial behaviour (1993) further postulates that late onset desisters (adolescent-limited offenders) and early onset 
persisters (life-course-persistent offenders) do not differ with respect to the frequency of antisocial acts during adolescence. What actually differentiates the two groups during that period is a combination of variety and seriousness of offending behaviours. By combining the two methods of assessment, it was thus possible to compensate for each measure's shortcomings. For instance, the inclusion of a seriousness component into a simple frequency assessment of criminal activity provides researchers with the added benefit of being able to distinguish among offenders who have engaged in a moderate number of offences of varying gravity (Potenza, Osgood \& Plake, 1992 cited by Chung et al., 2002).

Criminal seriousness scores were defined using seven levels. Table 1 summarizes the operational definitions of each level. Level 1 denotes no offence committed, Level 2 consists of one non-violent incident, and Level 3 represents more than one non-violent incidents. In contrast to the first three levels, levels 4 through 7 include at least one violent incident(s), with or without one or more non-violent conviction(s). Non-violent offences included all crimes against property (e.g., break and enter, theft), crimes against public morals and decency (e.g., indecent phone call, keeping a bawdy house), narcotics offences (e.g., possession of restricted drug, trafficking), liquor and traffic offences (e.g., driving while disqualified, failure to remain at a scene of an accident), as well as other offences such as causing a disturbance, failure to appear and probation/parole violation. In contrast, violent offences included all crimes against the person (e.g., armed robbery, assault), violent property offences (e.g., arson, malicious damage), and most sexual 
offences (e.g., rape, sexual assault). Sexual crimes related to prostitution and pornography were coded as non-violent (i.e., crimes against public morals and decency). Table 1

\section{Criminal Seriousness Index}

\begin{tabular}{lc}
\hline Score & Operational definition \\
\hline 1 & No offence \\
2 & 1 Non-violent incident \\
3 & $>1$ Non-violent incidents \\
4 & 1 Violent incident \\
5 & 1 Violent incident $+\geq 1$ non-violent incident(s) \\
6 & $>1$ Violent incidents \\
7 & $>1$ Violent incidents $+\geq 1$ non-violent incident(s) \\
\hline
\end{tabular}

Canadian Recidivism Index (Gendreau \& Leipciger, 1978). The Canadian Recidivism Index is a recidivism measure that was developed to address some of the problems and limitations in the measurement of crime and recidivism rates (e.g., variations in the conceptual meaning and operational definitions, lack of sensitivity to the degree of severity) as well as their applicability to Canadian jurisdictions and practicality of scoring. The measure represents a Canadian translation of Moberg and Erikson's (1972) recidivism outcome index, which quantifies recidivism on a continuum based upon the United States' legal dispositions of the offender. The rationale behind the 
development of such a recidivism measure is that the penalties imposed for known offences are related to society's interpretation of severity (Moberg \& Erikson, 1972).

The scale consists of eight categories, which range from 1 (incarceration for two years or more) to 8 (no illegal activities). Preliminary analyses examining rates of recidivism across the prognostic categories among a sample of first-time young adult incarcerates suggested that the measure was a valid index of the degree of seriousness in recidivism (Gendreau \& Leipciger, 1978). To ease interpretation and make the scale more relevant to the present study, however, a slightly modified version of the original instrument was used. Specifically, the index categories were inverted so that higher scores are reflective of an increased severity in offending behaviour. Furthermore, the category referring to "Absconder/Wanted" was dropped, as insufficient information was available on the offenders' criminal history records to code the items and/or because the items were not expected to be used frequently. A full description of the Canadian Recidivism Index as used in this study can be found in Table 2.

Given the scoring procedures, there was the possibility that an offender could receive multiple convictions (related to different incidents) during each wave of assessment. To address this potential issue, each offender's score on the Canadian Recidivism Index was based on the incident that resulted in the most serious conviction (as defined by the instrument's coding categories) during that particular period of assessment. 
Table 2

Canadian Recidivism Index

\begin{tabular}{|c|c|}
\hline Score & Operational definition \\
\hline 1 & No illegal activities of any kind \\
\hline 2 & $\begin{array}{c}\text { Convicted of an offence for which a fine }<\$ 100.00 \text { and/or a conditional } \\
\text { or absolute discharge has been imposed }\end{array}$ \\
\hline 3 & $\begin{array}{l}\text { Convicted of an offence and sentenced to probation and/or for which a } \\
\text { conditional or suspended sentence and/or a community service order or } \\
\text { restitution and/or a fine } \geq \$ 100.00 \text { has been imposed }\end{array}$ \\
\hline 4 & Recommitted and/or probation/parole violation \\
\hline 5 & $\begin{array}{l}\text { Convicted of an offence for which a sentence of } \leq 90 \text { days and/or time } \\
\text { served has been imposed }\end{array}$ \\
\hline 6 & $\begin{array}{c}\text { Convicted of an offence for which a sentence of }>90 \text { days but }<2 \text { years } \\
\text { has been imposed }\end{array}$ \\
\hline 7 & $\begin{array}{c}\text { Convicted of an offence for which a sentence of } \geq 2 \text { years has been } \\
\text { imposed }\end{array}$ \\
\hline
\end{tabular}

${ }^{a}$ Time Served was scored as a 5 unless specific information is available on the criminal history record indicating that the length of the sentence is $>90$ days.

\section{Adjustments for Time-at-risk}

It should be noted that the computation of both the Criminal Seriousness Index and the Canadian Recidivism Index was complicated by the fact that some offenders spent some time in confinement during the course of the study. This issue would have been less of a concern had self-report measures of offending been used as the individuals may still commit and report violent and non-violent acts while in detention (Chung et al., 2002). In the present study however, official records based on crimes in the community were used. As a consequence, adjustments for "time-at-risk" had to be made to the 
follow-up measures of offending. To do so, the offenders' scores on both indices were divided by the natural log of the number of months they were "street free" (i.e., not incarcerated) to commit an offence during the particular period of assessment (the resulting scores were further multiplied by 10 to facilitate interpretation $)^{14}$.

Adjusting for time-at-risk was employed as a means to address the limitation of previous research that failed to take into consideration incarceration time. Values on the CSI and CRI for offenders who did not reoffend during a particular age period due to having spent the entire period incarcerated and thus having had no opportunity to reoffend were treated as missing values. Similarly, to avoid making assumptions about the severity of offending in the absence of information, age categories that did not have a criminality score were also assigned missing values ${ }^{15}$.

\section{Timing of Assessment}

Offenders were given a score on both the Criminal Seriousness Index and the Canadian Recidivism Index at each of five periods starting with the age following which they were convicted for their index offence. Offending trajectories were modeled as a function of age rather than year, as there is considerable age heterogeneity at each year cohort. As a result, chronological age was judged to be a more appropriate and less

\footnotetext{
${ }^{14}$ The natural $\log$ of, rather than the raw, scores were used to augment the influence of actual outcome ratings (or reduce the influence of the time-at-risk indicator). By taking the natural log of the number of months, however, offenders' scores for whom time-at-risk equalled one month during a particular assessment period were treated as missing values. It should also be noted that the follow-up period during the last wave of assessment was greater than 60 months for approximately 80 offenders, roughly two-thirds of whom did not commit an offence during that time period. Although the effect is likely minimal, using a natural logarithmic function on those "non-recidivist" offenders would be expected to have a small impact on underestimating their offending frequency/severity scores during that last assessment period.

${ }^{15}$ An examination of the data demonstrated that this issue arose infrequently, and so was not of a concern. Specifically, five offenders were not at risk to commit a new offence during the first wave of assessments, while this was true for only two offenders during both the fourth and fifth age periods.
} 
biased measure of time. The age periods were theoretically defined, to reflect meaningful stages of human development. Those are: (1) Early Adolescence (12-15 years of age); (2) Late Adolescence (16-20 years of age); (3) Early Adulthood (21-25 years of age); (4) Adulthood (26-30 years of age); and (5) Middle Adulthood (31 years of age and over). Both outcome measures thus yielded a composite score reflecting the seriousness and frequency levels of criminal acts committed during that age period.

\section{Criminogenic Risk/Needs Factors}

With one exception, the predictors of offence trajectory were measured by the probation officers when the juvenile offenders were admitted to supervision, that is prior to gathering information on recidivism. One exception related to the criminal history variables for which follow-up criminal history records were used as a source of information. The juvenile predictors selected for inclusion sought to operationalize constructs that a review of the literature suggested were theoretically and empirically relevant to understanding developmental trajectories of offending. Those constructs reflect the peer, familial, education, accommodation, attitudinal, substance use, financial, and criminal history aspects of the offenders' lives. All eight general domains were coded on a three-point scale, with total scores ranging from 0 to 2 and higher scores indicating a higher risk for criminality. A general description of each predictor variable is presented below. This is followed by a table reporting the descriptive statistics of the criminogenic risk/needs factors for the sample in this study. Supplementary information on the actual scoring of the individual items is available from the author. 
Table 3

Descriptive Statistics of the Risk Factors

\begin{tabular}{|c|c|c|c|}
\hline Predictor variable (score) & $\%(n)$ & Predictor variable (score) & $\%(n)$ \\
\hline Associates & & Attitudes & \\
\hline No problem $(0)$ & $24.9(128)$ & No problem $(0)$ & $52.1(268)$ \\
\hline Some problems (1) & $60.9(313)$ & Some problems (1) & $34.4(177)$ \\
\hline Major problems (2) & $14.2(73)$ & Major problems (2) & $13.4(69)$ \\
\hline Family & & Substance Use & \\
\hline No problem (0) & $31.5(162)$ & No problem $(0)$ & $57.4(295)$ \\
\hline Some problems (1) & $43.6(224)$ & Some problems (1) & $35.8 \cdot(184)$ \\
\hline Major problems (2) & $24.9(128)$ & Major problems (2) & $6.8(35)$ \\
\hline Education & & Financial Management & \\
\hline At the exp. Level (0) & $22.8(117)$ & No problem $(0)$ & $45.1(232)$ \\
\hline 1 yr below norm (1) & $41.6(214)$ & Some problems (1) & $37.0(190)$ \\
\hline$\geq 2$ yrs below norm (2) & $35.6(183)$ & Major problems (2) & $17.9(92)$ \\
\hline Accommodation & & Criminal History & \\
\hline No problem $(0)$ & $50.2(258)$ & Low risk (0) & $86.2(443)$ \\
\hline Some problems (1) & $24.1(124)$ & Medium risk (1) & $8.2(42)$ \\
\hline Major problems (2) & $25.7(132)$ & High risk (2) & $5.7(29)$ \\
\hline
\end{tabular}

Associates. Associates is a nominal predictor variable that reflects the degree of opportunities, involvement and bonding with antisocial peers. Evidence of good peer support and influence (i.e., no adverse relationships) was scored as 0 . Offenders who 
periodically associated with negative peers received a score of 1 while those with regular and frequent unfavourable and unconstructive ties a score of 2.

Family. The familial domain of the juvenile offenders was evaluated using two individual risk factors: family relations and alcohol abuse in the family. Offenders received one point if the familial environment was disorganized and/or stressful, and another point if there was alcohol abuse evident in their family.

Education. For Education, the juvenile probationers were given a score of 0 if they were at the expected grade level according to their age when they were admitted to supervision for the index offence, a score of 1 if they were one grade below the standard educational level, and a score of 2 if their last grade completed was two or more years below the norm.

Accommodation. The Accommodation construct measured the stability of living arrangement and was coded using the actual number of address changes in the last 12 months (the year prior to incarceration if the offender received a custodial sentence preceding his/her term of probation). A score of 0 was given if no address change occurred in the year prior to the period of probation (or incarceration if the offender received custody preceding his/her term of probation), a score of 1 if the juvenile probationers changed address once, and a score of 2 if two or more address changes took place.

Attitudes. The attitudinal construct reflects the offenders' general attitudes to probation. Offenders received a score of 0 if they were receptive to assistance and motivated to change their behaviour, a score of 1 if they were relatively neutral towards 
their crime and the prospect to change their behaviour, and a score of 2 if they were generally negative, not motivated to change and/or rationalized their behaviour.

Substance Use. Substance Use measured the degree to which the probationers' alcohol and/or drug use was problematic. Offenders received a score of 0 if their alcohol/drug usage did not interfere with functioning, a score of 1 if there were signs of occasional abuse with some disruption of functioning, and a score of 2 if abuse was frequent and seriously disrupted functioning, showing a need for treatment.

Financial Management. The financial domain combined two dichotomous variables: reliance on social assistance and financial management. Offenders were given one point if they received social assistance during the year prior to the index offence (the year prior to incarceration if the offender received custody preceding his/her term of probation), and another point if there was any evidence of difficulties in the financial management area (e.g., bad checks, bankruptcy, garnishment) ${ }^{16}$.

Criminal History. Information on a number of static, unchangeable risk factors such as the offenders' age at first conviction, as well as the presence of a prior conviction, a prior sentence of incarceration, and a term of incarceration before the probation period was collected. Offenders received a score of 0,1 or 2 on the general Criminal History construct if they, respectively, had zero, one, and two or more points based on the following: (a) they were below the median age of the sample when they were first convicted; (b) they had one or more prior convictions; (c) they had received a period of

\footnotetext{
${ }^{16}$ This was the definition provided with the original data. However, the ratings may have had more to do with management of money (e.g., how the juvenile probationers did with their allowance and/or social assistance, whether or not they had debts).
} 
incarceration on a previous conviction (prior to the index offence); and (d) they had received a period of incarceration prior to their probation term (as part of the conviction for the index offence).

Some of the variables used to create those criminogenic risk/needs domains corresponded to individual items on a revised version of the Wisconsin Risk and Needs classification system (Bonta, Parkinson, Pang et al., 1994). Accordingly, we also report the offenders' scores on the youth version of the revised actuarial risk and needs scale.

The original Wisconsin instrument (Baird, Heinz \& Bemus, 1979) consisted of 11 risk items and 12 needs items summated to yield two separate total scores that placed the offenders into either a low, medium or high risk and needs category, respectively. A study investigating the predictive validity of the risk and need measures yielded mixed findings, pointing out to weaknesses for their use with young offenders (Sabourin, 1986). Following Sabourin's (1986) evaluation, some revisions were brought about to both the adult and youth version of the scales. Despite these modifications, a second study (Barkwell, 1991) on the revised risk and needs instruments still revealed limitations with the youth version.

In light of these studies, Bonta and his colleagues (Bonta, Parkinson, Pang et al., 1994) undertook a set of studies to examine the psychometric properties and predictive validity of the scales. The findings from their evaluation suggested a number of modifications, which included the removal of items that showed no predictive validity, the simplification of many of the scoring rules, and combining the risk and needs items into one scale rather than two individual assessments. It is the youth version of the 
classification instrument that resulted from these modifications that was used in the present study as it demonstrated improved predictive validity among young probationers (Bonta, Parkinson, Barkwell \& Wallace-Capretta, 1994). We call this instrument the Primary Risk Assessment - Version 1 (PRA - V1, 1994; the instrument was further revised for youths in the late 1990s with considerably more items added).

Data Management and Related Issues

In the present study, all data were entered in SPSS (Statistical Software for the Social Sciences 15.0). Analyses were conducted with the software package Mplus 4.2 (Muthén \& Muthén, 1998, 2006). Mplus facilitates the analysis of structural equation modeling relations by enabling researchers to gain insight into causal models and the strength of variable relationships and build models that more realistically reflect complex relationships by using observed variables and/or latent variables to predict any other numeric variable. In addition, Mplus has the unique capability of identifying clusters or groups of individuals with similar trajectories. The software program was designed to simultaneously use both continuous latent variables (e.g., random effects corresponding to individual differences in development) and categorical latent variables (e.g., latent trajectory groups corresponding to types of development). That is, the modeling framework allows estimation of trajectory shapes as random rather than fixed effects, thus modeling individual variation in trajectory shape within each latent group. A noteworthy strength of the Mplus statistical software is that it reports the statistical findings in the form of transparent graphical and tabular analyses. 
In addition, one of the valuable features of Mplus is that it allows missing data in all parts of the model, except observed background variables (i.e., predictors and/or covariates). When the program reads the data file and encounters missing values, it automatically computes maximum likelihood estimates (Anderson, 1957). Missing data in the present study was imputed using a regression method assuming ignorable missingness at random (MAR). In contrast to estimation under MCAR (missingness completely at random), MAR accepts that missingness can be a function of observed covariates and observed outcomes ${ }^{17}$. More specifically, after the model parameters are set equal to their maximum likelihood estimates, linear regression is used to predict the unobserved values for each case as a linear combination of the observed values for that same case.

In this study, data on the majority of the individual predictors were available for all participants. Two variables, however, had one or more missing values. Those were Education (13) and Accommodation (8). Given that participants' data on both variables were missing for no more than $10 \%$ of the sample, and to make use of all available cases for whom recidivism information was available, missing values were imputed using the sample median for the rest of the dataset.

\footnotetext{
${ }^{17}$ The tenability of this assumption appeared justified given that, by using official criminal history records, neither retention nor the presence of any systematic or selective attrition effects is expected to be a problem.
} 


\section{Results}

Data analysis proceeded in multiple stages. In the first stage, the functional form of the overall criminal pathway for the offenders included in the sample was explored using latent trajectory modeling to determine the optimal structural equation model to fit the data. Because the results on the best-fitting growth curve model indicated that there were individual differences in criminal behaviour at baseline as well as in the rate of progression over time, growth mixture modeling was then used to identify subgroups of young probationers with distinct offending trajectories from early adolescence to middle adulthood. Finally, the optimal unconditional models were expanded to include antecedent risk factors assessed at index as predictors of offending trajectory group membership.

Given that the study sample consisted of a group of adjudicated offenders, all juvenile probationers, including the non-recidivists who had no criminal conviction following the index offence ( $n=48$ or $9.3 \%$ of the sample) were included in the analyses. The non-recidivists also engaged in criminal activity (i.e., the behaviour of interest) at some point in time and thus contributed to an analysis of change. Table 4 presents some basic statistics describing the criminal behaviour of the offenders over the assessment periods $^{18}$. As can be seen, the general aggregated pattern of criminal activity generated for the Manitoba sample mirrored the classic age-crime curve in that the rate of offending peaked in late adolescence and declined gradually into adulthood.

\footnotetext{
${ }^{18}$ Simple correlations between the adjusted scores on the CSI and the CRI at each time period were $r=.76$, $r=.78, r=.80, r=.83$ and $r=.87$ (all $p s<.01$ ), respectively.
} 
Table 4

Descriptive Longitudinal Analyses of the Sample

\begin{tabular}{lcccc}
\hline $\begin{array}{l}\text { Time period } \\
\text { (age) }\end{array}$ & $N$ & $\begin{array}{c}\text { \% Any } \\
\text { recidivism }\end{array}$ & $\begin{array}{c}\text { Adjusted CSI } \\
M(S D)\end{array}$ & $\begin{array}{c}\text { Adjusted CRI } \\
M(S D)\end{array}$ \\
\hline $12-15$ & 221 & 32.1 & $6.97(4.59)$ & $8.26(7.27)$ \\
$16-20$ & 514 & 71.6 & $8.15(5.33)$ & $8.47(4.61)$ \\
$21-25$ & 510 & 63.5 & $8.04(5.74)$ & $7.98(5.59)$ \\
$26-30$ & 505 & 51.3 & $6.58(5.32)$ & $6.71(4.96)$ \\
31 onwards & 425 & 29.2 & $5.33(4.21)$ & $5.80(5.07)$ \\
\hline
\end{tabular}

Note . CSI = Criminal Seriousness Index; CRI = Canadian Recidivism Index. Scores on

the CSI and CRI were adjusted to control for time-at-risk in the community. A

considerably lower number of offenders were assessed during the first time period (ages

12-15) due to the fact that the mean age of the sample at the time of the conviction for the index offence was 16.

Temporal Patterns of Growth and Individual Variability in Offending Trajectories

The first series of analyses was aimed at uncovering the shape of the developmental trajectory of juvenile progression in criminal behaviour over the age periods. A number of unconditional (without covariates) latent trajectory models were estimated to explore the functional form of growth that best fitted the Criminal Seriousness Index and Canadian Recidivism Index data. Separate analyses were performed on each dependent variable.

The model-fitting strategy followed recommendations and examples from the literature (e.g., K. A. Bollen, personal communication, March 28, 2007; Bollen \& Curran, 
2004; Chassin et al., 2004). The analysis began by assuming a single group and applying a latent growth curve model with a linear growth function only. However, because antisocial and aggressive behaviour is often episodic (e.g., Lahey, Loeber, Hart, Frick, Applegate, Zhang, Green, \& Russo, 1995; LeBlanc, 1996), and given the shape of the age-crime curve, a quadratic growth function was fitted to the data. In contrast to the linear-only model, the quadratic model allows for curvilinear trends across the ages. As such, the quadratic growth model does not only contain an intercept factor and a linear factor, but also a quadratic factor. Subsequently, both the linear and quadratic latent trajectory models with autoregressive relations (i.e., ALT models) were estimated.

Parameterization of the Growth Curve Analyses. The estimator for the latent growth curve analyses was maximum likelihood with standard errors and a chi-square test statistic that are robust to non-normality (MLR). Some of the characteristics of the models were that the path loadings from the latent intercept to the outcome measures were fixed at 1.0 while the fixed loadings from the latent growth factors to each of the five outcome measures were $-1,0,1,2$ and 3 for the linear factor, and 1, 0, 1, 4 and 9 for the quadratic factor ${ }^{19}$. Furthermore, the means of the growth factors as well as their variances and covariances were estimated because the growth factors are exogenous (i.e., independent) variables, and as such do not influence any variable in the model except their own indicators. With one exception, residual variances across the assessment waves

\footnotetext{
${ }^{19}$ The zero time score for the slope growth factor at the second wave of assessment defines the intercept of this growth factor as the initial status factor.
} 
were also estimated and free to vary over time ${ }^{20}$. However, apart from the mean of the CSI or CRI at the first time point in the autoregressive latent trajectory models, which were estimated, the intercepts of the observed dependent variables were not estimated, but fixed to zero.

In the parameterization of the ALT models, the initial assessment of each repeated measure was treated as predetermined to avoid potential bias from the omission of influences from measures occurring prior to the initial assessment (i.e., infinite regress). The loadings from the latent growth factors to each of the last four outcome measures were fixed at $0,1,2$ and 3 for the linear factor, and $0,1,4$ and 9 to define the quadratic factor. Furthermore, given that with five waves of assessment the model is identified even without placing an equality constraint on the autoregressive parameter $\rho$ within each series and over time (Bollen \& Curran, 2006), no equality constraint was placed on $\rho$. To serve as examples, the quadratic unconditional latent growth curve (LGC) and autoregressive latent trajectory (ALT) models are illustrated graphically in Figures 1 and 2 , respectively. The diagrams are pictorial representations of the equations of the LGC and ALT models with five repeated measures.

\footnotetext{
${ }^{20}$ Constraining the time-specific residual variances to be equal over time either resulted in a significant decrement in model fit (based on a chi-square difference in test between two nested models), or in model convergence (i.e., the latent variable covariance matrix (psi) was not positive definite). It was however, necessary to impose an equality constraint on the residual variances of the observed dependent variables across the last four assessment waves in the quadratic ALT models in order for the models to be identified.
} 
Figure 1

Unconditional Quadratic Latent Growth Curve (LGC) Model

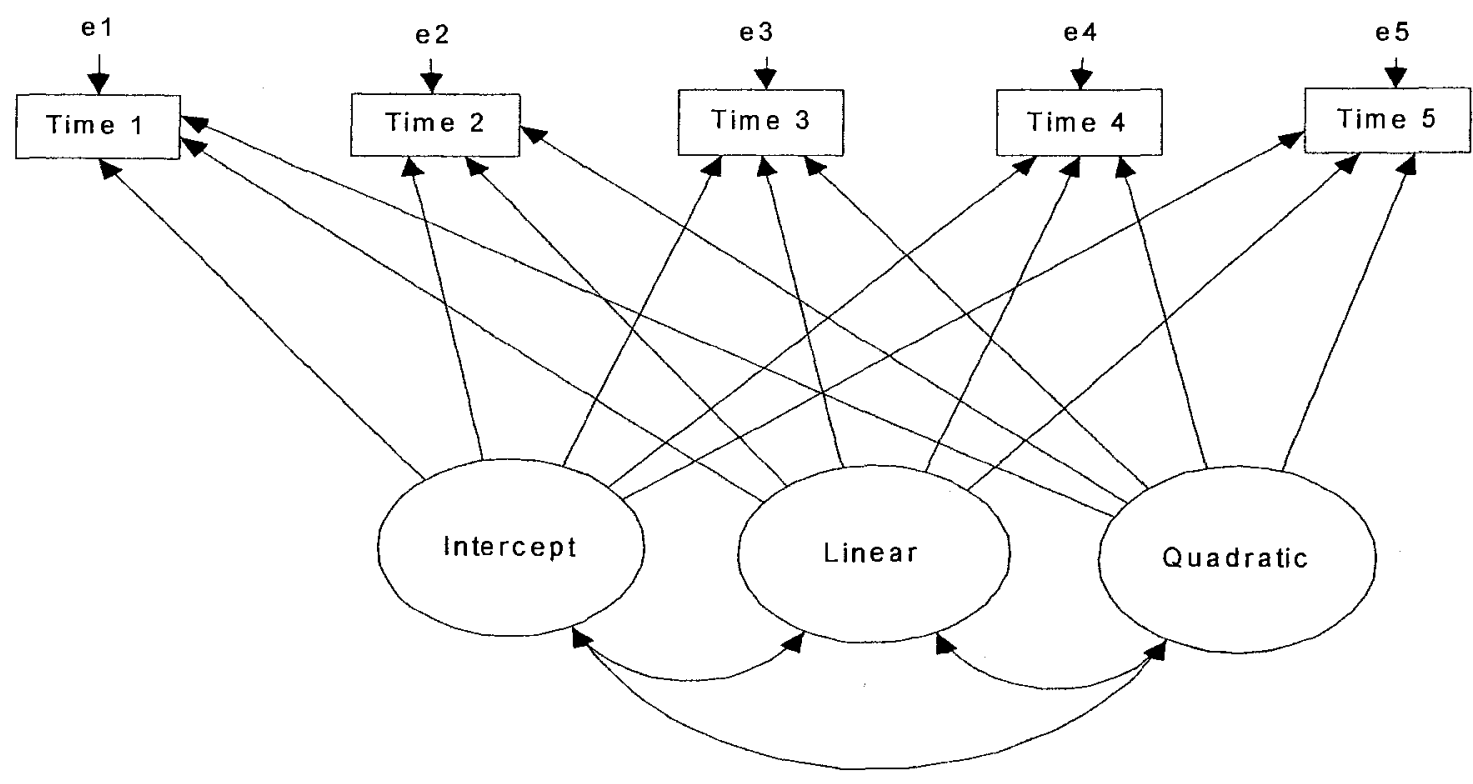

Figure 2

Unconditional Quadratic Autoregressive Latent Trajectory (ALT) Model

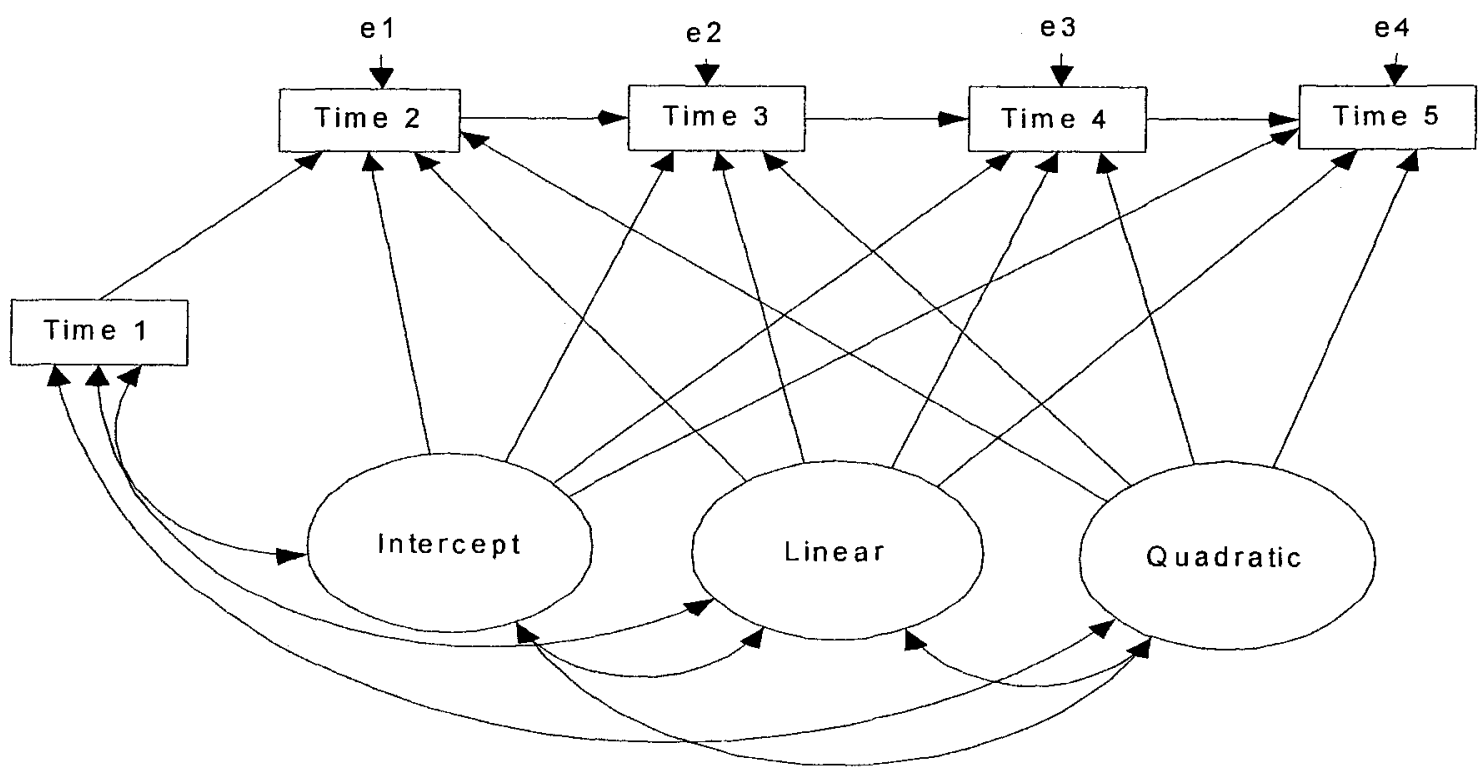


In the figures, latent variables (often referred to as growth factors) are enclosed in circles or ellipses, observed variables appear in rectangular boxes, and error terms are not enclosed in any circle or box. The straight single-headed arrows are parameters that signify the impact of the variable at the base of the arrow on the variable at the end of the arrow. The curved two-headed arrows represent the covariances of the two variables connected by the arrows.

As can be seen, there are three underlying and unobserved latent variables in the models. The first latent factor represents the intercept component of the trajectory, while the second and third latent factors represent the slope (i.e., linear and quadratic components, respectively) of the trajectory. Similarly, there are five multiple indicators representing the repeated measures of offending behaviour for every individual over each time point. In contrast to the latent factors, these are observed variables and so involve measurement error.

In order to study the individual and comparative fit of the growth curve models, a number of overall fit measures were considered. Specifically, the likelihood ratio statistic $T_{\mathrm{ML}}$ (or chi-square test) was examined, where a statistically significant test statistic suggests that the model specification does not adequately reproduce the means or the covariance matrix of the observed variables. Moreover, two baseline fit indices, the Tucker-Lewis index (TLI; Tucker \& Lewis, 1973), and the comparative fit index (CFI; Bentler, 1990) were calculated. Values on these two measures range between zero and one, where one is an ideal fit. Finally, a stand-alone index of fit was considered, the rootmean-square error of approximation index (RMSEA; Steiger \& Lind, 1980), as well as an 
information theory-based measure used to compare multiple models, the Bayes Information Criterion (BIC; Raftery, 1993; Schwartz, 1978). The RMSEA has a minimum of zero and no upper limit, the closer to zero the value is, the better is the model fit. Steiger (1989) as well as Browne and Cudeck (1993) suggest guidelines such that RMSEA values of less than 0.05 indicate a very good fit, those greater than 0.10 represent a poor fit, and those values in between a moderate fit. Similarly, smaller BIC values indicate better fit than that of higher values (no matter the actual BIC value).

However, it is possible to have a model that has good overall fit on several or all of the overall fit measures, but that has poor fit in terms of its components (or vice versa) (Bollen \& Curran, 2006). Consequently, diverse component fit measures were used to assess how well each model corresponded to the data as a whole. This involved an examination of the parameter estimates and screening for "improper solutions" (e.g., negative residual variances, correlations of absolute magnitude greater than one), and estimating the proportion of the variability in the observed variables accounted for by the underlying latent trajectory factors (i.e., $R^{2}$ yt). Tables 5 and 6 report on some of those findings for the Criminal Seriousness Index and Canadian Recidivism Index, respectively. The comparative fits of the models, obtained using chi-square difference tests for nested models, are shown in Table $7^{21}$.

\footnotetext{
${ }^{21}$ Throughout this paper, the chi-square difference tests for comparison of nested models were performed using Satorra-Bentler's (1999) formula of scaled chi-square for continuous non-normal outcomes to correct for the fact that a difference between two scaled chi-squares for nested models is not distributed as chisquare. Accordingly, the resultant scaled chi-square test statistics for moment structure analysis were accurate.
} 
Table 5

Fit Measures of the Linear and Quadratic Latent Growth Curve Models and Autoregressive Latent Trajectory Models for the CSI

\begin{tabular}{lcccccc}
\hline & \multicolumn{7}{c}{ Fit index } \\
\cline { 2 - 7 } Model & $T_{\mathrm{ML}}(d f)$ & TLI & CFI & RMSEA & BIC & $R^{2}$ \\
\hline Linear LGC & $107.66^{* *}(10)$ & .625 & .625 & .138 & 13120 & $.22-.50$ \\
Quadratic LGC & $9.95(6)$ & .975 & .985 & .036 & 13026 & $.34-.60$ \\
Linear ALT & $11.60^{*}(3)$ & .879 & .967 & .075 & 13048 & $.26-.51$ \\
Quadratic ALT & $1.25(1)$ & .991 & .999 & .022 & 13047 & $.26-.61$ \\
\hline$* p<.01 * * p<001$ & & & & & &
\end{tabular}

Table 6

Fit Measures of the Linear and Quadratic Latent Growth Curve Models and Autoregressive Latent Trajectory Models for the CRI

\begin{tabular}{llccccc}
\hline & \multicolumn{7}{c}{ Fit index } \\
\cline { 2 - 7 } Model & $T_{\mathrm{ML}}(d f)$ & TLI & CFI & RMSEA & BIC & $R^{2}{ }^{2}$ \\
\hline Linear LGC & $41.94^{* *}(10)$ & .895 & .895 & .079 & 13003 & $.24-.60$ \\
Quadratic LGC & $8.83(6)$ & .984 & .991 & .030 & 12986 & $.45-.67$ \\
Linear ALT & $0.67(3)$ & 1.026 & 1.000 & .000 & 12994 & $.39-.51$ \\
Quadratic ALT & $3.77(1)$ & .909 & .991 & .073 & 13009 & $.45-.60$ \\
\hline$* * p<.001$. & & & & & &
\end{tabular}


Table 7

Likelihood Ratio Tests for Comparison of Nested Models

\begin{tabular}{lcccc}
\hline Model & Linear LGC & Quadratic LGC & Linear ALT & Quadratic ALT \\
\hline Linear LGC & - & $33.11^{* * *}(4)$ & $41.27^{* * *}(7)$ & $38.17^{* * *}(9)$ \\
Quadratic LGC & $97.72^{* * *}(4)$ & - & $8.16^{*}(3)$ & $5.06(5)$ \\
Linear ALT & $96.07^{* * *}(7)$ & $0(3)$ & - & $0(2)$ \\
Quadratic ALT & $106.42^{* * *}(9)$ & $8.70(5)$ & $10.35^{* *}(2)$ & - \\
\hline
\end{tabular}

Note. Cells below the diagonal refer to the models involving the CSI whereas cells above the diagonal refer to the models involving the CRI. Differences in degrees of freedom are in parentheses.

${ }^{*} p<.05 .{ }^{* *} p<.01 . * * * p<.001$.

An examination of the parameter estimates indicated that all of the variance estimates and correlations of the random intercepts and slopes for both outcome variables were, respectively, positive and smaller than one in absolute magnitude. In spite of this, Table 7 shows that the quadratic LGC model best fitted the data for both the Criminal Seriousness Index and the Canadian Recidivism Index. The overall fit of the models based on the likelihood ratio statistic was $T_{\mathrm{ML}}=9.95$ with $d f=6$ for the CSI and $T_{\mathrm{ML}}=$ 8.83 with $d f=6$ for the CRI. These overall fit tests are non-significant, suggesting that for each outcome measure the population observed moment structure is equal to the model implied moment structure. Only on the quadratic ALT models were the likelihood ratio 
test statistics also non-significant $\left(T_{\mathrm{ML}}=1.25\right.$ with $d f=1$ for the CSI and $T_{\mathrm{ML}}=3.77$ with $d f=1$ for the CRI, both $p s>.05)^{22}$.

On the face of it, the fit differences between the LGC and ALT quadratic models were minimal, with both models providing a relatively equivalent fit for the Criminal Seriousness Index and the Canadian Recidivism data. However, neither chi-square difference test comparing one quadratic model to the other was statistically significant $\left(\chi^{2}\right.$ difference $=8.70$ with $d f=5$ for the CSI, $\chi^{2}$ difference $=5.06$ with $d f=5$ for the CRI, both $p$ s $>.05$ ). These results imply that, for both outcome measures, the addition of autoregression parameters to the more parsimonious quadratic latent growth curve models do not produce substantial improvement in model fit.

Similar conclusions were reached upon consideration of the other baseline fit indices for the quadratic latent growth curve and autoregressive latent trajectory models. With one exception (the quadratic ALT model involving the CRI), values on the TLI and CFI were very close to the ideal value of one and values on the RMSEA were below the recommended value of 0.05 , indicating that the models fitted the data very well.

Controlling for time-at-risk, the proportion of variance in the Criminal Seriousness Index and Canadian Recidivism Index accounted for by the underlying latent factors (i.e., random intercept and growth factors) was also similar. Regardless of the outcome measure, however, BIC values favoured the quadratic LGC model over the quadratic ALT model. Taken as a whole, these results indicate that, for both the CSI and the CRI, the latent growth curve model specified with a quadratic function best represented the

\footnotetext{
${ }^{22}$ Results for the linear-only ALT model involving the CRI may appear suitable, but are likely suggestive of data overfit (e.g., TLI value exceeding one, CFI value of one, and RMSEA value of zero).
} 
shape of the developmental trajectory of juvenile progression in criminal behaviour from early adolescence to middle adulthood.

Central to the present investigation, the magnitude and significance of the variances in the quadratic LGC models were examined to determine whether the juvenile offenders in this study differed in their initial level and rate of change in criminal behaviour over time. In fitting the latent growth curve models, a significant variance in intercept (defined as the average criminal behaviour rating during late adolescence, the second age period) would indicate substantial individual differences in criminal behaviour at baseline. Similarly, significant variation in latent growth factors (i.e., linear and/or quadratic components) would reveal individual differences in the rate of progression in criminal behaviour over the years ${ }^{23}$.

Findings showed that there was significant heterogeneity in the criminal behaviour status and growth factors on both the Criminal Seriousness Index and the Canadian Recidivism Index. That is, there was significant variability around the mean in the intercept and slope components of the quadratic latent growth curve models. The maximum likelihood variance estimates on the CSI and the CRI were, respectively, $\operatorname{VAR}(\zeta)=9.71(p<.001)$ and $\operatorname{VAR}(\zeta)=12.00(p<.001)$ for the intercept, $\operatorname{VAR}(\zeta)=$ $5.73(p<.001)$ and $\operatorname{VAR}(\zeta)=8.02(p<.001)$ for the linear factor, and $\operatorname{VAR}(\zeta)=0.86(p$ $<.001)$ and $\operatorname{VAR}(\zeta)=0.90(p<.001)$ for the quadratic factor. This implies that the juvenile offenders in this study differed in their average criminal behaviour ratings during

\footnotetext{
${ }^{23}$ The variance around the random intercept and random slope components give the variability in intercept and growth factors around the mean for the individuals in the sample. Estimates that are not statistically significant suggest that the group has the same intercept or slope of the trajectory.
} 
late adolescence, the second age period, as well as in their rate of change in criminal behaviour over time. Subsequent analyses thus attempted to explain this variability by using growth mixture modeling.

\section{Identifying the Number and Types of Offending Trajectories}

There was significant intra-individual variance in status and growth factors on the best fitting model for both the Criminal Seriousness Index and the Canadian Recidivism Index trajectories using a one-group solution, justifying the extraction of additional groups to account for this heterogeneity. Thus, after specifying a single group, two-group through four-group growth mixture solutions were tested to determine the optimal number of trajectory groups to extract. In the parameterization of the growth mixture analyses, growth factor variances and covariances, as well as residual variances of the observed dependent variables were constrained to be equal across groups. However, the mean parameters of the growth factors were allowed to vary across groups.

In growth mixture modeling, model selection requires determination of the number of groups that best describes the data. However, it is not appropriate to use the standard log likelihood ratio (i.e., Chi-Square difference) test for model comparison because a $k$ group model is not nested within a $k+1$ group model. Several statistics are available to help determine the optimal number of groups to extract. In the present study, model fit was evaluated using one of the more popular selection factors, namely the Bayes Information Criterion (BIC; Raftery, 1993; Schwartz, 1978) ${ }^{24}$. The Bayes

\footnotetext{
${ }^{24}$ It was planned to evaluate model fit using the entropy measure (ENT; Ramaswamy, DeSarbo, Reibstein \& Robinson, 1993), but because nothing beyond a 2-group model was obtained, this measure was not of any use.
} 
Information Criterion can be used for comparison of both nested and unnested models (Kass \& Raftery, 1995; Raftery, 1995). As previously commented, the model with the smallest absolute BIC value is generally chosen. It should be noted that the BIC formula rewards parsimony, and therefore tends to favour models with fewer groups.

In addition to comparing BIC values, visually inspecting the shapes of the resulting trajectories ensured that the findings were substantively significant or meaningful. Because recent work cautioned against over-extraction of latent groups in the presence of non-normal data (Bauer \& Curran, 2003), solutions that contained one or more groups with fewer than $5 \%$ of the sample were not considered for concern that they would have poor replicability. The results are displayed in Table 8.

Table 8

BIC Values of the Quadratic Latent Growth Curve Models for the CSI and CRI

$\mathrm{BIC}$

\begin{tabular}{lcc}
\cline { 2 - 3 } Model & CSI & CRI \\
\hline 1-group & 13026 & 12986 \\
2-group & 12766 & 12848 \\
3-group & - & - \\
4-group & - & - \\
\hline
\end{tabular}

Even though a four-group model was hypothesized, for both the CSI and CRI, the mixture models failed to converge to a trustworthy solution when more than two groups were specified. This suggests that the specification of additional groups (beyond two) did 
not improve the fit of the model for the data. However, for both outcome measures, the two-group solution produced substantial improvement in fit statistics over the one-group solution. As will be discussed in greater details later, these groups were labelled stable low and chronic high. The chronic high represented approximately $12 \%$ of the offenders depending on the outcome measure.

Inspection of the maximum likelihood variance estimates indicated that modeling the Criminal Seriousness Index and Canadian Recidivism Index data with a two-group mixture solution (compared to the one-group LGC model) generally decreased the variability in intercept and slope components. For both outcome variables, however, there was still significant heterogeneity in the criminal behaviour status and growth factors of the two-group quadratic latent trajectory models. The maximum likelihood variance estimates on the CSI and the CRI for the two-group mixture solutions were, respectively, $\operatorname{VAR}(\zeta)=9.27(p<.001)$ and $\operatorname{VAR}(\zeta)=11.01(p<.001)$ for the intercept, $\operatorname{VAR}(\zeta)=$ $5.60(p<.001)$ and $\operatorname{VAR}(\zeta)=7.80(p<.001)$ for the linear factor, and $\operatorname{VAR}(\zeta)=0.93(p$ $<.001)$ and $\operatorname{VAR}(\zeta)=0.91(p<.001)$ for the quadratic factor. To explain this remaining variability, various risk factors assessed when the juvenile probationers were admitted to supervision were introduced. Although one of the goals was to improve model fit, of substantive interest was the identification of significant and meaningful predictors of trajectory group membership.

\section{Risk Factors Associated with Offending Trajectories}

The relationships between the risk factors and group membership were examined in a series of binary logistic regression analyses. The initial regression analyses tested 
multiple "univariate" predictor models to assess the unique effect of each risk factor separately. To begin with, however, it was necessary to identify the appropriate parameterization for the latent growth curve models by modeling two separate conditional two-group mixture models for each combination of predictor-outcome variable. In the first model, the path coefficients from the exogenous predictors to the latent trajectory factors were free to vary across the groups, whereas in the second model the path coefficients were constrained to be equal across the groups. To examine the significance of the decrement in model fit when a parameter constraint is imposed on the model, chi-square difference testing based on the log likelihood values and scaling correction factors were obtained with the MLR estimator. A non-significant test statistic indicates that the model with the parameters constrained to be equal across the groups does not significantly worsen the fit of the model, whereas a statistically significant $\chi^{2}$ difference test demonstrates that the model with the parameters free to vary across the groups provides a significantly better fit to the data.

Results are displayed in Tables 9 and 10 for the Criminal Seriousness Index and the Canadian Recidivism Index, respectively. As can be seen, constraining the regression coefficients to be equal across the offending trajectory groups resulted in a significant decrement in model fit for Substance Use and Criminal History when the CSI was used as an outcome measure, and for Family, Substance Use and Accommodation when the CRI was used. It should also be noted that allowing the parameters to vary across the groups resulted in model non-convergence for the predictor variables Associates and Attitudes with the CRI, indicating a very poor fit to the data. 
Table 9

Comparison of Conditional Two-group Models for the CSI

\begin{tabular}{|c|c|c|c|c|c|c|}
\hline \multirow[b]{2}{*}{ Model } & \multicolumn{2}{|c|}{$\begin{array}{l}\text { No equality } \\
\text { constraint }\end{array}$} & \multicolumn{2}{|c|}{ Equality constraint } & \multicolumn{2}{|c|}{ Likelihood ratio test } \\
\hline & $\begin{array}{c}\text { Log } \\
\text { likelihood }\end{array}$ & $\mathrm{fp}$ & $\begin{array}{c}\log \\
\text { likelihood }\end{array}$ & $\mathrm{fp}$ & Diff. $\chi^{2}$ & Diff. $\mathrm{fp}$ \\
\hline Associates & -6304.081 & 32 & -6309.101 & 26 & 5.12 & 6 \\
\hline Family & -6310.471 & 32 & -6317.876 & 26 & 8.52 & 6 \\
\hline Education & -6305.317 & 32 & -6316.566 & 26 & 12.20 & 6 \\
\hline Accommodation & -6308.195 & 32 & -6316.691 & 26 & 8.57 & 6 \\
\hline Attitudes & -6316.052 & 32 & -6320.258 & 26 & 3.41 & 6 \\
\hline Substance Use & -6304.824 & 32 & -6315.162 & 26 & $13.37^{*}$ & 6 \\
\hline Financ. Management & -6301.549 & 32 & -6310.516 & 26 & 9.64 & 6 \\
\hline Criminal History & -6296.443 & 32 & -6307.147 & 26 & $12.85^{*}$ & 6 \\
\hline
\end{tabular}

Note. fp refers to the number of free parameters.

${ }^{*} p<.05$. 
Table 10

Comparison of Conditional Two-group Models for the CRI

\begin{tabular}{lcccccc}
\hline & \multicolumn{2}{c}{$\begin{array}{c}\text { No equality } \\
\text { constraint }\end{array}$} & \multicolumn{2}{c}{ Equality constraint } & Likelihood ratio test \\
\cline { 2 - 6 } Model & $\begin{array}{c}\text { Log } \\
\text { likelihood }\end{array}$ & fp & $\begin{array}{c}\text { Log } \\
\text { likelihood }\end{array}$ & fp & Diff. $\chi^{2}$ & Diff. fp \\
\hline Associates & - & 32 & -6352.389 & 26 & - & 6 \\
Family & -6352.872 & 32 & -6360.878 & 26 & $32.655^{* * *}$ & 6 \\
Education & -6354.578 & 32 & -6363.944 & 26 & & 6 \\
Accommodation & -6334.370 & 32 & -6352.221 & 26 & $549.26^{* * *}$ & 6 \\
Attitudes & - & 32 & -6360.561 & 26 & - & 6 \\
Substance Use & -6336.186 & 32 & -6355.684 & 26 & $39.51^{* * *}$ & 6 \\
Financ. Management & -6344.192 & 32 & -6357.235 & 26 & 6.82 & 6 \\
Criminal History & -6333.411 & 32 & -6341.480 & 26 & 9.91 & 6 \\
\hline
\end{tabular}

Note. fp refers to the number of free parameters.

${ }^{*} p<.05 .{ }^{* *} p<.01 . * * * p<.001$

Using the most appropriate model specifications for each respective univariate conditional regression analyses, only Associates dependably predicted group membership at a statistically significant level for both the Criminal Seriousness Index and the Canadian Recidivism Index. Substance Use was also associated with group differences, but the results reached statistical significance only when the CSI was used as an outcome measure $^{25}$

\footnotetext{
${ }^{25}$ To avoid redundancy, the actual results obtained from these analyses are not reported because the results changed slightly when the conditional analyses were re-conducted following detection of the optimal
} 
Given that both Associates and Substance Use met at least a marginal level of significance $(p<.05)$ in the univariate analyses involving the CSI, both predictors were simultaneously entered into a "multivariate" logistic regression model to investigate the effect of each risk factor conditioned on the other predictor variable in the model. In this latter analysis, only Associates remained a statistically significant predictor of group membership. The conditional latent growth curve model that includes Associates as a sole risk factor was thus chosen as the optimal model to determine group membership, and fit both the CSI and the CRI data for the sample.

Description of the Optimal Conditional Two-group Growth Mixture Solution

Following model selection, each offender was assigned to the group that best conformed to his/her criminal behaviour according to the maximum posterior probabilities of group membership. For each individual in the sample, the posterior probabilities of group membership estimate the probability of the individual belonging to each trajectory group. This procedure is based on the assumption that the error in classification made when placing an offender into only one trajectory group is small, and thus does not bias the parameter estimates of the standard errors to an important degree. This assumption appears reasonable in the present study. The average probabilities of group membership for offenders falling into each group were .929 and .975 for the CSI and .886 and .971 for the CRI. Furthermore, less than $7 \%$ of the sample ( 25 offenders for the CSI and 35 offenders for the CRI) could be considered "difficult to classify" in the

model. This is because group membership for a small number of offenders was revised in the final model selected, which was assumed to yield a better offending trajectory classification. 
sense that they had an above -.25 / below -.75 probability of being assigned to the other group.

A graphical depiction of the resulting solutions is presented in Figures 3 and 4 for the CSI and CRI, respectively. Solid lines on the graphs represent model-implied (i.e., estimated or predicted) trajectories, whereas dashed lines represent average observed trajectories. Inspection of the fitted growth curves bolsters the findings that the conditional two-group quadratic latent growth curve models perform well at reproducing the observed means (i.e., provide a good fit to the CSI and CRI data).

In addition, we can see that the great majority of the offenders engaged in relatively rare, less serious criminal behaviour over their life-course, while a minority of offenders were involved in more frequent, serious and persistent offending. The general pattern of results was strikingly similar across both outcome measures. To be more precise, one group, comprised of approximately $12 \%$ of the offenders showed a chronic high level of offending behaviour over the years. The offending frequency/severity of this group increased steadily from adolescence onwards. The largest group, low-rate offending, consisted of roughly $88 \%$ of the offenders in the sample. This group was characterized by infrequent and/or less serious involvement in criminal behaviour over the years. Their offending pattern remained relatively stable, although it tended to show a slight decline in frequency/severity, which was primarily evident during the last two periods of assessment (age 26 onwards). 
Figure 3

Estimated and Observed Growth Curves for the Criminal Seriousness Index with Two

\section{Offending Trajectory Groups}

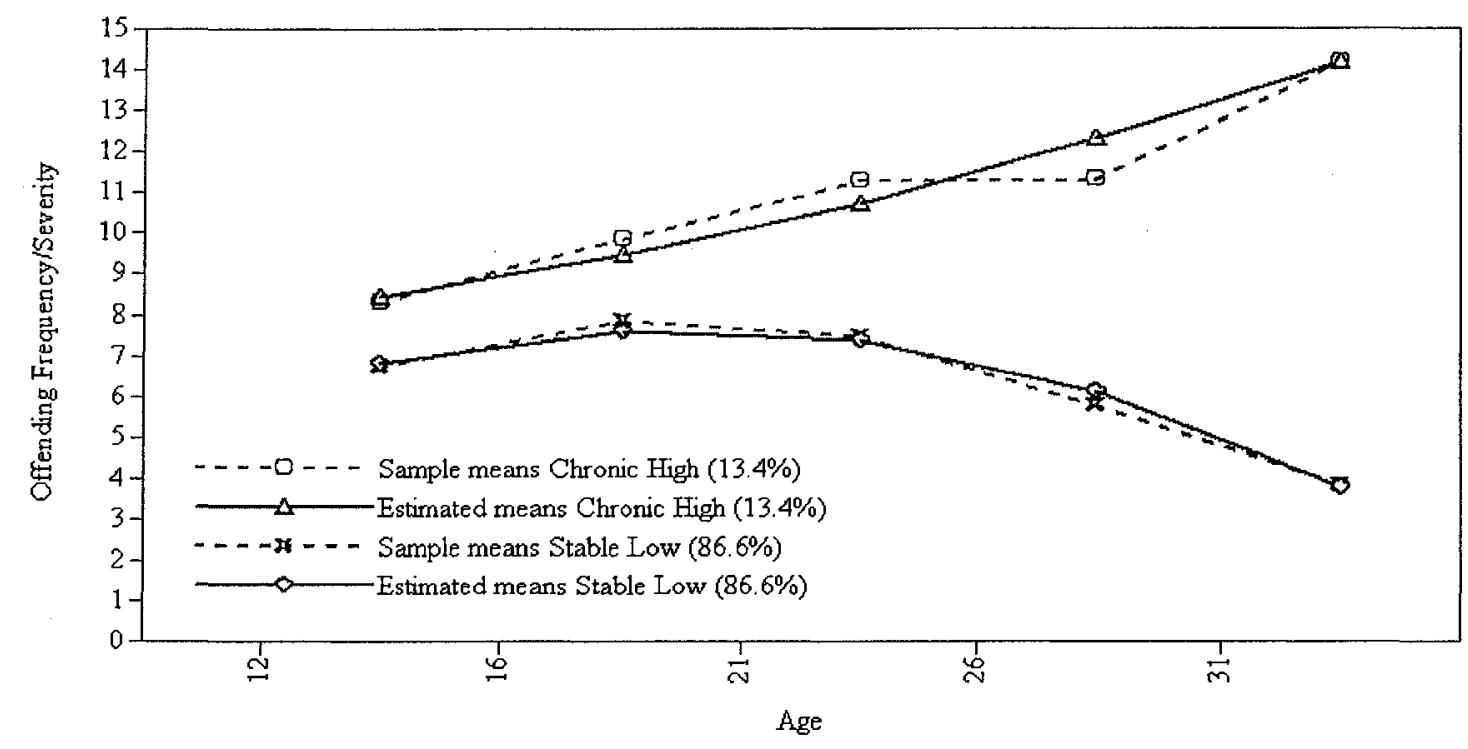

Figure 4

Estimated and Observed Growth Curves for the Canadian Recidivism Index with Two

Offending Trajectory Groups

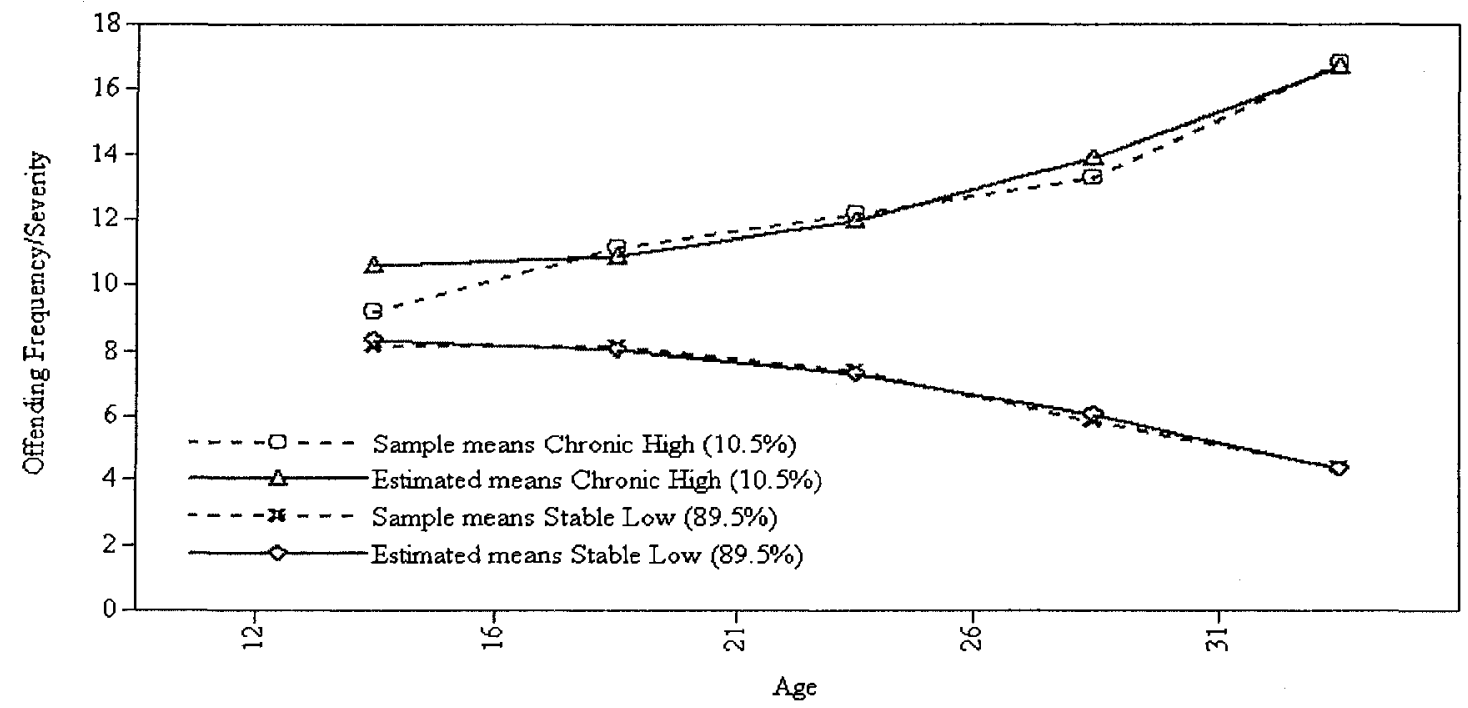


The actual recidivism rates of the two groups at each of the five waves of assessment are presented in Table 11. A few points deserve comment. First, at each assessment period, the chronic high offenders recidivated at a much higher rate than the stable low offenders. Second, the differences in recidivism rates between the two offending groups became progressively more pronounced over time, with the largest dissimilarities evidenced during (middle) adulthood (age 26 onwards). After the age of $15,80 \%$ to $90 \%$ of the chronic high offenders received at least one conviction in each of the last four assessment periods. In contrast, the recidivism rate for the stable low offenders declined from $70 \%$ during late adolescence (16-20 age period) to approximately $20 \%$ in the latest time period (when the offenders were 31 years or older). These findings are consistent with the fitted growth curves depicted in Figures 3 and 4, which show that the offending pathways of the two groups are reasonably similar up to early adulthood, and then begin diverging in such a way that the chronic high offending trajectory group maintained an increasingly more frequent and/or serious level of offending throughout adulthood. 
Table 11

Recidivism Rates of the Chronic High and Stable Low Offending Trajectory Groups at Each Time Period $(\% / n)$

\begin{tabular}{lccccc}
\hline & $\begin{array}{c}\text { Time 1 } \\
\text { (ages 12-15) }\end{array}$ & $\begin{array}{c}\text { Time 2 } \\
\text { (ages 16-20) }\end{array}$ & $\begin{array}{c}\text { Time 3 } \\
(\text { ages 21-25) }\end{array}$ & $\begin{array}{c}\text { Time 4 } \\
\text { (ages 26-30) }\end{array}$ & $\begin{array}{c}\text { Time 5 } \\
(\text { ages 31+) }\end{array}$ \\
\hline \multicolumn{5}{c}{ Group membership based on the Criminal Seriousness Index } \\
Chronic High & $40.0(25)$ & $85.5(69)$ & $82.6(69)$ & $81.2(69)$ & $91.9(62)$ \\
Stable Low & $31.1(196)$ & $69.4(445)$ & $60.5(441)$ & $46.1(436)$ & $17.9(363)$ \\
\hline \multicolumn{6}{c}{ Group membership based on the Canadian Recidivism Index } \\
Chronic High & $38.5(26)$ & $88.9(54)$ & $88.9(54)$ & $90.6(53)$ & $89.4(47)$ \\
Stable Low & $31.3(195)$ & $69.6(460)$ & $60.5(456)$ & $46.2(452)$ & $21.2(378)$ \\
\hline
\end{tabular}

Needless to say, all of the non-recidivist offenders were assigned to the stable low offending trajectory group. Also of interest, almost all of the chronic high offenders (95.7\%), while only $56.0 \%$ of the stable low offenders, were convicted of at least one violent offence $\left(\chi^{2}(1, N=510)=39.55, p<.001\right)$ during adulthood (age 21 onwards) ${ }^{26}$. Similarly, a significantly greater proportion of chronic high offenders received a conviction for a violent offence between the ages of 16 and 20, though the difference between the two groups during this earlier assessment period was a bit less marked. Specifically, $73.9 \%$ of the offenders in the chronic high trajectory group and $51.2 \%$ of the

\footnotetext{
${ }^{26}$ Unless otherwise specified, the present and subsequent analyses used group classification based on the CSI. Comparable results were obtained when the CRI was used as an outcome measure.
} 
offenders in the stable low trajectory group were convicted for a violent offence during late adolescence $\left(\chi^{2}(1, N=514)=12.38, p<.001\right)$.

Moreover, there were statistically significant differences between the two groups in both the overall number of convictions, and violent convictions received following the index offence. In fact, the chronic high offenders were reconvicted more than twice as many times as the stable low offenders in general and for violent offences specifically. The actual number of reconvictions was slightly more than ten for the chronic high offending group $(\approx 4$ violent reconvictions), compared to about five for the stable low group $(\approx 1.5$ violent reconvictions). Independent samples t-statistics were $t(512)=8.19$ for overall and $t(512)=7.12$ for violent-only (both $p s<.001$ ). The two groups also differed in terms of criminal versatility, with the chronic high offenders averaging nearly five different offence types throughout their life-course and the stable low offenders only about three $(t(512)=8.72, p<.001)$. The chronic high offenders were, however, not younger than the stable low offenders at the time of their first conviction with both groups being slightly less than 16 years of age $(t(512)=0.752, n s)^{27}$.

From a Canadian correctional perspective, there were significant differences between the chronic high and stable low offending trajectory groups in their experiences with provincial and federal corrections ${ }^{28}$. The overall rates of provincial and federal custodial admissions in the sample were $51.4 \%$ and $12.6 \%$, respectively (36\% of the

\footnotetext{
${ }^{27}$ This latter result was expected given that the sample was comprised of adjudicated juveniles, thereby restricting both the range and variability in age.

${ }^{28}$ In Canada, responsibility for corrections is divided between the federal and provincial/territorial governments. Offenders serving sentences of two years or longer (including life sentences) are dealt with under federal jurisdiction, whereas the provinces/territories are responsible for offenders sentenced to terms of less than two years.
} 
offenders did not enter a provincial nor a federal prison during their life-course). Using classification based on the Canadian Recidivism Index, $94.4 \%$ of the chronic high offenders were incarcerated under provincial jurisdiction during their life-course, whereas this was true for $60.4 \%$ of the stable low offenders $\left(\chi^{2}(1, N=514)=24.26, p<.001\right)$. Perhaps more noteworthy, $51.9 \%$ of the chronic high offenders, while only $8.0 \%$ of the stable low offenders eventually entered a federal penitentiary $\left(\chi^{2}(1, N=514)=83.96, p\right.$ $<.001)$. These latter findings provide support for the external validity and practical utility of the classification system to Canadian corrections.

\section{Juvenile Predictors of Offending Trajectory Group Membership}

It is clear from these findings that the chronic high group was comprised of offenders who were at greater risk and needs than the offenders assigned to the stable low group. For the interested reader, the actual percentages of offenders from each offending group falling into each subpopulation of criminogenic risk/needs level based on the final latent growth curve model (i.e., the model that included Associates as a predictor variable) are reported in Appendix B. Appendix B also provides the distribution of low, medium and high Primary Risk Assessment - Version 1 scores for the chronic high and stable low offending trajectory groups. Additionally, the univariate associations between the criminogenic risk/needs factors and the offending trajectory group membership are shown in Table 12. These are reported as odds ratios calculated from the data displayed in Appendix B ${ }^{29}$.

\footnotetext{
${ }^{29}$ The reader is reminded that these results differ slightly from the previous logistic regression analyses aimed at determining the best-fitting model for the data. Again, this can be explained by slight variation in
} 
Table 12

Relationship between Trajectory Group Membership and Juvenile Risk Factors

\begin{tabular}{|c|c|c|c|c|}
\hline \multirow[b]{2}{*}{ Risk factor } & \multicolumn{2}{|c|}{ CSI } & \multicolumn{2}{|c|}{ CRI } \\
\hline & OR & $95 \%$ C. I. & $\mathrm{OR}$ & $95 \%$ C. I. \\
\hline \multicolumn{5}{|l|}{ Associates } \\
\hline Some problems & $2.89^{*}$ & $1.30-6.42$ & $3.33^{*}$ & $1.33-8.31$ \\
\hline Major problems & $4.29 *$ & $1.70-10.83$ & $3.31^{*}$ & $1.11-9.86$ \\
\hline \multicolumn{5}{|l|}{ Family } \\
\hline Some problems & 1.67 & $0.90-3.11$ & 1.22 & $0.62-2.37$ \\
\hline Major problems & 1.57 & $0.79-3.12$ & 1.21 & $0.57-2.57$ \\
\hline \multicolumn{5}{|l|}{ Education } \\
\hline 1 yr below norm & 1.64 & $0.83-3.24$ & 1.19 & $0.61-2.32$ \\
\hline$\geq 2$ yrs below norm & 1.88 & $0.98-3.59$ & 0.75 & $0.38-1.49$ \\
\hline \multicolumn{5}{|l|}{ Accommodation } \\
\hline Some problems & 0.75 & $0.38-1.49$ & 0.84 & $0.40-1.78$ \\
\hline Major problems & 1.52 & $0.86-2.69$ & 1.57 & $0.84-2.96$ \\
\hline \multicolumn{5}{|l|}{ Attitudes } \\
\hline Some problems & 1.50 & $0.87-2.58$ & 0.98 & $0.53-1.82$ \\
\hline Major problems & 1.18 & $0.54-2.58$ & 1.17 & $0.52-2.64$ \\
\hline \multicolumn{5}{|l|}{ Substance Use } \\
\hline Some problems & $2.08 *$ & $1.21-3.55$ & 1.77 & $0.97-3.22$ \\
\hline Major problems & $2.90^{*}$ & $1.23-6.86$ & $3.05^{*}$ & $1.23-7.57$ \\
\hline
\end{tabular}

offender classification for different model specifications. The odds ratio for models other than the final model that included only Associates as predictor variable are expected to be less accurate. In the computation of the odds ratios, 0.5 was added to each cell to address problems related to small cell sizes. 
Table 12 (continued)

\begin{tabular}{lcccc}
\hline & \multicolumn{2}{c}{ CSI } & \multicolumn{2}{c}{ CRI } \\
\cline { 2 - 5 } Risk factor & OR & $95 \%$ C. I. & OR & $95 \%$ C. I. \\
\hline $\begin{array}{c}\text { Financial Management } \\
\text { Some problems }\end{array}$ & 1.03 & $0.59-1.80$ & 1.25 & $0.67-2.32$ \\
$\quad \begin{array}{l}\text { Major problems } \\
\text { Criminal History }\end{array}$ & 0.99 & $0.49-2.01$ & 1.19 & $0.55-2.59$ \\
$\quad$ Medium risk & 1.00 & $0.57-1.72$ & 1.51 & $0.79-2.86$ \\
$\quad$ High risk & 1.24 & $0.59-2.62$ & 2.19 & $0.98-4.92$ \\
\hline
\end{tabular}

Note. For each OR, the reference condition was "low risk" or no problem on the juvenile risk factor.

${ }^{*} p<.05$

As anticipated, Associates differentiated offenders in the chronic high trajectory group from those in the stable low group on both the Criminal Seriousness Index and the Canadian Recidivism Index. Specifically, the odds of being classified in the chronic high rather than in the stable low offending trajectory group was three times greater for offenders who experienced some or major problems in terms of their association patterns, compared to those who had no problem (ORs ranged from 2.89 to 4.29 ).

Moreover, substance use problems predicted increased odds of membership in the chronic high offending trajectory group relative to the stable low group, although the effects when the CRI was used as the outcome measure reached statistical significance only for the juvenile probationers with major substance use problems, compared to no problems $(\mathrm{OR}=3.05)$. For the CSI, odds ratios were 2.08 for some problems and 2.90 for 
major problems. That is, there was a greater proportion of the juvenile probationers who had substance use problems in the chronic high offending trajectory group $(47.8 \%$ for some and $11.6 \%$ for major) than was found in the stable low group $(33.9 \%$ for some and $6.1 \%$ for major).

Finally, it is worth noting that scores on the actuarial PRA - V1 risk measure also distinguished the two offending trajectory groups. The odds of having been classified in the chronic high group (compared to the stable low group) were between two and four times greater for offenders who were categorized in the high PRA - V1 risk/needs category than for those who were assessed as either medium or low risk and needs (ORs were 3.89 for the CSI and 1.99 for the CRI). In other words, the chronic high offending trajectory group was made up of a greater proportion of high risk/needs juvenile probationers $(\approx 45 \%)$ than the stable low group $(\approx 23 \%)$.

\section{Female Offending Behaviour}

The sample totalled 75 female offenders. When the CSI was used as an outcome measure, there were 373 stable low male offenders and 66 chronic high male offenders. Comparably, using the CSI, the stable low and chronic high male trajectory groups were comprised of 389 and 50 offenders, respectively. As expected, most $(\approx 96 \%)$ female offending behaviour was of the stable low type. From a different angle, the stable low offending trajectory group consisted of a male to female ratio of roughly 5 to 1 , whereas there were about 24 times more males than females in the chronic high group.

The criminal pathways of the female offenders, stable low male offenders, and chronic high male offenders are illustrated in Figures 5 and 6 for the Criminal 
Seriousness Index and the Canadian Recidivism Index, respectively. Although the offending pathways of the female offenders appeared less frequent and/or serious than that of the stable low male offenders, the previous growth mixture analyses failed to support the contention that the differences between the two groups were in fact meaningful in a sense that the results were not in favour of a three-group solution. 
Figure 5

Observed Offending Trajectories of the Female Offenders, Stable Low Male Offenders, and Chronic High Male Offenders for the Criminal Seriousness Index

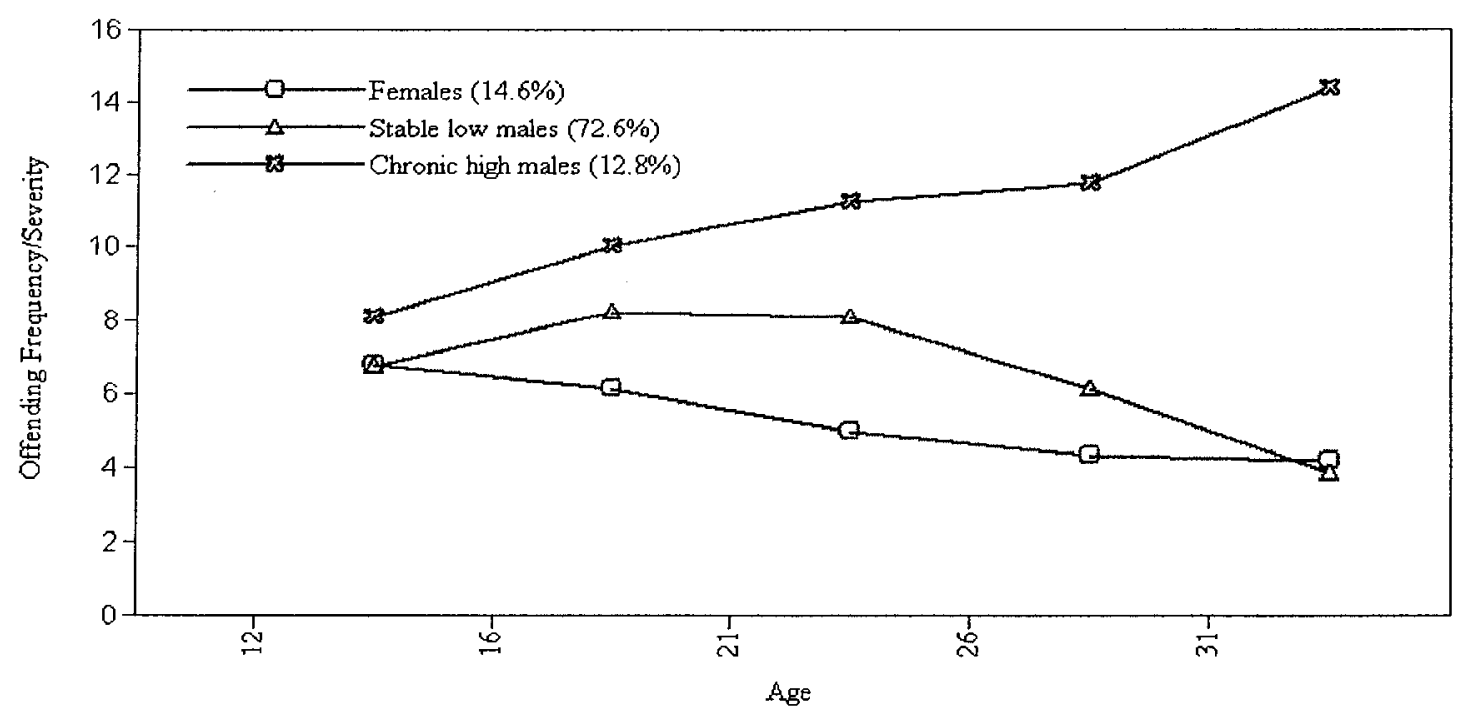

Figure 6

Observed Offending Trajectories of the Female Offenders, Stable Low Male Offenders, and Chronic High Male Offenders for the Canadian Recidivism Index

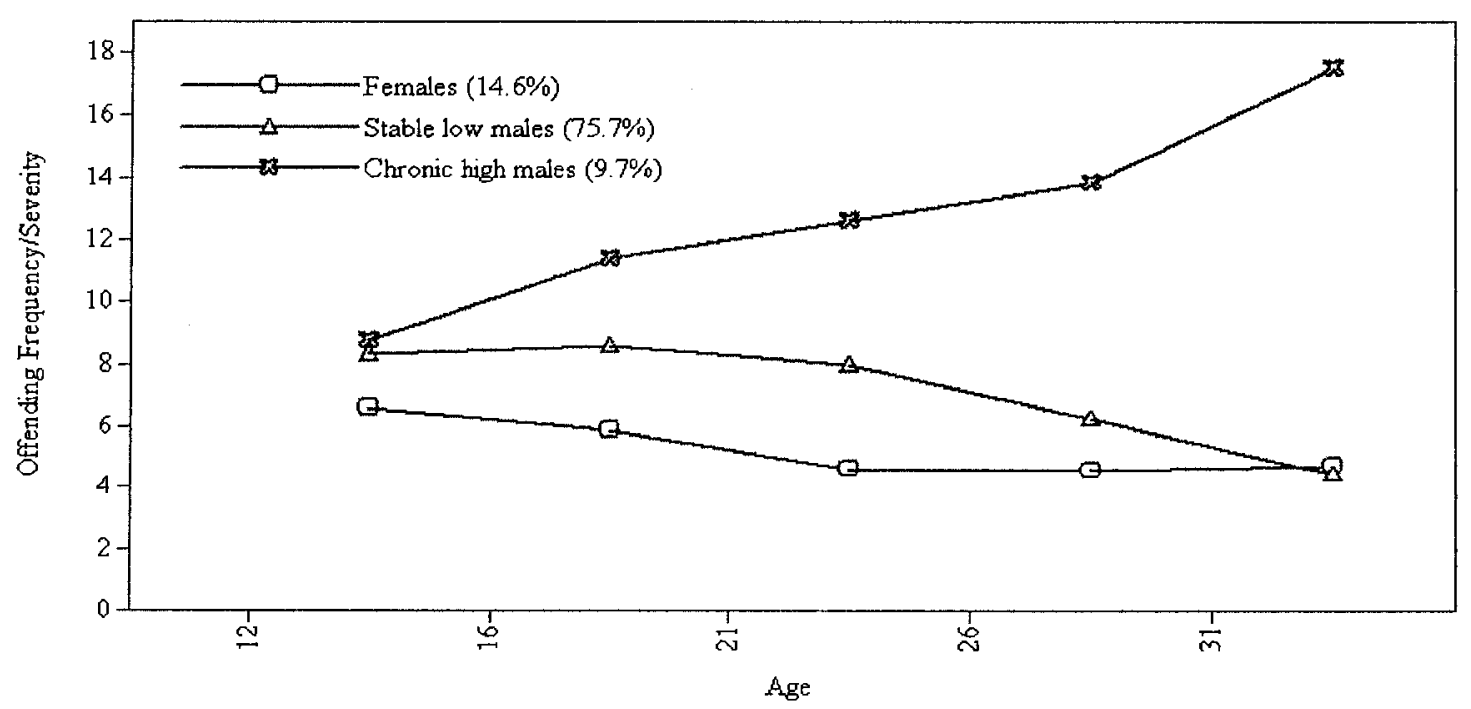


Stability of Estimate Parameters

Cliff (1983), among others (e.g., Nagin \& Tremblay, 2005; Sampson \& Laub, 2005), cautioned researchers about the sophistication of structural equation modeling techniques, and the facility with which they can be applied. This word of warning appears especially pertinent with the recent release of programs such as Mplus, which makes the implementation of complex statistical analyses even easier. One of the main vulnerabilities concerns the susceptibility of the techniques to capitalization on chance. Evidence of replicability, although often missing from reported research, is therefore a must. Results derived from one sample that are not obtained on an independent sample from the same population have no generalizability, and hence are of limited scientific. utility.

Practically speaking, the problem is that repeating the study by drawing a new sample (i.e., external replication) is difficult in the social sciences. However, other methods of exploring replicability internally are available. One of these methods, bootstrapping, offers a unique and effective method for testing the stability and replicability of results (K. A. Bollen, personal communication, June 20, 2007; Guthrie, 2001). Bootstrapping procedures were developed by Efron (1979) and his colleagues (Diaconis \& Efron, 1983) as a means to creating an empirical sampling distribution that can be used, for instance, to test statistical hypotheses, estimate standard errors, and create confidence intervals. Essentially, bootstrapping involves sampling with replacement. All resamples have the same number of individuals as the original sample, 
and each individual from the original sample could be drawn more than once (or not at all) in a given resample.

In the present study, the findings were replicated across two different outcome measures of offending behaviour. Then again, the issue of replication was addressed by using bootstrapping procedures. Specifically, the statistical software SPSS was used to generate one bootstrap sample. This one bootstrap data file was then imputed into Mplus, and the statistical analyses were repeated to see whether the same results (as when the original data were analyzed) were obtained. If the parameters estimated with the original data are relatively similar to those obtained with the bootstrap sample, then the parameters can be thought of as stable. This would provide additional evidence for the validity and reliability of the results. In contrast, if the estimates obtained using the bootstrap sample are considerably different from the actual sample statistics, then caution in interpreting the sample data is warranted, as the findings show some instability.

The results using the bootstrap data are reported in Appendix C. The vast majority of the bootstrap statistical analyses produced findings analogous to those reported throughout the paper that used the authentic 514 juvenile probationers sample. Among other things, the results indicated that a two-group latent growth curve model specified with a quadratic function best represented the shape of the developmental trajectory of juvenile progression in criminal behaviour from early adolescence to middle adulthood for the data ${ }^{30}$. An examination of the estimated and observed growth curves further

\footnotetext{
${ }^{30}$ As obtained with the original sample, the quadratic LGC model best described the CSI data. The reader should nonetheless note that the chi-square difference test comparing the quadratic LGC model to the linear ALT model for the CRI was statistically significant at the $p=.05$ level, suggesting that the latter model
} 
revealed a very similar general pattern of offending with a comparable proportion of offenders falling into a chronic high and a stable low offending trajectory group. In addition, the average probabilities of group membership for the two outcome measures were excellent, and few offenders could be considered difficult to classify. In terms of criminogenic risk/needs factors, Associates and Substance Use once again revealed to be the strongest predictors of group membership. Other juvenile predictors (Family, Education and Accommodation) came through as statistically significant, but their effect was not as meaningful in terms of absolute magnitude and consistency across the two outcome measures.

better represented the functional form of the data. However, the fit differences between the two models were minimal, with some indices indicating that the quadratic LGC model was superior to the linear ALT model. In light of this, and bearing in mind the susceptibility of the linear ALT model to overfit the CRI data, the quadratic LGC model was regarded as most favourable. 


\section{Discussion}

The current study sought to describe and predict the offending developmental pathways of a group of Canadian juvenile probationers. A primary objective was to provide empirical support for the theoretical conceptualizations proposed by Loeber and Stouthamer-Loeber (1996), Moffitt (1993) and Patterson et al. (1992). While doing so, some of the limitations in previous research were addressed. A sample of 514 male and female juveniles under a probation sentence in the province of Manitoba, Canada, were followed over time. The frequency and severity of their offending behaviour was assessed at five meaningful developmental stages during their life-course. To be more explicit, the study sought to identify distinct subgroups of adjudicated youths with different offending trajectories from early adolescence to middle adulthood. In addition, efforts were made to determine which of the major criminogenic risk/needs factors assessed when the juvenile offenders were admitted to supervision would help distinguish the offending trajectories from one another.

Temporal Patterns of Offending Behaviour

Preliminary analyses demonstrated that the age-crime curve generated from averaging the conviction histories of all offenders in the present research was comparable to the curve reported in many studies (e.g., Blockland et al., 2005; Day et al., 2007; Farrington et al., 2006; Loeber et al., 1999). Like the curve typically reported, the aggregated age-crime relationship for the sample was unimodal and positively skewed, showing a steep rise during adolescence followed by a more gradual decline during adulthood. 
What is interesting to note is that the age-crime relationship found in this study was based on longitudinal data that assessed both the frequency and severity of offending. Despite the fact that previous studies have generally focused on a single dimension (e.g., Blockland et al., 2005; Chung et al., 2002), both the rate of incidence and the gravity of offending are equally important to consider when measuring criminal conduct. Among other things, simple frequency counts do not have the potential to differentiate offenders who have committed a moderate number of offences of varying gravity, whereas seriousness scales, when used by themselves, cannot distinguish offenders who have all engaged in some type of criminal activity but at various rates of recurrence. By combining the two methods each method's shortcomings were addressed. Offending Trajectory Groups

Acknowledging these initial findings, the question arose as to whether the shape of the aggregated age-crime curve originated from simply superimposing individual offending trajectories of similar shape, or whether it concealed underlying diversity in developmental pathways of offending. Taking advantage of the strengths and capabilities of the newest generation of growth modeling techniques, two subgroups of juvenile probationers who followed distinct offending trajectories from early adolescence to middle adulthood were identified. These two groups differed statistically in terms of the parameters of the growth mixture models (i.e., initial level of offending and rate of progression in offending over time). In other words, beyond detecting individual differences in offending frequency/severity at any one time point, which could have been detected with a cross-sectional examination, the analyses also identified groups that 
varied by the amount of change in the frequency and/or severity of offending behaviour that occurred over the waves of assessment.

These findings contrasted with the outcomes of recent empirical studies that suggested the presence of more than two distinct offending trajectory groups (e.g., Day et al., 2007; Blockland et al., 2005; Moffitt, 2003; Wiesner \& Silbereisen, 2003). However, the two offending trajectories singled out in the present study corresponded closely to Loeber and Stouthamer-Loeber's (1996), Moffitt's (1993) and Patterson et al.'s (1992) proposed categories of early onset persisters and late onset desisters. A minor portion of youths $(\approx 12 \%)$ engaged in frequent and/or serious levels of offending behaviour throughout their life-course. The frequency/severity of offending behaviour for offenders within that group escalated gradually from early adolescence (ages 12-15) onwards, and showed very little evidence of decline. Also found was a much more common trajectory $(\approx 88 \%)$ that uncovered relatively less frequent and/or serious offending behaviour over time.

The size of the chronic group was slightly larger than the $3 \%-8 \%$ of the population that has been hypothesized to reveal sustained (or chronic) criminal careers (e.g., Cohen \& Vila, 1996; Farrington et al., 2006; Moffitt, 1993), and/or that comprised high-rate chronic offender groups in other empirical studies (e.g., Chung et al., 2002; D'Unger et al., 2002; Farrington et al., 2006). This was anticipated if not for the simple reason that the study explored the developmental offending pathways of adjudicated youths (i.e., known juvenile offenders), rather than those of a sample that comprised both offenders and non-offenders. 
It did not, either, come as a surprise that practically all of the female offenders $(\approx$ $96 \%$ ) were classified in the stable low offending trajectory group. As a matter of fact, the chronic high group was comprised of over 20 times more males than females, while the male to female ratio in the stable low group was only about 5 to 1 . These results are in line with Moffitt's original theoretical propositions (1993) as well as the outcomes of empirical studies that specifically examined the criminal pathways of female offenders (e.g., D’Unger et al., 2002; Fergusson et al., 2000; Kratzer \& Hodgins, 1999).

In light of these findings, supplementary analyses were conducted to examine the criminal pathways of female offenders separately from those of stable low male offenders and chronic high male offenders. In doing so, the shape of the female offending trajectory paralleled that of the stable low male offenders, but involved slightly less frequent and/or serious criminal acts. On this note, the reader is reminded that the growth mixture analyses were not in favour of a three-group solution, justifying the inference that, empirically, the female offending pattern was not sufficiently different from that of the stable low male offenders to define a distinct trajectory group.

Caution is, however, called for when interpreting this last series of findings. On the one hand, the statistical gender invariance may be due to the relatively small number of female offenders comprised in the present sample. On the other hand, the discernible gender difference could be explained by the fact that offending behaviour was operationalized using a combination of offence frequency and severity. That is, relative to their female counterparts, the ratio of violent (e.g., assault) to non-violent (e.g., property offences) crimes is much higher among male offenders (for a review, see Blanchette \& 
Brown, 2006). Consequently, it remains a possibility that the female offenders in this study would have exhibited a heightened criminal pattern (i.e., closer to the one revealed by the stable low male offenders) had a measure of offending that relied solely on rates of incidence and ignored the gravity of the acts been employed.

Based on Loeber and Stouthamer-Loeber's (1996), Moffitt's (1993) and Patterson et al.'s (1992) dual taxonomy as well as recent research findings (e.g., Eklund \& af Klinteberg, 2006), it was further expected that the chronic high offenders would disproportionally engage in a wider variety of offence types as well as more of the violent crimes, compared to the stable low offenders ${ }^{31}$. The results are in line with these theoretical and empirical implications. In the present study, the offenders classified in the chronic high trajectory group engaged in approximately twice as many different types of offences as those assigned to the stable low group. There also was a clear distinction between the chronic high and stable low offending trajectory groups in terms of violence. While more than $95 \%$ of the chronic high offenders were convicted of at least one violent offence from late adolescence onwards (age 16 onwards), roughly three quarters of the stable low offenders received a conviction for a violent offence during these periods of their life-course. If the age periods were restricted to include adulthood and middle adulthood only (age 26 onwards), the percentage of violent convictions among the chronic high offenders remained relatively unchanged (94.2\%), whereas it dropped to about $30 \%$ among the stable low offenders.

\footnotetext{
${ }^{31}$ The males on the life-course persistent and adolescent-limited antisocial pathways in the Dunedin longitudinal study reported a similar variety of different offence types at age 26 (Moffitt et al., 2002). However, this latter finding may be due to differences in the length of the follow-up period as well as in the operationalization of the outcome measures (i.e., self-reported offences $v s$. official criminal convictions).
} 
The actual percentages of violent crimes for both offending trajectory groups were higher than expected, and appreciably higher than those reported in other longitudinal studies that used a comparable methodology and/or follow-up period. For instance, using their sample of identified male lawbreakers, Eklund and af Klinteberg (2006) recorded that $45 \%$ of the offenders on the persistent (i.e., chronic high) criminal pathway, and only $2.8 \%$ of those on the desisting (i.e., stable low) pathway were convicted for one or more violent crimes between the ages of 25 and 34 .

What might explain the relatively high incidence of violent behaviour of the present sample, compared to that of other groups of offenders? The answer to this is somewhat speculative, as good data pertaining to the details of the criminal acts is lacking. Similarly, thorough knowledge of what specifically represented a violent crime in other studies was also unavailable. This could explain some of the discrepancy in findings. As noted by Tremblay (2006), the term violence is used to encompass a broad spectrum of behaviours, which during the adolescent years, can range from bullying at school to murder.

Nevertheless, there is reason to believe that the offenders in this study sample were higher risk to begin with than those comprising other studies. Many of the adolescents were likely clients of a number of different social agencies before coming to the attention of the criminal justice system. An examination of the data revealed that $14 \%$ of the adolescents had been placed in a foster or group home, about half had one or more address change(s) in the year prior to their probation term, and almost one-third were relying on social assistance at the time they were admitted to supervision. In addition to 
involvement with various social service agencies, as much as $30 \%$ of the juvenile probationers had a criminal history record before they reached their fifteenth birthday. Risk Factors Associated with Offending Trajectories

Evidence that the present sample consisted of high-risk offenders with several needs was provided from an examination of the Primary Risk Assessment - Version 1. In the current study, not only was the PRA - V1 found to be a significant predictor of offending trajectory group membership, but more than three quarters of the offenders were categorized as either medium or high risk and needs. Given that this actuarial assessment instrument draws its total score from a variety of constructs traditionally linked to criminal behaviour, these results suggest that the majority of the offenders in the sample had multiple criminogenic needs, placing them at risk for reoffending.

Taking these findings as a whole, it appears reasonable to presume that the offending trajectory groups generated in this study were reliably distinctive such that the patterns of offending could be usefully examined for characteristics that may reflect different etiological pathways. Accordingly, it is interesting to consider what characterized the juvenile probationers assigned to the chronic high offending trajectory group apart from their more transient counterparts.

Of the criminogenic risk/needs domains studied, only Associates reliably predicted group membership across the two outcome measures and after controlling for other competing risk factors. Not surprisingly, the chronic high offending trajectory group comprised more offenders who had negative and unconstructive ties with their peers than the stable low group. Compared to the youths who had a generally prosocial 
pattern of associations, the odds of membership in the chronic high group were significantly increased (roughly three to four times higher) for the juvenile probationers who experienced problems in terms of their association patterns.

Although it was not measured directly, it is logical to deduce that the offenders who followed a chronic high offending trajectory received social support from their peers to engage in criminal behaviour and other related deviant acts. As expected from a social learning perspective and from the principles of differential association theory, interacting with peers who tolerate or even commit antisocial behaviour and who function as sources of reinforcement and role models, increases the risk for criminal behaviour (Coie, Terry, Zakriski \& Lochman, 1995; Dishion, Eddy, Haas, Li \& Spracklen, 1997; Tremblay, Masse, Vitaro \& Dobkin, 1995). The importance of antisocial peer support is not only theoretically relevant, but has also been repeatedly validated. In fact, numerous studies have demonstrated that the role of associates is one of the most important risk factors in the study of delinquency and persistent criminality, especially when dealing with the behaviour of youths (e.g., Brendgen, Vitaro \& Bukowski, 1998; Chung et al., 2002; Farrington et al., 2006; Lacourse, Nagin, Tremblay, Vitaro \& Claes, 2003; Wiesner \& Silbereisen, 2003).

Despite demonstrating a less convincing association with group membership, it should be pointed out that Substance Use also distinguished offenders in the chronic high and stable low offending trajectory groups. Specifically, a greater proportion of young probationers who had substance use problems were identified as chronic high offenders, compared to those who did not evidence difficulty in this area. The statistically 
significant effect of this criminogenic risk/needs factor, however, disappeared when considered in conjunction with Associates. Surprisingly, none of the other relatively wellestablished juvenile risk and needs factors significantly and reliably predicted membership in the chronic high and stable low offending trajectory groups.

As noted earlier, the chronic high group comprised a medium to high risk group as measured by the PRA - V1. Although they had problems related to many different aspects of their personal and social lives, the current results highlighted the peer group as a predominant influence that made the juvenile probationers vulnerable to recurrent and enduring contacts with the criminal justice system. This finding suggests that patterns of association are so closely entrenched in other areas of a youth's daily life (e.g., family, school) and other potential risk factors (e.g., substance abuse, attitudes) that it indirectly accounts for a good share of the influence attributable to these other criminogenic risk/needs factors.

Prediction to Provincial and Federal Custodial Admissions

Another interesting set of findings concerns the risk of the offenders assigned to each trajectory group for becoming involved with the adult provincial and federal custodial correctional systems. Additional analyses indicated that the risk for being admitted into either a provincial or a federal prison was markedly greater for offenders assigned to the chronic high group, compared to those best represented as stable low offenders. Approximately $50 \%$ of the offenders assigned to the chronic high trajectory group entered a federal penitentiary during their life-course, $40 \%$ were admitted to a provincial prison, and $10 \%$ never set foot in the adult Canadian custodial systems. In 
contrast, the stable low trajectory group was comprised of roughly $10 \%$ federal custodial offenders, $50 \%$ provincial custodial offenders, and $40 \%$ non-custodial offenders. Evidently, considerably more juvenile probationers in the chronic high offending trajectory group were at risk for becoming involved with the Canadian federal prison system during their life-course. This implies that the two offending trajectory groups generated in our study have some practical value in the prediction of long-term criminal outcomes.

\section{Policy and Practical Implications}

In this study the terms of incarceration were taken into consideration in the computation of time-at-risk in the community. As a consequence, the "window of opportunities" for criminal behaviour was considerably reduced for many of the offenders assigned to the chronic high offending trajectory group, especially during later phases in their developmental life-course. Making such adjustments, however, did not seem to have any impact on their offending behaviour in the community, as they nevertheless continued to engage in relatively frequent and/or serious criminal activity over the years. These results are in line with the literature on offender rehabilitation, which suggests that sanctions and punishment do not have any suppressive impact on recidivism (Andrews \& Bonta, 2006; Pratt \& Cullen, 2005; Smith, Goggin \& Gendreau, 2002; von Hirsch, Bottoms, Burney \& Wikström, 1999). In order to produce positive change in offenders, services are needed. This is especially true when dealing with highrisk, persistent offenders. 
Until recently, theorists and researchers interested in understanding desistance have focused their research questions on the social processes by which offenders cease to engage in criminal activity by themselves, that is without any deliberate assistance from the criminal justice system (McNeill, Batchelor, Burnett \& Knox, 2005; Sampson \& Laub, 2003). This explanation may work well for most offenders. In the present study, it is reasonable to believe that a good number of the offenders assigned to the stable low offending trajectory group naturally disengaged from criminal behaviour as they grew up. The question on whether the age-related decline in crime observed for the majority of the sample merely reflects a change in an individual's attachment to various social institutions, a change in opportunities, or a more deep-seated psychological change (i.e., growth and maturity) that relates to Moffitt's (1993) notion of social mimicry is beyond the scope of the present research. Yet, one probable contention insinuates that those offenders are simply responding to changing levels of social controls (e.g., marriage, employment, childrearing) with the transition into adulthood (Sampson \& Laub, 1993, 2003; Sampson, Laub \& Wimer, 2006).

What is perhaps more central to the present investigation is the finding that desistance was not, as Laub and Sampson (2003) claimed, equally inevitable for all offenders. This is consistent with several other studies (e.g., Blockland et al., 2005; Schaffer, Petras, Ialongo, Poduska \& Kellam, 2003). In point of fact, there appears to be a small proportion of offenders who engage in a disproportionate share of the criminal acts, and the most serious types of offences, and who require deliberate interventions in 
order to eventually desist from crime. These are the offenders towards whom resources and efforts should be directed.

Sufficient research exists reporting on the characteristics of programs and services that can lessen the probability of youths continuing on a life of crime (Leschied et al., 2006). In a nutshell, the major sources of variability in the outcome of deliberate interventions for offenders relate to the risk principle (i.e., reserve intensive services to high-risk offenders), the need principle (i.e., target criminogenic needs), and the responsivity principle (i.e., use cognitive-behavioural intervention strategies that take into consideration the learning style and abilities of the offender) (Andrews \& Bonta, 2006; Bonta \& Andrews, 2007). Without going into too much detail, there exist additional characteristics of effective correctional programs. These include a sound theoretical basis, the use of advocacy and brokerage, a respect for both the relationship (i.e., quality of interpersonal influence facilitating or not learning) and contingency (i.e., direction of interpersonal influence favouring or not crime) principles, the provision of the services in the community or non-residential settings, and treatment integrity. Treatment integrity is concerned with the management structures (e.g., sufficient resources) and practices (e.g., adequate training) that are necessary for the effective delivery of the programs (Bonta \& Andrews, 2007).

Given the current state of knowledge, it is important for organizations to use the available information to design programs that respect the principles of effective offender rehabilitation, and to implement them at developmentally appropriate periods in an individual's life-course. The findings obtained in this study stress the importance for 
adolescents to develop and sustain positive social relationships with prosocial peers. To a lesser degree, the results also indicate the need for parents and other influential adults involved in an adolescent's life to monitor and restrain their drug and alcohol consumption. Prevention and intervention programs should therefore consider targeting and changing both negative peer influence and substance use, as they place adolescents at risk of embarking on a criminal career. In all probability, programs and services that succeed in reducing those two criminogenic risk/needs factors will likely affect other dynamic factors typically linked with criminal behaviour, and as noted by Farrington (in press) will have wide-ranging benefits in reducing the occurrence of other types of social problems as well.

In order to allocate resources more effectively, and reduce the negative consequences associated with serious and persistent offending, it is thus important to offer the programs and services to offenders who, during adolescence, affiliate with deviant peers and show signs of a problematic consumption of alcohol and/or drugs. The current findings further suggest the need for policy-makers and practitioners to focus their intervention strategies on offenders who, over the course of a number of months following a first encounter with the criminal justice system, exhibit behavioural patterns indicative of frequent and/or increasingly serious forms of deviant and criminal activity. By doing so, it then becomes possible to identify juvenile offenders before they become chronic offenders, and to manage their behaviour in an efficient and timely fashion so as to reduce their likelihood of eventually becoming involved with provincial and federal custodial corrections. 


\section{Limitations and Directions for Future Research}

The present findings clearly suggest that intervention strategies should be put into operation in the early developmental phases of an offender's criminal career. On this point, it is important to mention that this study examined the offending trajectories and associated risk factors of adjudicated youths during the early and middle adolescent years. The results may have invoked the need to intervene at an even earlier time had data been collected on a normative sample during developmental periods that cover childhood.

Using data from the Seattle Social Development Project, Chung et al. (2002) demonstrated that a number of social developmental constructs such as antisocial peers, school bonding, and drug availability measured in late childhood (ages 10 to 12) influenced offending pathways from adolescence to young adulthood. In a recent study, Côté, Vaillancourt, LeBlanc, Nagin and Tremblay (2006) further found that family risk factors traditionally associated with antisocial behaviour during adolescence (e.g., hostile/ineffective parenting strategies) were associated with the use of frequent and regular physical aggression during early and middle childhood (ages 2 to 11). These latter results are worthy of consideration given that physical aggression between the ages of 6 and 12 was, in turn, shown to predict physical violence at age 17 (Kokko, Tremblay, Lacourse, Nagin \& Vitaro, 2006).

In a similar vein, there is a need for additional longitudinal studies that track a large number of offenders over follow-up periods that extend into late adulthood. Not only would this produce greater confidence that desisters have been genuinely identified, but it would also allow researchers to examine different phases in the desistance process. 
As suggested by Loeber and Stouthamer-Loeber (1998), it cannot be assumed that the causes of desisting from crime are the same across different developmental periods. For a more efficient allocation of prevention and rehabilitative resources, longitudinal studies that gather data over protracted periods of time are thus warranted.

The current literature would also benefit from broadening the scope of this research in other ways. One of the most important shortcomings concerns the choice or availability of the risk factors, which was restricted to the use of time-invariant variables. However, the contemporary growth curve modeling techniques offer the possibility to investigate the relationships between distinct offending trajectories and time-varying predictors (i.e., dynamic variables whose actual scores for some individuals fluctuate across the assessment periods). These growth curve models are complex, and to date, there has not been any published study that examined offending trajectories using timevarying predictor variables. The closest piece of work to this cutting edge methodological and analytical strategy was executed by Wiesner and Silbereisen (2003) who explored associations between trajectories of juvenile delinquency and time-averaged risk factors $^{32}$.

In this regard, recent evidence indicates that psychological problems among justice-involved juveniles remain relatively stable throughout time (Wareham \& Dembo, 2007), and that researchers can predict offending and estimate career length from variables available at the first court conviction (Francis, Soothill \& Piquero, 2007).

\footnotetext{
${ }^{32}$ Time-invariant variables reflect the initial status of the factors, whereas time-averaged variables reflect the average level of the factors throughout the entire study period. For both of these methods, an individual receives one score for every factor. In contrast, with time-varying variables, an individual's score at each wave of assessment is entered for every factor.
} 
Nevertheless, the inclusion of time-varying predictors could help researchers establish whether changes in some variables are associated with offending (or desistance) during various developmental stages of the life-course. Moreover, it could allow a more precise and thorough investigation of both cause and effect relations and person-by-situation interactions.

Also related to the choice of predictor variables, only factors that reflected the person and his/her social environment were assessed. What was missing in this study were social-cognitive indicators such as the individual's goals and motives. Examining the relations between underlying psychological processes and offending behaviour could provide a more representative and comprehensive picture of the phenomenon under study. For instance, it might help explain why early onset persisters (chronic high offenders) are more violent, or why late onset desisters (stable low offenders) become relatively crime-free.

To attend to the abovementioned shortcomings implies addressing a number of central themes on Moffitt's (2003) research agenda. For instance, there is a need to fill the critical gap in the early childhood periods regarding the neurodevelopmental correlates of persistent offending and to investigate the effect of serious and chronic criminal behaviour on other generally negative patterns of behaviour or life outcomes. Some areas worthy of examination have already been proposed. These include employment and educational success, overall physical and mental health, substance misuse, as well as family, marital and social relationships (e.g., Aalsma \& Lapsley, 2001; Moffitt et al., 2002; Piquero \& White, 2003). 
Another methodological limitation of the present study concerns attrition. Subject loss was an issue due to the reasons described earlier (e.g., purging of criminal records), and to the extent that information on current status (e.g., death, emigration) was not gathered. Although the analyses of selection effects failed to indicate that the findings were biased in a very important way due to subject loss, they nonetheless suggest that the group of offenders who were excluded from the study probably comprised a larger number of offenders who followed a desisting criminal pathway than a serious, persistent offending pathway.

Furthermore, official conviction records was the sole measure of offending behaviour. Prior research has suggested that predicting serious and/or persistent offending is at least somewhat dependent on the measurement strategy used (see Brennan, Grekin \& Mednick, 1999; Piquero, Gibson, Tibbetts, Turner \& Kratz, 2002). Not only could the use of self-report questionnaires in conjunction with official police records have yielded additional valuable information relating to goals, motives, and contexts (among other things), but it could also have provided a more accurate (less biased) representation of recidivism rates ${ }^{33}$. Still, in this study, a review of a number of cases found a high level of agreement or validity of the criminal behaviour information among data retrieved from multiple independent sources (i.e., RCMP's Criminal Records Branch, Offender Profile Manitoba Corrections, CSC's Offender Management System). As a final commentary, the reader is reminded that this study sample was sizeable and not restricted to males. Then again, additional research that has complete, accurate

\footnotetext{
${ }^{33}$ In all likelihood, the present rates should be interpreted as underestimates.
} 
information on a larger number of high-risk, chronic offenders and/or female offenders is needed. This would facilitate a more systematic examination of two essential areas of enquiry that have been neglected in past research, which are the study of interaction effects (i.e., combined influences of various risk factors) and/or gender differences on distinct trajectories of offending. Similarly, a replication of the current study with another sample of Canadian offenders who, ideally, originate from a variety of provinces and/or territories is warranted.

Acknowledging the aforementioned limitations, the present study contributes to the existing developmental criminological literature in several important ways. Perhaps most notably, there was full use of the longitudinal data employing a state-of-the-art analytical strategy that allowed the capture of the complex patterns of stability and change in criminal behaviour across developmental periods. What is now hoped for is that the current findings provide some valued guidance to policy-makers and criminal justice authorities, and eventually translate into practice. 


\section{References}

Aalsma, M. C., \& Lapsley, D. K. (2001). A typology of adolescent delinquency: Sex differences and implications for treatment. Criminal Behaviour and Mental Health, 11, 173-191.

af Klinteberg, B. (2002). Underlying vulnerability influencing outcome factors/behaviors in psychosocial disturbances. In R. R. Corrado, R Roesch, S. D. Hart, \& J. K. Gierowski (Eds.), Multiproblem violent youth: A Foundation for comparative research on needs, interventions, and outcomes (pp. 138-149). Amsterdam: IOS Press.

Agnew, P. (1992). Foundation for a general strain theory of crime and delinquency. Criminology, 30, 47-87.

Aguilar, B., Stroufe, L. A., Egeland, B., \& Carlson, E. (2000). Distinguishing the earlyonset-persistent and adolescent-onset antisocial behavior types: From birth to 16 years. Development and Psychopathology, 12, 109-132.

Anderson, T. W. (1957). Maximum-likelihood estimates for a multivariate normal distribution when some observations are missing. Journal of the American Statistical Association, 52, 200-203.

Andrews, D. A., \& Bonta, J. (1994). The psychology of criminal conduct. Cincinnati, OH: Anderson Publisher Ltd.

Andrews, D. A., \& Bonta, J. (1998). The psychology of criminal conduct ( $2^{\text {nd }}$ ed.). Cincinnati, OH: Anderson Publisher Ltd. 
Andrews, D. A., \& Bonta, J. (2003). The psychology of criminal conduct ( $3^{\text {rd }}$ ed.). Cincinnati, OH: Anderson Publisher Ltd.

Andrews, D. A., \& Bonta, J. (2006). The psychology of criminal conduct ( $4^{\text {th }} \mathrm{ed}$.). Newark, NJ: LexisNexis.

Andrews, D. A., Zinger, I., Hoge, R. D., Bonta, J., Gendreau, P., \& Cullen, F. T. (1990). Does correctional treatment work? A clinically relevant and psychologically informed meta-analysis. Criminology, 28, 369-404.

Baird, C. S., Heinz, R. C., \& Bemus, B. J. (1979). The Wisconsin case classification/staff deployment project: A two-year follow-up report (Project \#14). Wisconsin: Department of Health and Social Services.

Bandura, A. (1977). Social learning theory. London: Prentice-Hall.

Barkwell, L. (1991). Offender classification and risk assessment. Winnipeg: Community and Youth Corrections.

Bast, J., \& Reitsma, P. (1997). Matthew effects in reading: A comparison of latent growth curve models and simplex models with structural means. Multivariate Behavioral Research, 32, 135-167.

Bauer, D. J., \& Curran, P. J. (2003). Distributional assumptions of growth mixture models: Implications for overextraction of latent trajectory classes. Psychological Methods, 8, 338-363.

Bauer D. J., \& Curran, P. J. (2004). The integration of continuous and discrete latent variables models: Potential problems and promising opportunities. $P_{\text {sychological }}$ Methods, 9, 3-29. 
Bentler, P. M. (1990). Comparative fit indexes in structural models. Psychological Bulletin, 107, 238-246.

Blanchette, K., \& Brown, S. L. (2006). The assessment and treatment of women offenders: An integrative perspective. Chichester: John Wiley \& Sons Ltd.

Blokland, A. A., Nagin, D. S., \& Nieuwbeerta, P. (2005). Life span offending trajectories of a Dutch conviction cohort. Criminology, 43, 919-954.

Blokland, A. A. J., \& Nieuwbeerta, P. (2005). The effects of life circumstances on longitudinal trajectories of offending. Criminology, 43, 1203-1240.

Blumstein, A., \& Cohen, J. (1987). Characterizing criminal careers. Science, 237, 985991.

Blumstein, A., Cohen, J., \& Farrington, D. P. (1988). Criminal career research: It's value for criminology. Criminology, 26, 1-35.

Blumstein, A., Cohen, J., Roth, J., \& Visher, C. A. (1986). Criminal careers and "career criminals" (Vol. 1). Washington, DC: National Academy Press.

Bollen, K. A., \& Curran, P. J. (2004). Autoregressive latent trajectory (ALT) models: A synthesis of two traditions. Sociological Methods and Research, 32, 336-383.

Bollen, K. A., \& Curran, P. J. (2006). Latent curve models: A structural equation perspective. John Wiley \& Sons, Inc. Hoboken, New Jersey.

Bonta, J. (2002). Offender risk assessment: Guidelines for selection and use. Criminal Justice and Behavior, 29, 355-379. 
Bonta, J., \& Andrews, D. A. (2007). Risk-need-responsivity model for offender assessment and rehabilitation (Research Report No. 2007-06). Ottawa: Public Safety Canada.

Bonta, J., Parkinson, R., Pang, B., Barkwell, L., \& Wallace-Capretta, S. (1994). The revised Manitoba classification system for probationers (Research Report). Ottawa: Solicitor General Canada.

Bonta, J., Parkinson, B., Barkwell, L., \& Wallace-Capretta, S. (1994). The classification of young offenders in Manitoba: Post-probation recidivism (Research Report). Ottawa: Solicitor General Canada.

Brendgen, M., Vitaro, F., \& Bukowski, W. M. (1998). Affiliation with delinquent friends: Contributions of parents, self-esteem, delinquent behavior, and rejection by peers. Journal of Early Adolescence, 18, 244-265.

Brennan, P., Grekin, E. R., \& Mednick, S. A. (1999). Maternal smoking during pregnancy and adult male criminal outcomes. Archives of General Psychiatry, 56, 215-219.

Brezina, T. (2000). Delinquent problem-solving: An interpretive framework for criminological theory and research. Journal of Research in Crime and Delinquency, 37, 3-30.

Broidy, L. M. (2001). A test of general strain theory. Criminology, 39, 9-33.

Browne, M. W., \& Cudeck, R. (1993). Alternative ways of assessing model fit. In K. A., Bollen \& J. L. Horn (Eds.), Best methods for the analysis of change (pp. 47-68). Washington, DC: American Psychological Association. 
Campbell, M. A., French, S., \& Gendreau, P. (2007). Assessing the utility of risk assessment tools and personality measures in the prediction of violent recidivism for adult offenders (Research Report No. 2007-04). Ottawa: Public Safety Canada.

Chassin, L., Flora, D. B., \& King, K. M. (2004). Trajectories of alcohol and drug use and dependence from adolescence to adulthood: The effects of familial alcoholism and personality. Journal of Abnormal Psychology, 113, 483-498.

Chess, S., \& Thomas, A. (1984). Origins and evolution of behavior disorders: From infancy to early adult life. New York: Brunner/Mazel.

Chung, I-J., Hill, K. G., Hawkins, J. D., Gilchrist, L. D., \& Nagin, D. S. (2002). Childhood predictors of offense trajectories. Journal of Research in Crime and Delinquency, 39, 60-90.

Cliff, N. (1983). Some cautions concerning the application of causal modeling methods. Multivariate Behavioral Research, 18, 115-126.

Cloward, R. A., \& Ohlin, L. E. (1960). Delinquents and opportunity: A theory of delinquent gangs. New York, NY: Free Press.

Cohen, A. K. (1955). Delinquent Boys: The culture of the gang. Glencoe, IL: Free Press. Cohen, L. E., \& Vila, B. J. (1996). Self-control and social control: An exposition of the Gottfredson-Hirschi/Sampson-Laub debate. Studies on Crime \& Crime Prevention, 5, 125-150. 
Coie, J. D., Terry, R., Zakriski, A., \& Lochman, J. (1995). Early adolescent social influences on delinquent behavior. In J. McCord (Ed.), Coercion and punishment in long-term perspectives (pp. 229-244). Cambridge: Cambridge University Press.

Collins, L. M., \& Wugalter, S. E. (1992). Latent class models for stage-sequential dynamic latent variables. Multivariate Behavioral Research, 27, 131-157.

Coid, J. (1993). Current concepts and classifications of psychopathic disorder. In P. Tyrer \& G. Stein (Eds.), Personality disorder reviewed (pp. 113-164). London: Gaskell.

Côté, S. M., Vaillancourt, T., LeBlanc, J. C., Nagin, D. S., \& Tremblay, R. E. (2006). The development of physical aggression from toddlerhood to pre-adolescence: A nation wide longitudinal study of Canadian children. Journal of Abnormal Child Psychology, 34, 71-85.

Côté, S. M., Zoccolillo, M., Tremblay, R. E., Nagin, D., \& Vitaro, F. (2001). Predicting girl's conduct disorder in adolescence from childhood trajectories of disruptive behaviors. Journal of the American Academy of Child and Adolescent Psychiatry, $40,678-684$.

Curran, P. J. (2000). A latent curve framework for studying development trajectories of adolescent substance use. In J. Rose, L. Chassin, C. Presson \& J. Sherman (Eds.), Multivariate applications in substance use research (pp. 1-42). Hillsdale, NJ: Erlbaum. 
Day, D. M., Beve, I., Duschene, T., Rosenthal, J. S., Sun, Y., \& Theodor, F. (2007). Criminal trajectories from adolescence to adulthood in an Ontario sample of offenders. Paper presented at the Canadian Psychological Association/North American Correctional and Criminal Justice Psychology conference. Ottawa, ON.

Diaconis, P., \& Efron, B. (1983). Computer-intensive methods in statistics. Scientific American, 248, 116-130.

Diggle, P. J., Liang, K. Y., \& Zeger, S. L. (1994). Analysis of longitudinal data. Clarendon Press: Oxford.

Dishion, T. J., Eddy, J. M., Haas, E., Li, F., \& Spracklen, K. M. (1997). Friendships and violent behavior during adolescence. Social Development, 6, 207-225.

Dollard, J., Doob, L., Miller, N., Mowrer, O., \& Sears, R. (1939). Frustration and aggression. New Haven: Yale University Press.

Duncan, S. C., \& Duncan, T. E. (1994). Modeling in complete longitudinal substance use data using latent variable growth curve methodology. Multivariate Behavioral Research, 29, 313-338.

D'Unger, A. V., Land, K. C., \& McCall, P. L. (2002). Sex differences in age patterns of delinquent/criminal careers: Results from Poisson latent class analyses of the Philadelphia cohort study. Journal of Quantitative Criminology, 18, 349-375.

D’Unger, A. V., Land, K. C., McCall, P. L., \& Nagin, D. S. (1998). How many latent classes of delinquent criminal careers? Results from mixed Poisson regression analyses of the London, Philadelphia and Racine cohorts studies. American Journal of Sociology, 103, 1593-1630. 
Efron, B. (1979). Bootstrap methods: Another look at the jackknife. The Annals of Statistics, 7, 1-26.

Eggleston, E. P., Laub, J., \& Sampson, R. J. (2004). Methodological sensitivities to latent class analysis of long-term criminal trajectories. Journal of Quantitative Criminology, 20, 1-26.

Eklund, J. M, \& af Klinteberg, B. (2006). Stability and change in criminal behavior: A prospective study of young male lawbreakers and controls. International Journal of Forensic Mental Health Services, 5, 83-95.

Elander, J., Rutter, M., Simonoff, E., \& Pickles, A. (2000). Explanations for apparent late-onset criminality in a high-risk sample of children followed up in adult life. British Journal of Criminology, 40, 497-509.

Elliott, D. S. (1994). Serious violent offenders: Onset, developmental course, and termination - The American Society of Criminology 1993 Presidential Address. Criminology, 32, 1-21.

Farrington, D. P. (1983). Offending from 10 to 25 years of age. In K. Van Dusen \& S. A. Mednick (Eds.), Prospective studies of crime and delinquency (pp. 17-38). Boston: Kluwer-Nijhoff.

Farrington, D. P. (1986). Age and crime. In M. Tonry \& N. Morris (Eds.), Crime and justice: An annual review of research (Vol. 7, pp. 189-250). Chicago: University of Chicago Press. 
Farrington, D. P. (1995). The $12^{\text {th }}$ Jack Tizard memorial lecture: The development of offending and antisocial behavior from childhood: Key findings from the Cambridge Study in Delinquent Development. Journal of Child Psychology and Psychiatry, 360, 929-964.

Farrington, D. P. (1997). Early prediction of violent and non-violent youthful offending. European Journal on Criminal Policy and Research, 5, 51-66.

Farrington, D. P. (in press). Childhood risk factors and risk-focussed prevention. In M. Maguire, R. Morgan, \& R. Reiner (Eds.). The Oxford handbook of criminology ( $4^{\text {th }}$ ed.). Oxford: Oxford University Press.

Farrington, D. P., Coid, J. W., Harnett, L., Jolliffe, D., Soteriou, N., Turner, R., \& West, D. J. (2006). Criminal careers and life success: New findings from the Cambridge study in delinquent development $\left(2^{\text {nd }}\right.$ ed.). Research Study No. 299. London: Home Office Research.

Farrington, D. P., Lambert, S., \& West, D. J. (1998). Criminal careers of two generations of family members in the Cambridge study in delinquent development. Studies on Crime and Crime Prevention, 7, 85-106.

Fergusson, D. M., Horwood, L. J., \& Nagin, D. S. (2000). Offending trajectories in a New Zealand birth cohort. Criminology, 38, 525-551.

Francis, B., Soothill, K., \& Piquero, A. R. (2007). Estimation issues and generational changes in modeling criminal length. Crime and Delinquency, 53, 84-105.

Freud, S. (1953). A General introduction to psychoanalysis. New York: Permabooks. 
Ge, X., Donnellan, M. B., \& Wenk, E. (2001). The development of persistent criminal offending in males. Criminal Justice and Behavior, 28, 731-755.

Gendreau, P., \& Leipciger, M. (1978). The development of a recidivism measure and its application in Ontario. Canadian Journal of Criminology, 20, 3-17.

Gendreau, P., Little, T., \& Goggin, C. (1996). A meta-analysis of the predictors of adult recidivism: What works! Criminology, 34, 401-433.

Giordano, P. C., Cernkovich, S. A., \& Rudolph, J. L. (2002). Gender, crime, and desistance: Toward a theory of cognitive transformation. American Journal of Sociology, 107, 990-1064.

Glover, A. J. J., Nicholson, D. E., Hemmati, T., Bernfeld, G. A., \& Quinsey, V. L. (2002). A comparison of predictors of general and violent recidivism among highrisk federal offenders. Criminal Justice and Behavior, 29, 235-249.

Goldstein, H., Healy, M. J. R., \& Rasbash, J. (1994). Multilevel time series models with applications to repeated measures data. Statistics in Medicine, 13, 1643-1655.

Gottfredson, M., \& Hirschi, T. (1990). A General theory of crime. Stanford, CA: Stanford University Press.

Glueck, S., \& Glueck, E. T. (1950). Unraveling juvenile delinquency. Cambridge, MA: Harvard University Press.

Greenbaum, P. E., Del Boca, F. K., Darkes, J., Wang, C.-P., \& Goldman, M. S. (2005). Variation in the drinking trajectories of freshman college students. Journal of Consulting and Clinical Psychology, 73, 229-238. 
Grove, W. M., \& Meehl, P. E. (1996). Comparative efficiency of informal (subjective, impressionistic) and formal (mechanical, algorithmic) prediction procedures: The clinical-statistical controversy. Psychology, Public Policy, and Law, 2, 293-323.

Grove, W. M., Zald, D. H., Lebow, B. S., Snitz, B. E., \& Nelson, C. (2000). Clinical versus mechanical prediction: A meta-analysis. Psychological Assessment, 12, $19-$ 30.

Guthrie, A. (2001). Using bootstrap methods with popular statistical programs. Paper presented at the annual meeting of the Southwest Educational Research Association, New Orleans: LA.

Hanson, K. R., \& Morton-Bourgon, K. (2007). The accuracy of recidivism risk assessments for sexual offenders: A meta-analysis (Research Report No. 200701). Ottawa: Public Safety Canada.

Hare, R. D. (1993). Without Conscience: The disturbing world of the psychopaths among us. New York: Pocket Books.

Harris, G. T., Rice, M. E., \& Lalumière, M. L. (2001). Criminal violence: The roles of psychopathy, neurodevelopmental insults, and antisocial parenting. Criminal Justice and Behavior, 28, 402-426.

Hart, S. D., Kropp, P. R., \& Hare, R. D. (1988). Performance of male psychopaths following conditional release from prison. Journal of Consulting and Clinical Psychology, 56, 237-232.

Hemphill, J. F., Hare, R. D., \& Wong, S. (1998). Psychopathy and recidivism: A review. Legal and Criminological Psychology, 3, 139-170. 
Henry, B., Caspi, A., Moffitt, T. E., \& Silva, P. A. (1996). Temperamental and familial predictors of violent and nonviolent criminal convictions: Age 3 and age 18 . Developmental Psychology, 32, 614-623.

Hindelang, M. J. (1972). The relationship of self-reported delinquency to scales of the CPI and MMPI. Journal of Criminal Law, Criminology and Police Science, 63, $75-81$.

Hirschi, T. (1969). Causes of Delinquency. Berkeley: University of California Press.

Hirschi, T., \& Gottfredson, M. (1983). Age and the explanation of crime. American Journal of Sociology, 89, 552-584.

Hirschi, T., \& Hindelang, M. J. (1977). Intelligence and delinquency: A revisionist review. American Sociological Review, 42, 571-587.

Howell, J. C., \& Hawkins, J. D. (1998). Prevention of youth violence. Crime and Justice: A Review of Research, 24, 263-316.

Jedidi, K., Jagpal, H. S., \& DeSarbo, W. S. (1997). STEMM: A general finite mixture structural equation model. Journal of Classification, 14, 23-50.

Jeglum-Bartusch, D., Lynam, D., Moffitt, T. E., \& Sylva, P. A. (1997). Is age important?: Testing general versus developmental theories of antisocial behavior. Criminology, 35, 13-47.

Kass, R. E., \& Raftery, A. E. (1995). Bayes factor. Journal of the American Statistical Association, 90, 773-795. 
Kazemian, L., \& Farrington, D. P. (2006). Exploring residual career length and residual number of offenses for two generations of repeat offenders. Journal of Research in Crime and Delinquency, 43, 89-113.

Kemshall, H., \& Macguire, M. (2001). Public protection, partnership and risk penalty: The multi-agency risk management of sexual and violent offenders. Punishment and Society, 3, 237-264.

Kenny, D. A., \& Campbel1, D. T. (1989). On the measurement of stability in over-time data. Journal of Personality, 57, 445-481.

Kenny, D. A., \& Zautra, A. (2001). Trait-state models for longitudinal data. In L. M. Collins \& A. G. Sayer (Eds.). New methods for the analysis of change: Decade of behavior (pp. 243-263). Washington, DC: American Psychological Association.

Kessler, R. C., \& Greenberg, D. F. (1981). Linear Panel Analysis. NY: Academic Press. Kokko, K., Tremblay, R. E., Lacourse, E., Nagin, D. S., \& Vitaro, F. (2006). Trajectories of prosocial behavior and physical aggression in middle childhood: Links to adolescent school dropout and physical violence. Journal of Research on Adolescence, 16, 403-428.

Kratzer, L., \& Hodgins, S. (1999). A typology of offenders: A test of Moffitt's theory among males and females from childhood to age 30. Criminal Behaviour and Mental Health, 9, 57-73.

Krueger, R. F., Schnutte, P. S., Caspi, A., Moffitt, T. E., Campbell, K., \& Silva, P. A. (1994). Personality traits are linked to crime among men and women: Evidence from a birth cohort. Journal of Abnormal Psychology, 103, 328-338. 
Lacourse, E., Nagin, D., Tremblay, R. E., Vitaro, F., \& Claes, M. (2003). Developmental trajectories of boys' delinquent group membership and facilitation of violent behaviors during adolescence. Development and Psychopathology, 15, 183-197.

Lahey, B. B., Loeber, R., Hart, E. L., Frick, P. J., Applegate, B., Zhang, Q., Green, S. M., \& Russo, M. F. (1995). Four-year longitudinal study of conduct disorder I boys: Patterns and predictors of persistence. Journal of Abnormal Psychology, 104, 8393.

Lahey, B. B., Waldman, I. D., \& McBurnett, K. (1999). The development of antisocial behavior: An integrative causal model. Journal of Child Psychology and Psychiatry, 40, 669-682.

Lalumière, M. L., Harris, G. T., \& Rice, M. E. (2001). Psychopathy and developmental instability. Behavioral and Brain Sciences, 22, 75-92.

Land, K. C., \& Nagin, D. S. (1996). Micro-models of criminal careers: A synthesis of the criminal careers and life-course approaches via semiparametric mixed poisson regression models, with empirical applications. Journal of Quantitative Criminology, 12, 163-191.

Laub, J. H., Nagin, D. S., \& Sampson, R. J. (1998). Trajectories of change in criminal offending: Good marriages and the desistance process. American Sociological Review, 63, 225-238.

Laub, J. H., \& Sampson, R. J. (2001). Understanding desistence from crime. Crime and Justice: An Annual Review of Research, 28, 1-69. 
Laub, J. H., \& Sampson, R. J. (2003). Shared beginnings, divergent lives: Delinquent boys to age 70. Cambridge, MA: Harvard University Press.

LeBlanc, M. (1996). Changing patterns in the perpetration of offenses over time: Trajectories from early adolescence to the early 30 's. Studies on Crime and Crime Prevention, 5, 151-165.

Leschied, A. W., Nowicki, E., Rodger, A., \& Chiodo, D. (2006). Better to build a child than fix an adult (Research Report). Ottawa: Canadian National Crime Prevention Council.

Li, F., Duncan, T. E., \& Duncan, S. C. (2001). Latent growth modeling of longitudinal data: A finite growth mixture modeling approach. Structural Equation Modeling, $8,493-530$.

Litwack, T. R. (2001). Actuarial versus clinical assessments of dangerousness. Psychology, Public Policy, and Law, 7, 409-443.

Loeber, R., \& Dishion, T. J. (1983). Early predictors of male delinquency. Psychological Bulletin, 94, 68-99.

Loeber, R., Farrington, D. P., Stouthamer-Loeber, M., Moffitt, T. E., \& Caspi, A. (1998). The development of male offending: Key findings from the first decade of the Pittsburgh Youth Study. Studies on Crime and Crime Prevention, 7, 141-171.

Loeber, R., Lahey, B. B., \& Thomas, C. (1991). Diagnostic conundrum of oppositional defiant disorder and conduct disorder. Journal of Abnormal Psychology, 100, 379-390. 
Loeber, R., \& LeBlanc, M. (1990). Toward a developmental criminology. In M. Tonry \& N. Morris (Eds.), Crime and justice: A review of research (pp. 375-471). Chicago, IL: University of Chicago Press.

Loeber, R., Pardini, D., Homish, D. L., Wei, E. H., Crawford, A. M., Farrington, D. P., Stouthamer-Loeber, M., Creemer, J., Koehler, S. A., Rosenfeld, R. (2005). The prediction of violence and homicide in young men. Journal of Consulting and Clinical Psychology, 73, 1074-1088.

Loeber, R., \& Stouthamer-Loeber, M. (1996). The development of offending. Criminal Justice and Behavior, 23, 12-24.

Loeber, R., \& Stouthamer-Loeber, M. (1998). Development of juvenile aggression and violence: Some common misconceptions and controversies. American Psychologist, 53, 242-259.

Loeber, R., Wei, E., Stouthamer-Loeber, M., Huizinga, D., \& Thornberry, T. P. (1999). Behavioral antecedents to serious and violent offending: Joint analyses from the Denver youth survey, Pittsburgh youth study and the Rochester youth development study. Studies on Crime and Crime Prevention, 8, 245-263.

Marsh, H. W. (1993). Stability of individual differences in multiwave panel studies: Comparison of simplex models and one-factor models. Journal of Educational Measurement, 30, 157-183.

McArdle, J. J., \& Epstein, D. (1987). Latent growth curves within developmental structural equation models. Child Development, 58, 110-133. 
McArdle, J. J., \& Hamagami, F. (2001). Latent difference score structural models for linear dynamic analyses with incomplete longitudinal data. In L. M. Collins \& A. G. Sayer (Eds.). New methods for the analysis of change: Decade of behavior (pp. 139-175). Washington, DC: American Psychological Association.

McNeill, F., Batchelor, S., Burnett, R., \& Knox, J. (2005). $21^{\text {st }}$ Century social work: Reducing re-offending: Key practice skills (Research Report No. B40448 3/05). Edinburgh: Scottish Executive.

Merton, R. K. (1938). Social structure and anomie. American Sociological Review, 3, $672-682$.

Merton, R. K. (1957). Social theory and social structure. New York: Free Press.

Moberg, D. D., \& Erikson, R. C. (1972). A new recidivism outcome index. Federal Probation, 36, 50-57.

Moffitt, T. E. (1993). Adolescence-limited and life-course-persistent antisocial behavior: A developmental taxonomy. Psychological Review, 100, 674-701.

Moffitt, T. E. (2003). Causes of conduct disorder and juvenile delinquency. In B. Lahey, T. E. Moffitt \& A. Caspi (Eds.), Life-course-persistent and adolescent-limited antisocial behavior: A 10-year research review and a research agenda (pp. 4975). New York, NY: Guilford Press.

Moffitt, T. E., \& Caspi, A. (2001). Childhood predictors differentiate life-course persistent and adolescence-limited pathways, among males and females. Development and Psychopathology, 13, 355-375. 
Moffitt, T. E., Caspi, A., Dickson, N., Silva, P., \& Stanton, W. (1996). Childhood-onset versus adolescent-onset antisocial conduct problems in males: Natural history from ages 13 to 18 years. Development and Psychopathology, 8, 399-424.

Moffitt, T. E., Caspi, A., Harrington, H., \& Milne, B. J. (2002). Males on the life-course persistent and adolescence-limited antisocial pathways: Follow-up at age 26 years. Development and Psychopathology, 14, 179-207.

Moffitt, T. E., Lynam, D., \& Sylva, P. A. (1994). Neuropsychological tests predicting persistent male delinquency. Criminology, 32, 277-300.

Morizot, J., \& LeBlanc, M. (2007). Behavioral, self, and social control predictors of desistance from crime. Journal of Contemporary Criminal Justice, 23, 50-71.

Mulvihill, D. J., \& Tumin, M. M. (1969). Crimes of violence (Vol. 12). National Commission on the Causes and Prevention of Violence.

Muthén, B. O. (2003). Statistical and substantive checking in growth mixture modeling : Comment on Bauer and Curran (2003). Psychological Methods, 8, 369-377.

Muthén, B. O., Brown, C. H., Masyn, K., Jo, B., Khoo, S. T., Yang, C. C., Wang, C. P., Kellam, S., Carlin, J., \& Liao, J. (2002). General growth mixture modeling for randomized preventive interventions. Biostatistics, 3, 459-475.

Muthén, B. O., \& Curran, P. J. (1997). General longitudinal modeling of individual differences in experimental designs: A latent variable framework for analysis and power estimation. Psychological Methods, 2, 371-402.

Muthén, B. O., \& Khoo, S.-T. (1998). Longitudinal studies of achievement growth using latent variable modeling. Learning and Individual Differences, 10, 73-101. 
Muthén, B. O., \& Shedden, K. (1999). Finite mixture modeling with mixture outcomes using the EM algorithm. Biometrics, 55, 463-469.

Muthén, L. K., \& Muthén, B. O. (1998, 2006). Mplus user's guide (4th ed.). Los Angeles, CA: Muthén \& Muthén.

Nagin, D. S. (1999). Analyzing developmental trajectories: A semi-parametric, groupbased approach. Psychological Methods, 4, 139-157.

Nagin, D. S. (2004). Response to "Methodological sensitivities to latent class analysis of long-term criminal trajectories". Journal of Quantitative Criminology, 20, 27-35.

Nagin, D. S., Farrington, D. P., \& Moffitt, T. E. (1995). Life-course trajectories of different types of offenders. Criminology, 33, 111-139.

Nagin, D. S., \& Land, K. C. (1993). Age, criminal careers, and population heterogeneity: Specification and estimation of a nonparametric, mixed poisson model. Criminology, 31, 327-362.

Nagin, D. S., \& Tremblay, R. (2001). Analyzing developmental trajectories of distinct but related behaviors: A group-based method. Psychological Methods, 6, 18-34.

Nagin, D. S., \& Tremblay, R. (2005). Developmental trajectory groups: Fact or a useful statistical fiction? Criminology, 43, 873-904.

Ouimet, M., \& LeBlanc, M. (1996). The role of life experiences in the continuation of the adult criminal career. Criminal Behaviour and Mental Health, 6, 73-97.

Osgood, D. W. (1998). Interdisciplinary integration: Building criminology by stealing from our friends. The Criminologist, 23, 1-4, 41. 
Pardini, D., Obradovic, J., \& Loeber, R. (2006). Interpersonal callousness, hyperactivity/impulsivity, inattention, and conduct problems as precursors to delinquency persistence in boys: A comparisons of three grade-based cohorts. Journal of Clinical Child and Adolescent Psychology, 35, 46-59.

Patterson, G. R. (1982). Coercive family process. Eugene, OR: Castalia.

Patterson, G. R., DeGarmo, D. S., \& Knutson, N. (2000). Hyperactive and antisocial behaviors: Comorbid or two points in the same process? Development and Psychopathology, 12, 91-106.

Patterson, G. R., Reid, J. B., \& Dishion, T. J. (1992). A Social interactional approach: Vol. 4. Antisocial boys. Eugene, OR: Castalia.

Piquero, A. R. (2001). Testing Moffitt's neuropsychological variation hypothesis for the prediction of life-course persistent offending. Psychology, Crime and Law, 7, 193-215.

Piquero, A. R., Blumstein, A., Brame, R., Haapanen, R., Mulvey, E. P., \& Nagin, D. S. (2001). Assessing the impact of exposure time and incapacitation on longitudinal trajectories of criminal offending. Journal of Adolescent Research, 16, 54-74.

Piquero, A. R., \& Brezina, T. (2001). Testing Moffitt's account of adolescence-limited delinquency. Criminology, 39, 353-370.

Piquero, A. R., Gibson, C., Tibbetts, S., Turner, M. G., \& Kratz, S. H. (2002). Maternal prenatal cigarette smoking and life-course persistent offending. International Journal of Offender Therapy and Comparative Criminology, 46, 231-248. 
Piquero, A. R., \& White, N. A. (2003). On the relationship between cognitive abilities and life-course-persistent offending among a sample of African Americans: A longitudinal test of Moffitt's hypothesis. Journal of Criminal Justice, 31, 399409.

Potenza, M. T., Osgood, D. W., \& Plake, B. S. (1992). Application of latent trait item response models to adolescent research. Paper presented at the biennial meeting of the Society for Research on Adolescence. Washington, DC.

Pratt, T. C., \& Cullen, F. T. (2005). Assessing macro-level predictors and theories of crime: A Meta-analysis. In M. Tonry (Ed.), Crime and justice: A review of research (Vol. 32, pp. 373-450). Chicago, IL: University of Chicago Press.

Quinsey, V. L., Skilling, T. A., Lalumière, M. L., \& Craig, W. M. (2004). Juvenile delinquency: Understanding the origins of individual differences. Washington, DC: American Psychological Association.

Raftery, A. E. (1993). Bayesian model selection in structural equation models. In K. A. Bollen \& J. S. Long (Eds.). Testing structural equation models (p. 163-180). Newbury Park, CA: Sage.

Raftery, A. E. (1995). Bayesian model selection in social research. Sociological Methodology, 25, 111-164.

Raine, A., Moffitt, T. E., Caspi, A., Loeber, R., Stouthamer-Loeber, M., \& Lynam, D. (2005). Neurocognitive impairments in boys on the life-course persistent antisocial path. Journal of Abnormal Psychology, 114, 38-49. 
Ramaswamy, V., DeSarbo, W., Reibstein, D., \& Robinson, W. (1993). An empirical pooling approach for estimating marketing mix elasticities with PIMS data. Marketing Science, 12, 103-124.

Raykov, T. (1997). Growth curve analysis of ability means and variances in measures of fluid intelligence of older adults. Structural Equation Modeling, 4, 283-319.

Reboussin, B. A., Reboussin, D. M., Liang, K. L., \& Anthony, J. C. (1998). Latent transition modeling of progression of health-risk behavior. Multivariate Behavioral Research, 33, 457-478.

Reckless, W. C. (1967). The crime problem. New York: Appleton-Century-Crofts.

Rice, M. E., \& Harris, G. T. (1997). Cross-validation and extension of the Violence Risk Appraisal Guide for child molesters and rapists. Law and Human Behavior, 21, $231-241$.

Roeder, K., Lynch, K. G., \& Nagin, D. S. (1999). Modeling uncertainty in latent class membership: A case study in criminology. Journal of the American Statistical Association, 94, 766-776.

Rogosa, D. R., \& Willett, J. B. (1985). Satisfying simplex structure is simpler than it should be. Journal of Educational Statistics, 10, 99-107.

Rutter, M., Giller, H., \& Hagell, A. (1998). Antisocial behavior by young people. New York, NY: Cambridge University Press.

Sabourin, D. (1986). Validation of Manitoba probation risk-assessment scale. Winnipeg: Community and Youth Corrections. 
Sampson, R. J., \& Laub, J. H. (1993). Crime in the making: Pathways and turning point through life. Cambridge, MA: Harvard University Press.

Sampson, R. J., \& Laub, J. H. (2003). Life-course desisters? Trajectories of crime among delinquent boys followed to age 70. Criminology, 41, 555-592.

Sampson, R. J., \& Laub, J. H. (2005). Seductions of method: Rejoinder to Nagin and Tremblay's “Developmental trajectory groups: Fact or fiction?". Criminology, 43, 905-913.

Sampson, R. J., Laub, J. H., \& Wimer, C. (2006). Does marriage reduce crime? A counterfactual approach to within-individual causal effects. Criminology, 44, 465505.

Satorra, A., \& Bentler, P. M. (1999). A scaled difference chi-square test statistic for moment structure analysis (UCLA statistics electronic publications No. 260). Retrieved September 5, 2007, from the Internet.

Schaffer, C. M., Petras, H., Ialongo, N., Poduska, J., \& Kellam, S. (2003). Modeling growth in boys' aggressive behavior across elementary school: Links to later criminal involvement, conduct disorder, and antisocial personality disorder. Developmental Psychology, 39, $1020-1035$.

Schwartz, G. (1978). Estimating the dimension of a model. The Annals of Statistics, 6, 461-464.

Schwartz, C. E., Snidman, N., \& Kagan, J. (1996). Early childhood temperament as a determinant of externalizing behavior in adolescence. Development and Psychopathology, 8, 527-537. 
Scott, E. S., \& Grisso, T. (1997). The evolution of adolescence: A developmental perspective on juvenile justice reform. Journal of Criminal Law and Criminology, $88,137-189$.

Shadish, W. R., Cook, T. D., \& Campbell, D. T. (2002). Experimental and quasiexperimental designs for generalized causal inference. Boston, NY: Houghton Mifflin Company.

Skilling, T. A., Quinsey, V. L., \& Craig, W. M. (2001). Evidence of a taxon underlying serious antisocial behavior in boys. Criminal Justice and Behavior, 28, 450-470.

Simons-Morton, B., \& Chen, R. S. (2006). Over time relationships between early adolescent and peer substance use. Addictive Behavior, 31, 1211-1223.

Smith, W. R., \& Aloisi, M. F. (1999). Prediction of recidivism among "second timers" in the juvenile justice system: Efficiency in screening chronic offenders. American Journal of Criminal Justice, 23, 201-222.

Smith, P., Goggin, C., \& Gendreau, P. (2002). The effects of prison sentences and intermediate sanctions on recidivism: General effects and individual differences (Research Report No. 2002-01). Ottawa: Public Safety and Emergency Preparedness Canada.

Stattin, H, \& Magnusson, D. (1991). Stability and change in criminal behaviour up to age 30. The British Journal of Criminology, 31, 327-346.

Steiger, J. H. (1989). EzPATH: A supplementary module for SYSTAT and SYGRAPH (Computer Program Manual). Evanston, IL: Systat, Inc. 
Steiger, J. H., \& Lind, J. C. (1980). Statistically based tests for the number of common factors. Presented at the Psychometric Society, Iowa City, IA.

Sutherland, E. H., \& Cressey, D. R. (1978). Criminology. Philadelphia: Lippincott.

Tolan, P. H., \& Gorman-Smith, D. (1998). Development of serious and violent offending careers. In R. Loeber \& D. P. Farrington (Eds.), Serious and violent juvenile offenders: Risk factors and successful interventions (pp. 68-85). Thousand Oaks, CA: Sage.

Tremblay, R. E. (2006). Prevention of youth violence: Why not start at the beginning? Journal of Abnormal Child Psychology, 34, 481-487.

Tremblay, R. E., Masse, L. C., Vitaro, F., \& Dobkin, P. L. (1995). The impact of friends' deviant behavior on early onset of delinquency: Longitudinal data from 6 to 13 years of age. Development and Psychopathology, 7, 649-661.

Tucker, L. R., \& Lewis, C. (1973). A reliability coefficient for maximum likelihood factor analysis. Psychometrika, 38, 1-10.

Vincent, G. M., Vitacco, M. J., Grisso, T., \& Corrado, R. R. (2003). Subtypes of adolescent offenders: Affective traits and antisocial behavior patterns. Behavioral Sciences and the Law, 21, 695-712.

von Hirsch, A., Bottoms, A. E., Burney, E., \& Wikström, P.-O. (1999). Criminal deterrence and sentence severity: An analysis of recent research. Oxford, UK: Hart. 
Wang, C.-P., Brown, C. H., \& Bandeen-Roche, K. (2005). Model diagnostics for general growth mixture models: Examining the impact of a preventive intervention on differential pathways to aggressive behavior. Journal of the American Statistical Association, 100, 1054-1076.

Wareham, J., \& Dembo, R. (2007). A longitudinal study of psychological functioning among juvenile offenders: A latent growth model analysis. Criminal Justice and Behavior, 34, 259-273.

Warr, M. (2002). Companions in crime: The social aspects of criminal conduct. New York: Cambridge University Press.

White, H. R., Bates, M. E., \& Buyske, S. (2001). Adolescence-limited versus persistent delinquency: Extending Moffitt's hypothesis into adulthood. Journal of Abnormal Psychology, 110, 600-609.

Wiesner, M., \& Silbereisen, R. K. (2003). Trajectories of delinquent behaviour in adolescence and their covariates: Relations with initial and time-averaged factors. Journal of Adolescence, 26, 753-771.

Wiesner, M., \& Windle, M. (2004). Assessing covariates of adolescent delinquency trajectories: A latent growth mixture modeling approach. Journal of Youth and Adolescence, 33, 431-442.

Wolfgang, M. E., Thornberry, T. P., \& Figlio, R. M. (1987). From boy to man, from delinquency to crime. Chicago: University of Chicago Press.

Wright, J. P., \& Cullen, F. E. (2004). Employment, peers, and life-course transitions. Justice Quarterly, 21, 183-203. 
Yochelson, S., \& Samenow, S. E. (1976). The criminal personality: A profile for change (Vol. 1). New York: Jason Aronson. 
Appendix $A$

Comparison Analyses of Offenders Included in, and Excluded from, the Study

\begin{tabular}{|c|c|c|c|c|}
\hline & $\begin{array}{l}\text { Included } \\
(n=514)\end{array}$ & $\begin{array}{l}\text { Excluded } \\
(n=73)\end{array}$ & & \\
\hline Variable & $(M(S D)) / \%$ & $(M(S D)) / \%$ & Difference & $t / \chi^{2}$ \\
\hline Age & $16.02(1.59)$ & $16.29(1.92)$ & -0.27 & -1.31 \\
\hline Gender (male) & 85.4 & 68.5 & & $13.15^{*}$ \\
\hline Race (Aboriginal) & 55.4 & 39.7 & & $6.35^{*}$ \\
\hline \multicolumn{5}{|l|}{ PRA - V1 scores } \\
\hline Low risk-needs & 19.8 & 35.6 & & $9.68^{*}$ \\
\hline Medium risk-needs & 54.3 & 46.6 & & \\
\hline High risk-needs & 25.9 & 17.8 & & \\
\hline Associates & & & & 0.97 \\
\hline No problem & 24.9 & 30.1 & & \\
\hline Some problems & 60.9 & 57.5 & & \\
\hline Major problems & 14.2 & 12.3 & & \\
\hline Family & & & & 1.18 \\
\hline No problem & 31.5 & 32.9 & & \\
\hline Some problems & 43.6 & 47.9 & & \\
\hline Major problems & 24.9 & 19.2 & & \\
\hline Education & & & & 2.74 \\
\hline At the expected level & 31.7 & 41.1 & & \\
\hline 1 year below norm & 31.1 & 24.7 & & \\
\hline$\geq 2$ years below norm & 37.2 & 34.2 & & \\
\hline
\end{tabular}


Comparison Analyses of Offenders Included in, and Excluded from, the Study (continued)

\begin{tabular}{|c|c|c|c|c|}
\hline & $\begin{array}{l}\text { Included } \\
(n=514) \\
\end{array}$ & $\begin{array}{c}\text { Excluded } \\
(n=73)\end{array}$ & & \\
\hline Variable & $(M(S D)) / \%$ & $(M(S D)) / \%$ & Difference & $t / \chi^{2}$ \\
\hline Accommodation & & & & 0.50 \\
\hline No problem & 50.2 & 53.4 & & \\
\hline Some problems & 24.1 & 24.7 & & \\
\hline Major problems & 25.7 & 21.9 & & \\
\hline Attitudes & & & & 2.42 \\
\hline No problem & 52.1 & 61.6 & & \\
\hline Some problems & 34.4 & 28.8 & & \\
\hline Major problems & 13.4 & 9.6 & & \\
\hline Substance Use & & & & 2.37 \\
\hline No problem & 57.4 & 64.4 & & \\
\hline Some problems & 35.8 & 32.9 & & \\
\hline Major problems & 6.8 & 2.7 & & \\
\hline Financial Management & & & & 0.89 \\
\hline No problem & 45.1 & 49.3 & & \\
\hline Some problems & 37.0 & 37.0 & & \\
\hline Major problems & 17.9 & 13.7 & & \\
\hline
\end{tabular}


Comparison Analyses of Offenders Included in, and Excluded from, the Study (continued)

\begin{tabular}{|c|c|c|c|c|}
\hline & $\begin{array}{l}\text { Included } \\
(n=514)\end{array}$ & $\begin{array}{c}\text { Excluded } \\
(n=73)\end{array}$ & & \\
\hline Variable & $(M(S D)) / \%$ & $(M(S D)) / \%$ & Difference & $t / \chi^{2}$ \\
\hline \multicolumn{5}{|l|}{ Criminal History $^{a}$} \\
\hline Low Risk & 40.1 & & & \\
\hline Medium Risk & 46.1 & & & \\
\hline High Risk & 13.9 & & & \\
\hline
\end{tabular}

${ }^{\mathrm{a}}$ Data for the offenders excluded from the study were unavailable as criminal history records were used to code this variable.

${ }^{*} p<.01$. 
Appendix $B$

Risk/need Distribution of the Offending Groups Based on the CSI and CRI (n/\%)

\begin{tabular}{|c|c|c|c|c|}
\hline \multirow[b]{2}{*}{ Risk factor } & \multicolumn{2}{|c|}{ Criminal Seriousness Index } & \multicolumn{2}{|c|}{ Canadian Recidivism Index } \\
\hline & $\begin{array}{l}\text { Chronic High } \\
\qquad(N=69)\end{array}$ & $\begin{array}{c}\text { Stable Low } \\
(N=445)\end{array}$ & $\begin{array}{l}\text { Chronic High } \\
\qquad(N=54)\end{array}$ & $\begin{array}{l}\text { Stable Low } \\
(N=460)\end{array}$ \\
\hline \multicolumn{5}{|l|}{ Associates } \\
\hline No problem & $7(10.1)$ & $121(27.2)$ & $5(9.3)$ & $123(26.7)$ \\
\hline Some problems & $47(68.1)$ & $266(59.8)$ & $40(74.1)$ & $273(59.3)$ \\
\hline Major problems & $15(21.7)$ & $58(13.0)$ & $9(16.6)$ & $64(13.9)$ \\
\hline \multicolumn{5}{|l|}{ Family } \\
\hline No problem & $17(24.6)$ & $145(32.6)$ & $15(27.8)$ & $147(32.0)$ \\
\hline Some problems & $32(46.4)$ & $192(43.1)$ & $25(46.3)$ & $199(43.3)$ \\
\hline Major problems & $20(29.0)$ & $108(24.3)$ & $14(25.9)$ & $114(24.8)$ \\
\hline \multicolumn{5}{|l|}{ Education } \\
\hline At the exp. level & $15(21.7)$ & $148(33.3)$ & $16(29.6)$ & $147(32.0)$ \\
\hline 1 yr below norm & $23(33.3)$ & $137(30.8)$ & $16(29.6)$ & $144(31.3)$ \\
\hline$\geq 2$ yrs below norm & $31(44.9)$ & $160(36.0)$ & $22(40.7)$ & $169(36.7)$ \\
\hline \multicolumn{5}{|l|}{ Accommodation } \\
\hline No problem & $33(47.8)$ & $225(50.6)$ & $25(46.3)$ & $233(50.7)$ \\
\hline Some problems & $12(17.4)$ & $112(25.2)$ & $10(18.5)$ & $114(24.8)$ \\
\hline Major problems & $24(34.8)$ & $108(24.3)$ & $19(35.2)$ & $113(24.6)$ \\
\hline
\end{tabular}


Risk/need Distribution of the Offending Groups Based on the CSI and CRI (n/\%) (continued)

\begin{tabular}{lcccc}
\hline & \multicolumn{2}{c}{ Criminal Seriousness Index } & \multicolumn{2}{c}{ Canadian Recidivism Index } \\
\cline { 2 - 5 } Risk factor & $\begin{array}{c}\text { Chronic High } \\
(N=69)\end{array}$ & $\begin{array}{c}\text { Stable Low } \\
(N=445)\end{array}$ & $\begin{array}{c}\text { Chronic High } \\
(N=54)\end{array}$ & $\begin{array}{c}\text { Stable Low } \\
(N=460)\end{array}$ \\
\hline Attitudes & & & & \\
No problem & $31(44.9)$ & $237(53.3)$ & $28(51.9)$ & $240(52.2)$ \\
Some problems & $29(42.0)$ & $148(33.3)$ & $18(33.3)$ & $159(34.6)$ \\
Major problems & $9(13.0)$ & $60(13.5)$ & $8(14.8)$ & $61(13.3)$ \\
Substance Use & & & & \\
No problem & $28(40.6)$ & $267(60.0)$ & $23(42.6)$ & $272(59.1)$ \\
Some problems & $33(47.8)$ & $151(33.9)$ & $24(44.4)$ & $160(34.8)$ \\
Major problems & $8(11.6)$ & $27(6.1)$ & $7(13.0)$ & $28(6.1)$ \\
Financial Management & & & & \\
No problem & $31(44.9)$ & $201(45.2)$ & $22(40.7)$ & $210(45.7)$ \\
Some problems & $26(37.7)$ & $164(36.9)$ & $22(40.7)$ & $168(36.5)$ \\
Major problems & $12(17.4)$ & $80(18.0)$ & $10(18.5)$ & $82(17.8)$ \\
Criminal History & & & & $16(20.4)$ \\
Low risk & $27(39.1)$ & $179(40.2)$ & $16(29.6)$ & $190(41.3)$ \\
Medium risk & $31(44.9)$ & $206(46.3)$ & $27(50.0)$ & $210(45.7)$ \\
High risk & $11(15.9)$ & $60(13.5)$ & $11.1)$ \\
\hline
\end{tabular}


Risk/need Distribution of the Offending Groups Based on the CSI and CRI (n/\%) (continued)

\begin{tabular}{lcccc}
\hline & \multicolumn{2}{c}{ Criminal Seriousness Index } & \multicolumn{2}{c}{ Canadian Recidivism Index } \\
\cline { 2 - 5 } Risk factor & $\begin{array}{c}\text { Chronic High } \\
(N=69)\end{array}$ & $\begin{array}{c}\text { Stable Low } \\
(N=445)\end{array}$ & $\begin{array}{c}\text { Chronic High } \\
(N=54)\end{array}$ & $\begin{array}{c}\text { Stable Low } \\
(N=460)\end{array}$ \\
\hline PRA - V1 & $7(10.1)$ & $95(21.3)$ & $8(14.8)$ & $94(20.4)$ \\
Low risk & $26(37.7)$ & $253(56.9)$ & $25(46.3)$ & $254(55.2)$ \\
Medium risk & $36(52.2)$ & $97(21.8)$ & $21(38.9)$ & $112(24.3)$ \\
High risk & & & &
\end{tabular}


Appendix C

Bootstrap Sample Comparison Results

Table C1

Descriptive Longitudinal Analyses of the Bootstrap Sample

\begin{tabular}{lcccc}
\hline $\begin{array}{l}\text { Time period } \\
\text { (age) }\end{array}$ & $N$ & \% Any recidivism & $\begin{array}{c}\text { Adjusted CSI } \\
M(S D)\end{array}$ & $\begin{array}{c}\text { Adjusted CRI } \\
M(S D)\end{array}$ \\
\hline $12-15$ & 229 & 29.7 & $7.37(4.94)$ & $8.52(7.66)$ \\
$16-20$ & 514 & 70.4 & $8.30(5.54)$ & $8.54(4.69)$ \\
$21-25$ & 509 & 61.3 & $7.86(5.73)$ & $7.92(6.17)$ \\
$26-30$ & 506 & 51.4 & $6.56(5.33)$ & $6.53(4.83)$ \\
31 onwards & 436 & 26.8 & $5.22(4.08)$ & $5.49(4.58)$ \\
\hline
\end{tabular}

Note. The bootstrap sample comprised $8.4 \%(n=43)$ non-recidivist offenders.

Table C2

Fit Measures of the Linear and Quadratic LGC Models and ALT Models for the CSI

\begin{tabular}{lcccccc}
\hline & \multicolumn{7}{c}{ Fit index } \\
\cline { 2 - 7 } Model & $T_{\mathrm{ML}}(d f)$ & TLI & CFI & RMSEA & BIC & $R^{2}$ \\
\hline Linear LGC & $119.14^{* * *}(10)$ & .612 & .612 & .146 & 13088 & $.27-.42$ \\
Quadratic LGC & $12.08(6)$ & .964 & .978 & .044 & 12985 & $.43-.75$ \\
Linear ALT & $10.21^{*}(3)$ & .914 & .974 & .068 & 13003 & $.32-.50$ \\
Quadratic ALT & $55.97^{* * *}(8)$ & .787 & .829 & .108 & 13028 & $.27-.39$ \\
\hline${ }^{*} p<.05 .{ }^{* *} p<.01 .^{* * *} p<.001$. & & & & &
\end{tabular}


Table C3

Fit Measures of the Linear and Quadratic LGC Models and ALT Models for the CRI

\begin{tabular}{lcccccc}
\hline & \multicolumn{7}{c}{ Fit index } \\
\cline { 2 - 7 } Model & $T_{\mathrm{ML}}(d f)$ & TLI & CFI & RMSEA & BIC & $R_{y t}^{2}$ \\
\hline Linear LGC & $55.69^{* *}(10)$ & .837 & .837 & .094 & 13059 & $.26-.63$ \\
Quadratic LGC & $13.62^{*}(6)$ & .955 & .973 & .050 & 13037 & $.40-.63$ \\
Linear ALT & $5.32(3)$ & .972 & .992 & .039 & 13047 & $.27-.62$ \\
Quadratic ALT & $4.25^{*}(1)$ & .884 & .998 & .080 & 13061 & $.95-97$ \\
\hline
\end{tabular}

Table C4

Likelihood Ratio Tests for Comparison of Nested Models

\begin{tabular}{lcccc}
\hline Model & Linear LGC & Quadratic LGC & Linear ALT & Quadratic ALT \\
\hline Linear LGC & - & $41.53^{* * *}(4)$ & $50.63^{* * *}(7)$ & $52.30^{* * *}(9)$ \\
Quadratic LGC & $103.29^{* * *}(4)$ & - & $8.41^{*}(3)$ & $7.66(5)$ \\
Linear ALT & $110.76^{* * *}(7)$ & $1.16(3)$ & - & $0(2)$ \\
Quadratic ALT & $72.20^{* * *}(2)$ & $37.58^{* * *}(-2)$ & $44.12^{* * *}(-2)$ & - \\
\hline
\end{tabular}

Note. Cells below the diagonal refer to the models involving the CSI whereas cells above the diagonal refer to the models involving the CRI. Differences in degrees of freedom are in parentheses.

${ }^{*} p<.05 .{ }^{* *} p<.01 . * * * p<.001$. 
Table C5

Maximum Likelihood Variance Estimates of the Growth Factors for the CSI and CRI

Quadratic LGC Models

\begin{tabular}{|c|c|c|}
\hline \multirow[b]{2}{*}{ Growth factor } & \multicolumn{2}{|c|}{ Maximum likelihood variance estimates } \\
\hline & CSI & CRI \\
\hline Intercept & $12.78 * * *$ & $13.15 * * *$ \\
\hline Linear & $5.33 * * *$ & $8.13^{* * *}$ \\
\hline Quadratic & $1.07 * * *$ & $1.11^{* * *}$ \\
\hline \multicolumn{3}{|l|}{$* * * p<.001$} \\
\hline \multicolumn{3}{|l|}{ Table C6 } \\
\hline \multicolumn{3}{|c|}{ BIC Values of the Quadratic Latent Growth Curve Models for the CSI and CRI } \\
\hline & \multicolumn{2}{|c|}{$\mathrm{BIC}$} \\
\hline Model & CSI & CRI \\
\hline 1-group & 12985 & 13037 \\
\hline 2-group & 12840 & 12886 \\
\hline 3-group & - & - \\
\hline 4-group & - & - \\
\hline
\end{tabular}


Table C7

Maximum Likelihood Variance Estimates of the Growth Factors for the CSI and CRI Quadratic LGC Models with Two Offending Trajectory Groups

\begin{tabular}{lcc}
\hline & \multicolumn{2}{c}{ Maximum likelihood variance estimates } \\
\cline { 2 - 3 } Growth factor & CSI & CRI \\
\hline Intercept & $2.16^{* * *}$ & $11.95^{* * *}$ \\
Linear & 0 & $7.96^{* * *}$ \\
Quadratic & 0 & $1.09^{* * *}$ \\
\hline
\end{tabular}

$* * * p<.001$.

- Average probabilities of group membership: $\mathrm{CSI}=.943 / .977 ; \mathrm{CRI}=.902 / .977$.

- Difficult to classify: $<6 \%$ of the bootstrap sample (CSI $=23$ offenders; $C R I=30$ offenders).

- Group membership distribution of the bootstrap sample: Chronic high group (CSI

$=16.3 \%$ and $\mathrm{CRI}=12.5 \%)$ vs. stable low group $(\mathrm{CSI}=83.7$ and $\mathrm{CRI}=87.5 \%)$.

- Total of 82 female offenders: CSI $=367$ stable low and 65 chronic high male offenders; CRI $=390$ stable low and 42 chronic high male offenders.

- Approximately $90 \%$ of the females were classified in the stable low offending trajectory group. 


\section{Figure C1}

Estimated and Observed Growth Curves for the CSI with Two Offending Trajectory

\section{Groups}

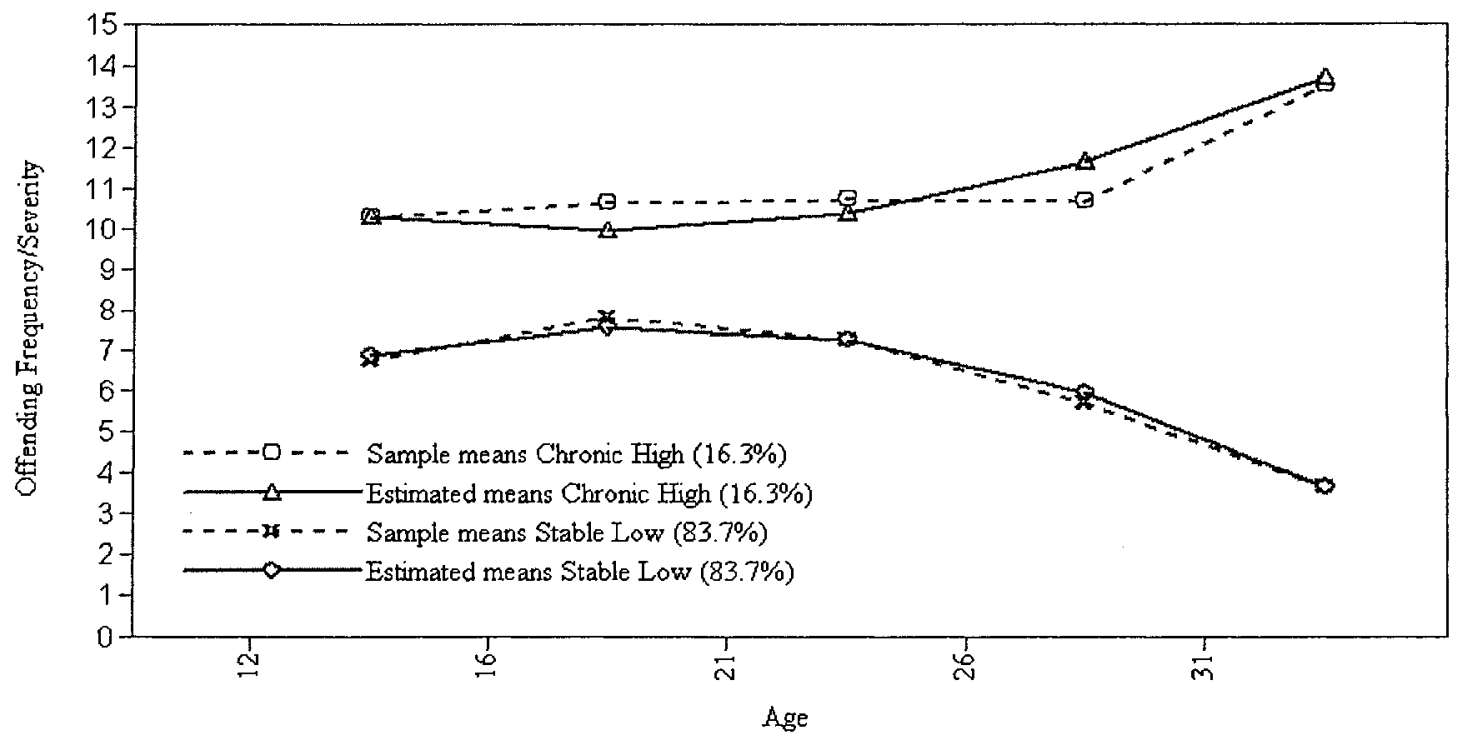

Figure $\mathrm{C} 2$

Estimated and Observed Growth Curves for the CRI with Two Offending Trajectory

\section{Groups}

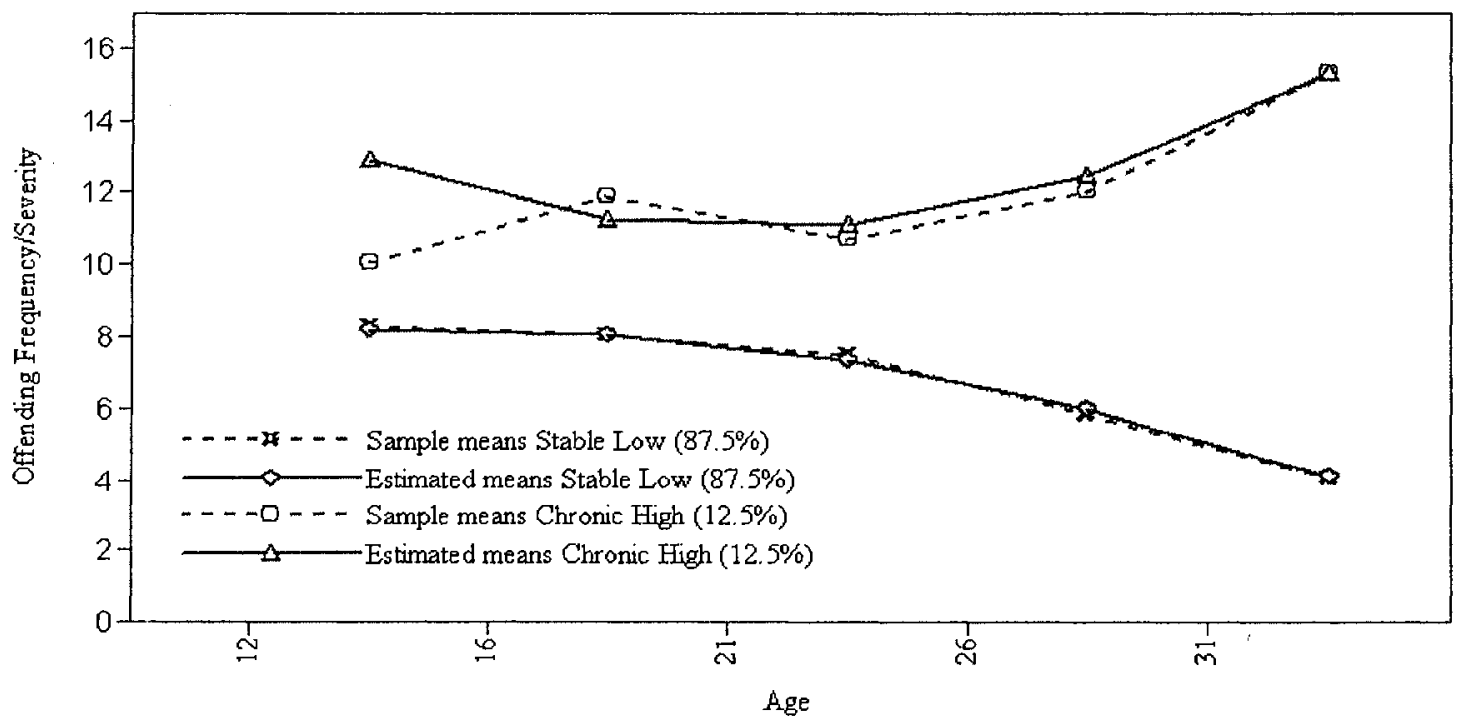


Table C8

Recidivism Rates of the Two Offending Trajectory Groups at Each Time Period \% (n)

\begin{tabular}{|c|c|c|c|c|c|}
\hline & $\begin{array}{c}\text { Time } 1 \\
\text { (ages 12-15) }\end{array}$ & $\begin{array}{c}\text { Time } 2 \\
\text { (ages } 16-20)\end{array}$ & $\begin{array}{c}\text { Time } 3 \\
\text { (ages } 21-25 \text { ) }\end{array}$ & $\begin{array}{c}\text { Time } 4 \\
\text { (ages } 26-30 \text { ) }\end{array}$ & $\begin{array}{c}\text { Time } 5 \\
(\text { ages } 31+\text { ) }\end{array}$ \\
\hline \multicolumn{6}{|c|}{ Group membership based on the Criminal Seriousness Index } \\
\hline Chronic High & $48.5(33)$ & $82.7(81)$ & $75.3(81)$ & $75.3(81)$ & $86.3(73)$ \\
\hline Stable Low & 26.5 (196) & $68.1(433)$ & $58.6(428)$ & $46.8(425)$ & $14.9(363)$ \\
\hline \multicolumn{6}{|c|}{ Group membership based on the Canadian Recidivism Index } \\
\hline Chronic High & $53.6(28)$ & $88.6(70)$ & $82.9(70)$ & $91.4(70)$ & $87.9(58)$ \\
\hline Stable Low & $26.4(201)$ & $67.6(444)$ & $57.9(439)$ & $45.0(436)$ & $17.5(378)$ \\
\hline
\end{tabular}

- Violent conviction during adulthood (age 21 onwards): chronic high offenders $(95.1 \%) v s$. stable low offenders $(54.2 \%)\left(\chi^{2}(1, N=511)=47.66, p<.001\right)$.

- Violent conviction during late adolescence (ages 16- 20): chronic high offenders $(74.1 \%) v s$. stable low offenders $(50.6 \%)\left(\chi^{2}(1, N=514)=15.18, p<.001\right)$.

- Overall number of convictions following the index offence: chronic high offenders $(\approx 10) v s$. stable low offenders $(\approx 5)(t(512)=7.59, p<.001)$

- Number of violent convictions following the index offence: chronic high offenders $(\approx 4) v s$. stable low offenders $(\approx 1.5)(t(512)=6.95, p<.001)$.

- Criminal versatility: chronic high offenders $(\approx 4.5) v s$. stable low offenders $(\approx 3)$ $(t(512)=6.81, p<.001)$ 
- Overall rates of provincial and federal custodial admissions: $52.1 \%$ and $12.8 \%$, respectively $(35.0 \%$ of the offenders did not enter a provincial nor a federal prison during their life-course).

- Admissions into an adult provincial custody: chronic high offenders (91.4\%) vs. stable low offenders $(60.8 \%)\left(\chi^{2}(1, N=514)=24.91, p<.001\right)$.

- Admissions into a federal penitentiary: chronic high offenders (35.7\%) vs. stable low offenders $(9.2 \%)\left(\chi^{2}(1, N=514)=37.88, p<.001\right)$.

Table C9

Comparison of Conditional Two-group Models for the CSI

\begin{tabular}{lcccccc}
\hline & \multicolumn{2}{c}{$\begin{array}{c}\text { No equality } \\
\text { constraint }\end{array}$} & Equality constraint & Likelihood ratio test \\
\cline { 2 - 7 } Model & Loglikelihood & fp & Loglikelihood & fp & Diff. $\chi^{2}$ & Diff. fp \\
\hline Associates & -6338.911 & 27 & -6358.469 & 21 & $20.46^{* *}$ & 6 \\
Family & -6338.171 & 27 & -6368.122 & 21 & $34.12^{* * *}$ & 6 \\
Education & -6362.064 & 27 & -6369.761 & 21 & 6.56 & 6 \\
Accommodation & -6331.020 & 27 & -6370.460 & 21 & $32.71 * * *$ & 6 \\
Attitudes & -6317.644 & 27 & -6371.813 & 21 & 9.93 & 6 \\
Substance Use & -6339.051 & 27 & -6364.919 & 21 & $26.99 * * *$ & 6 \\
Financ. Management & -6351.918 & 27 & -6363.419 & 21 & $13.20^{*}$ & 6 \\
Criminal History & -6317.644 & 27 & -6342.018 & 21 & $27.98^{* * *}$ & 6 \\
\hline
\end{tabular}

Note. fp refers to the number of free parameters.

${ }^{*} p<.05 .{ }^{* *} p<.01 .{ }^{* * *} p<.001$ 
Table C10

Comparison of Conditional Two-group Models for the CRI

\begin{tabular}{|c|c|c|c|c|c|c|}
\hline \multirow[b]{2}{*}{ Model } & \multicolumn{2}{|c|}{$\begin{array}{l}\text { No equality } \\
\text { constraint }\end{array}$} & \multicolumn{2}{|c|}{ Equality constraint } & \multicolumn{2}{|c|}{ Likelihood ratio test } \\
\hline & Loglikelihood & $\mathrm{fp}$ & Loglikelihood & $\mathrm{fp}$ & Diff. $\chi^{2}$ & Diff. $f p$ \\
\hline Associates & - & - & -6369.916 & 26 & - & \\
\hline Family & - & - & -6381.921 & 26 & - & \\
\hline Education & - & - & -6381.600 & 26 & - & \\
\hline Accommodation & -6356.242 & 32 & -6375.607 & 26 & $19.08 * *$ & 6 \\
\hline Attitudes & - & - & -6378.799 & 26 & - & \\
\hline Substance Use & - & - & -6369.708 & 26 & - & \\
\hline Financ. Management & - & - & -6381.922 & 26 & - & \\
\hline Criminal History & - & - & -6352.406 & 26 & - & \\
\hline
\end{tabular}

Note. fp refers to the number of free parameters.

${ }^{*} p<.05 .{ }^{* *} p<.01 .{ }^{* * *} p<.001$. 
Table C1 1

Relationship between Trajectory Group Membership and Juvenile Risk Factors (Odds

Ratios from the Models that Included Only Associates as Predictor Variable)

\begin{tabular}{|c|c|c|c|c|}
\hline \multirow[b]{2}{*}{ Risk factor } & \multicolumn{2}{|c|}{ CSI } & \multicolumn{2}{|c|}{ CRI } \\
\hline & OR & $95 \%$ C. I. & OR & $95 \%$ C. 1. \\
\hline \multicolumn{5}{|l|}{ Associates } \\
\hline Some problems & $5.08^{*}$ & $2.20-11.75$ & 1.89 & $0.97-3.66$ \\
\hline Major problems & $8.56^{*}$ & $3.35-21.86$ & $2.94^{*}$ & $1.31-6.59$ \\
\hline \multicolumn{5}{|l|}{ Family } \\
\hline Some problems & $2.36^{*}$ & $1.31-4.27$ & 1.69 & $0.93-3.08$ \\
\hline Major problems & 1.79 & $0.89-1.79$ & 1.38 & $0.68-2.80$ \\
\hline \multicolumn{5}{|l|}{ Education } \\
\hline 1 yr below norm & 1.23 & $0.64-2.35$ & 1.66 & $0.80-3.43$ \\
\hline$\geq 2$ yrs below norm & 1.67 & $0.93-3.00$ & $2.29 *$ & $1.19-4.44$ \\
\hline \multicolumn{5}{|l|}{ Accommodation } \\
\hline Some problems & 0.75 & $0.40-1.41$ & 1.32 & $0.69-2.52$ \\
\hline Major problems & 1.38 & $0.81-2.36$ & $2.03 *$ & $1.13-3.62$ \\
\hline \multicolumn{5}{|l|}{ Attitudes } \\
\hline Neutral & 1.15 & $0.67-1.97$ & 0.68 & $0.37-1.26$ \\
\hline Negative & 1.73 & $0.90-3.32$ & 1.45 & $0.74-2.86$ \\
\hline \multicolumn{5}{|l|}{ Substance Use } \\
\hline Some problems & $2.08^{*}$ & $1.23-2.08$ & 1.53 & $0.87-2.68$ \\
\hline Major problems & $4.81^{*}$ & $2.34-4.81$ & $4.65^{*}$ & $2.23-9.67$ \\
\hline
\end{tabular}


Table C11 (continued)

\begin{tabular}{lcccc}
\hline & \multicolumn{2}{c}{ CSI } & \multicolumn{2}{c}{ CRI } \\
\cline { 2 - 5 } Risk factor & OR & $95 \%$ C. I. & OR & $95 \%$ C. I. \\
\hline $\begin{array}{l}\text { Financial Management } \\
\text { Some problems }\end{array}$ & 1.42 & $0.86-1.42$ & 1.14 & $0.66-1.98$ \\
$\quad$ Major problems & 0.70 & $0.33-1.50$ & 1.10 & $0.54-2.25$ \\
Criminal History & & & & \\
Medium risk & 1.00 & $0.60-1.68$ & 1.01 & $0.58-1.75$ \\
High risk & 1.18 & $0.60-2.33$ & 1.31 & $0.65-2.65$ \\
\hline
\end{tabular}

Note. For each OR, the reference condition was "low risk" or no problem on the juvenile risk factor.

${ }^{*} p<.05$. 
Table C12

Risk/need Distribution of the Offending Groups Based on the CSI and CRI n (\%)

\begin{tabular}{|c|c|c|c|c|}
\hline \multirow[b]{2}{*}{ Risk factor } & \multicolumn{2}{|c|}{ CSI } & \multicolumn{2}{|c|}{ CRI } \\
\hline & $\begin{array}{c}\text { Chronic High } \\
\qquad(N=81)\end{array}$ & $\begin{array}{l}\text { Stable Low } \\
(N=433)\end{array}$ & $\begin{array}{l}\text { Chronic High } \\
\qquad(N=70)\end{array}$ & $\begin{array}{c}\text { Stable Low } \\
(N=444)\end{array}$ \\
\hline \multicolumn{5}{|l|}{ Associates } \\
\hline No problem & $6(7.4)$ & $142(32.8)$ & $12(17.1)$ & $136(30.6)$ \\
\hline Some problems & $55(67.9)$ & $239(55.2)$ & $43(61.4)$ & $251(56.5)$ \\
\hline Major problems & $20(24.7)$ & $52(12.0)$ & $15(21.4)$ & $57(12.8)$ \\
\hline \multicolumn{5}{|l|}{ Family } \\
\hline No problem & $17(21.0)$ & $159(36.7)$ & $18(25.7)$ & $158(35.6)$ \\
\hline Some problems & $45(55.6)$ & $175(40.4)$ & $36(51.4)$ & $184(41.4)$ \\
\hline Major problems & $19(23.5)$ & $99(22.9)$ & $16(22.9)$ & $102(23.0)$ \\
\hline \multicolumn{5}{|l|}{ Education } \\
\hline At the exp. level & $19(23.5)$ & $136(31.4)$ & $13(18.6)$ & $142(32.0)$ \\
\hline 1 yr below norm & $22(27.2)$ & $128(29.6)$ & $20(28.6)$ & $130(29.3)$ \\
\hline$\geq 2$ yrs below norm & $40(49.4)$ & $169(39.0)$ & $37(52.9)$ & $172(38.7)$ \\
\hline \multicolumn{5}{|l|}{ Accommodation } \\
\hline No problem & $38(46.9)$ & $209(48.3)$ & $26(37.1)$ & $221(49.8)$ \\
\hline Some problems & $15(18.5)$ & $112(25.9)$ & $17(24.3)$ & $110(24.8)$ \\
\hline Major problems & $28(34.6)$ & $112(25.9)$ & $27(38.6)$ & $113(25.5)$ \\
\hline
\end{tabular}


Table C12 (continued)

\begin{tabular}{lcccc}
\hline & \multicolumn{2}{c}{ CSI } & \multicolumn{2}{c}{ CRI } \\
\cline { 2 - 5 } Risk factor & $\begin{array}{c}\text { Chronic High } \\
(N=81)\end{array}$ & $\begin{array}{c}\text { Stable Low } \\
(N=433)\end{array}$ & $\begin{array}{c}\text { Chronic High } \\
(N=70)\end{array}$ & $\begin{array}{c}\text { Stable Low } \\
(N=444)\end{array}$ \\
\hline Attitudes & & & & \\
No problem & $42(51.9)$ & $253(58.4)$ & $42(60.0)$ & $253(57.0)$ \\
Some problems & $24(29.6)$ & $127(29.3)$ & $15(21.4)$ & $136(30.6)$ \\
Major problems & $15(18.5)$ & $53(12.2)$ & $13(18.6)$ & $55(12.4)$ \\
Substance Use & & & & \\
No problem & $33(40.7)$ & $275(63.5)$ & $32(45.7)$ & $286(62.2)$ \\
Some problems & $33(40.7)$ & $132(30.5)$ & $24(34.3)$ & $141(31.8)$ \\
Major problems & $15(18.5)$ & $26(6.0)$ & $14(20.0)$ & $27(6.1)$ \\
Financial Management & & & & \\
No problem & $34(42.0)$ & $199(46.0)$ & $30(42.9)$ & $203(45.7)$ \\
Some problems & $38(46.9)$ & $156(36.0)$ & $28(40.0)$ & $166(37.4)$ \\
Major problems & $9(11.1)$ & $78(18.0)$ & $12(17.1)$ & $75(16.9)$ \\
Criminal History & & & & $187(15.1)$ \\
Low risk & $33(40.7)$ & $181(41.8)$ & $28(33.3)$ & $186(41.9)$ \\
Medium risk & $34(42.0)$ & $186(43.0)$ & $29(49.3)$ & $191(43.0)$ \\
High risk & $14(17.3)$ & $66(15.2)$ & $13(18.6)$ & $67(15)$ \\
\hline
\end{tabular}

